\title{
WestVirginiaUniversity
}

THE RESEARCH REPOSITORY @ WVU

Graduate Theses, Dissertations, and Problem Reports

2016

\section{Effect of clay and salinity on asphaltene stability}

Ahmet Birkan Demir

Follow this and additional works at: https://researchrepository.wvu.edu/etd

\section{Recommended Citation}

Demir, Ahmet Birkan, "Effect of clay and salinity on asphaltene stability" (2016). Graduate Theses,

Dissertations, and Problem Reports. 5470.

https://researchrepository.wvu.edu/etd/5470

This Thesis is protected by copyright and/or related rights. It has been brought to you by the The Research Repository @ WVU with permission from the rights-holder(s). You are free to use this Thesis in any way that is permitted by the copyright and related rights legislation that applies to your use. For other uses you must obtain permission from the rights-holder(s) directly, unless additional rights are indicated by a Creative Commons license in the record and/ or on the work itself. This Thesis has been accepted for inclusion in WVU Graduate Theses, Dissertations, and Problem Reports collection by an authorized administrator of The Research Repository @ WVU. For more information, please contact researchrepository@mail.wvu.edu. 


\title{
EFFECT OF CLAY AND SALINITY ON ASPHALTENE STABILITY
}

\author{
Ahmet Birkan Demir \\ Thesis submitted \\ to the Benjamin M. Statler College of Engineering and Mineral Resources \\ at West Virginia University \\ in partial fulfillment of the requirements for the degree of \\ Master of Science \\ in \\ Department of Petroleum and Natural Gas Engineering
}

\author{
H. Ilkin Bilgesu, Ph.D., Chair \\ Berna Hascakir, Ph.D., Co-Chair \\ Samuel Ameri, M.S. \\ Kashy Aminian, Ph.D.
}

Department of Petroleum and Natural Gas Engineering

Morgantown, West Virginia

2016

Keywords: Asphaltene, Asphaltene Problems, Flow Assurance, Near-Wellbore Damage, Wettability Alteration

Copyright 2016 Ahmet Birkan Demir 


\title{
ABSTRACT \\ EFFECT OF CLAY AND SALINITY ON ASPHALTENE STABILITY
}

\begin{abstract}
Ahmet Birkan Demir
Asphaltenes are fractions of crude oil and precipitate out due to change in pressure, temperature, and composition. Because the most significant pressure and temperature change occur at near wellbore region, asphaltenes precipitation occurs at this area which prevents oil flow due to significant reduction in permeability.
\end{abstract}

This study investigates the effect of salinity and clay type on asphaltene stability. To reach this goal, the stability of asphaltenes from five different crude oil samples were evaluated after exposing them to different brine concentrations with the absence and presence of porous medium. Porous mediums were prepared by using either Ottawa Sand or Ottawa Sand+Clay mixture. Illite+kaolinite mixture was used as clay. Brine solutions were prepared by either $\mathrm{NaCl}$ or $\mathrm{CaCl}_{2}$. For both salts, solutions were prepared by mixing $0.2 \%$, $2 \%, 4 \%, 6 \%$, and $8 \%$ of salt with deionized water. Asphaltene behavior was visualized for each case under optical microscope. The impact of asphaltene-brine interaction on wettability alteration was determined through contact angle measurements.

Our experimental results suggest that asphaltenes from all five crude oil samples are dispersed in water, and they aligned themselves within water due to their polar-polar interaction with water. In asphaltene-clay-brine systems, divalent salt $\left(\mathrm{CaCl}_{2}\right)$ interacts more with asphaltenes than monovalent salt $(\mathrm{NaCl})$. Further, increasing salinity promotes clay dispersion which increases the size of asphaltene-clay clusters. Also, the contact angle measurements demonstrated that wettability alters with salinity, however, no direct relation was observed between salinity and asphaltene stability.

This study aimed to characterize the stability of asphaltenes from five different crude oils. Based on crude oils which may aid to produce methods to prevent asphaltenes deposition. 


\section{DEDICATION}

To my family and fiancée 


\section{ACKNOWLEDGMENTS}

I would first like to thank my thesis advisor Dr. Bilgesu of the Petroleum and Natural Gas Department at West Virginia University. The door to Prof. Bilgesu office was always open whenever I ran into a trouble spot or had a question about my research or writing. He consistently allowed this thesis to be my own work, but steered me in the right direction whenever he thought I needed it.

I would also like to thank my co-advisor Dr. Hascakir of the Petroleum Engineering Department at Texas A\&M University. I am gratefully indebted for her support and very valuable comments for my research.

I would also like to thank Turkish Petroleum Corporation to support me economically and scientifically whenever I need. I am grateful to them to give me education opportunity.

I also acknowledge Samuel Ameri, the head of Petroleum and Natural Gas Engineering Department at West Virginia University, to provide financial support to complete my research experiments.

I also acknowledge the financial support and the opportunity provided by the Texas A\&M University to conduct experiments in the Ramey Thermal Recovery Laboratory. I also acknowledge the members of Heavy Oil, Oil shales, Oil sands, \& Carbonate Analysis and Recovery Methods (HOCAM) Research Team at Texas A\&M University, Petroleum Engineering Department, for their help.

Finally, I must express my very profound gratitude to my parents, to my fiancée, and to my friends for providing me with unfailing support and continuous encouragement throughout my years of study and through the process of researching and writing this thesis. My accomplishment would not have been possible without them. Thank you. 


\section{TABLE OF CONTENTS}

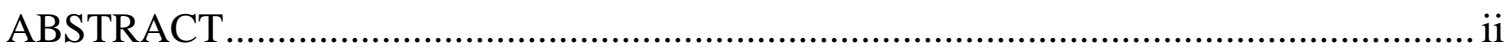

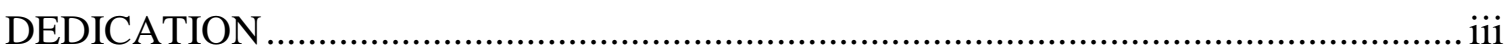

ACKNOWLEDGMENTS …………………….................................................... iv

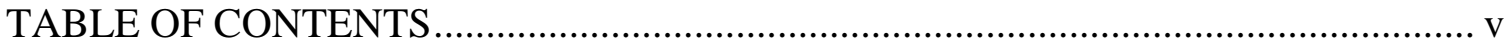

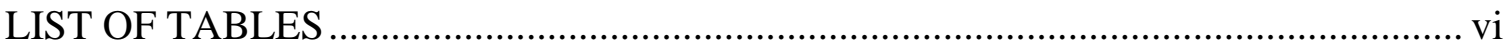

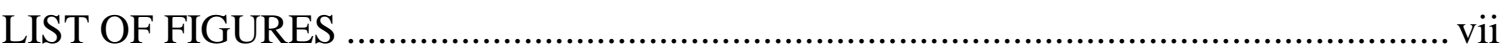

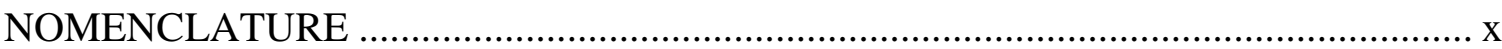

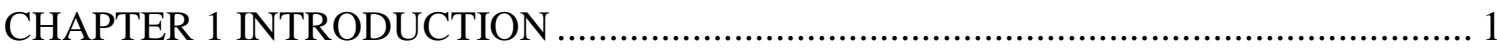

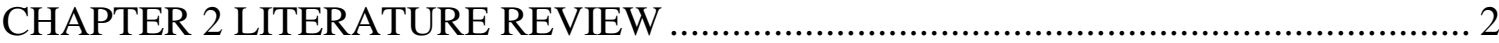

CHAPTER 3 EXPERIMENTAL METHODOLOGY ................................................. 7

$3.1 \quad$ Asphaltene

3.1.1 Asphaltene Sample Preparation ......................................................... 7

3.1.2 Visualizing Asphaltene Behavior Under Optic Microscope.......................... 11

3.2 Characterization of Clay........................................................................... 12

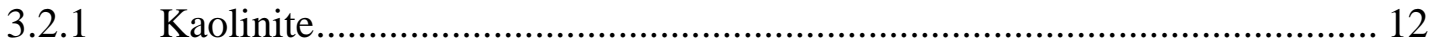

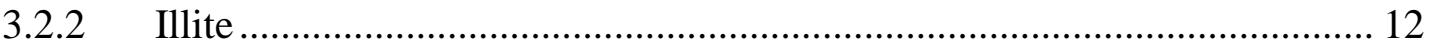

3.2.3 Cation Exchange Capacity of the Clay Minerals ........................................ 13

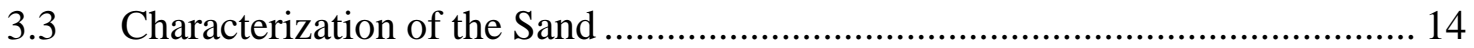

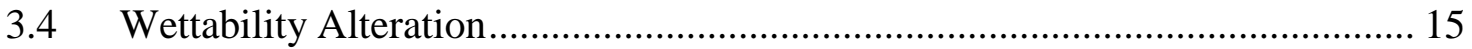

3.4.1 Sample Preparation ............................................................................. 15

3.4.2 Contact Angle Measurements ……………………................................. 16

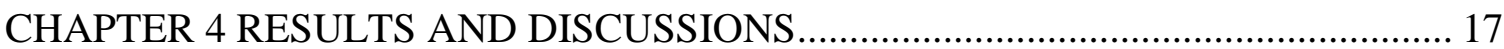

4.1 Asphaltene-Water/Brine Interaction ....................................................... 17

4.2 Asphaltene+Clay-Water/Brine Interaction..................................................... 25

4.3 Asphaltene+Sand-Water/Brine Interaction ...................................................... 33

4.4 Asphaltene+Sand+Clay-Water/Brine Interaction ........................................... 38

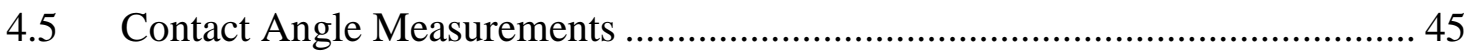

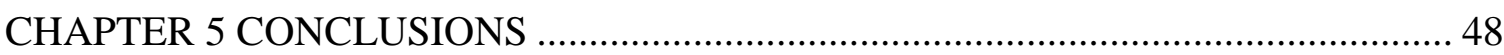

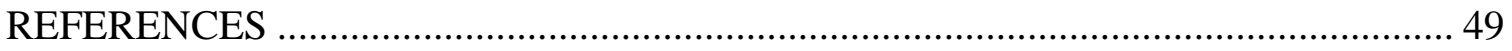

APPENDIX 


\section{LIST OF TABLES}

Table 1: Properties of crude oils used in this study (Prakoso et al. 2015) ......................... 7 Table 2: CII Index, Carbon, Hydrogen, and Heteroatoms Content of the Crude

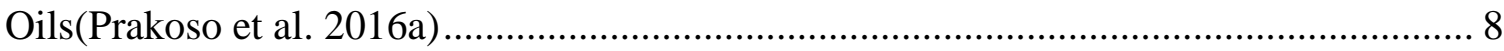

Table 3: Elemental Analysis for 5 Crude Oil Samples (ppm) (Prakoso et al. 2016) ........ 10

Table 4: Features of Ottawa Sand (Zhuang et al. 2003) ................................................ 15

Table 5: Water-air Contact angle measurements and the calculated water-oil contact angle

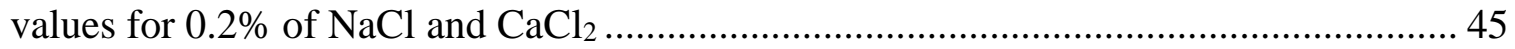

Table 6: Water-air Contact angle measurements and the calculated water-oil contact angle

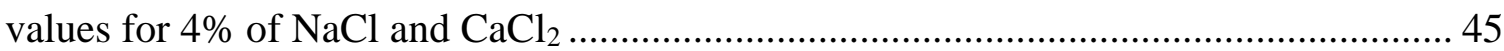




\section{LIST OF FIGURES}

Figure 1: Fractional yield from Athabasca bitumen diluted with different $n$-alkanes (Sabbagh et al. 2006) 4

Figure 2: Fractional yield from Athabasca bitumen diluted with n-heptane at $0{ }^{\circ} \mathrm{C}$ and 0.1 MPa and at 23, 50, and $100{ }^{\circ} \mathrm{C}$ all at 2.1 MPa (Sabbagh et al. 2006).. 4

Figure 3: Fractional yield from Athabasca bitumen diluted with n-heptane at $23^{\circ} \mathrm{C}$ and 0.1 , 2.1, and 6.9 MPa (Sabbagh et al. 2006) ...................................................................... 5

Figure 4: Elemental Analysis of Ottawa Sand (wt\%) …………………..................... 15

Figure 5: Asphaltene-water and asphaltene- $0.2 \%$ brine interactions for both n-pentane and n-heptane insoluble fractions of crude oils at 40X magnification ................................... 18 Figure 6: Asphaltene-water and asphaltene-2\% brine interactions for both n-pentane and $\mathrm{n}$-heptane insoluble fractions of crude oils at $5 \mathrm{X}$ magnification 18 Figure 7: Asphaltene-water and asphaltene-4\%, $6 \%$ and $8 \%$ brine interactions for both $\mathrm{n}$ pentane insoluble fractions of crude oils at $5 \mathrm{X}$ magnification 19 Figure 8: Asphaltene-water and asphaltene- $4 \%, 6 \%$ and $8 \%$ brine interactions for both $n$ heptane insoluble fractions of crude oils at $5 \mathrm{X}$ magnification 19

Figure 9: Asphaltene-water and asphaltene- $0.2 \%$ brine interactions for both $\mathrm{n}$-pentane and $\mathrm{n}$-heptane insoluble fractions of crude oils within porous media prepared by only clay at 40X magnification 25

Figure 10: Asphaltene-water and asphaltene-2\% brine interactions for both n-pentane and $\mathrm{n}$-heptane insoluble fractions of crude oils within porous media prepared by only clay at $5 \mathrm{X}$ magnification 26

Figure 11: Asphaltene-water and asphaltene- $4 \%, 6 \%$ and $8 \%$ brine interactions for both $\mathrm{n}$ pentane insoluble fractions of crude oils within porous media prepared by only clay at $5 \mathrm{X}$ magnification 26

Figure 12: Asphaltene-water and asphaltene- $4 \%, 6 \%$ and $8 \%$ brine interactions for both $\mathrm{n}$ heptane insoluble fractions of crude oils within porous media prepared by only clay at $5 \mathrm{X}$ magnification 27

Figure 13: Critical coagulation concentrations of kaolinite/illite as a function of $\mathrm{pH}$ and SAR (Goldberg et al. 1991) 29 
Figure 14: Asphaltene-water and asphaltene-2\%,4\%.6\%, and 8\% brine interactions for npentane insoluble fraction of crude oils within porous media prepared by only clay at $10 \mathrm{X}$

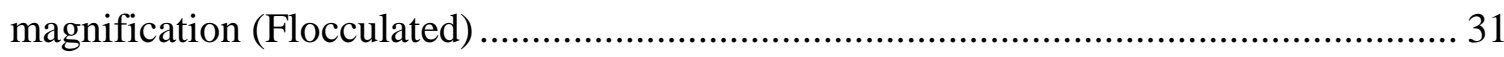

Figure 15: Asphaltene-water and asphaltene-2\%, 4\%.6\%, and 8\% brine interactions for nheptane insoluble fraction of crude oils within porous media prepared by only clay at 10X

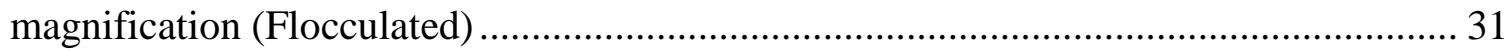

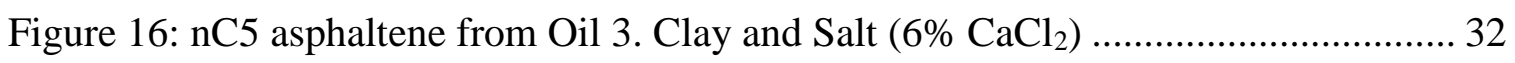
Figure 17: Asphaltene-water and asphaltene-0.2\% brine interactions for both n-pentane and n-heptane insoluble fractions of crude oils within porous media prepared by only sand at 40X magnification 33

Figure 18: Asphaltene-water and asphaltene-2\% brine interactions for both n-pentane and n-heptane insoluble fractions of crude oils within porous media prepared by only sand at $5 \mathrm{X}$ magnification 34

Figure 19: Asphaltene-water and asphaltene-4\%, 6\% and 8\% brine interactions for both npentane and insoluble fractions of crude oils within porous media prepared by only sand at $5 \mathrm{X}$ magnification 34

Figure 20: Asphaltene-water and asphaltene-4\%, 6\% and 8\% brine interactions for both nheptane and insoluble fractions of crude oils within porous media prepared by only sand at $5 \mathrm{X}$ magnification 35

Figure 21: Asphaltene-water and asphaltene-0.2\% brine interactions for both n-pentane and n-heptane insoluble fractions of crude oils within porous media prepared by sand-clay

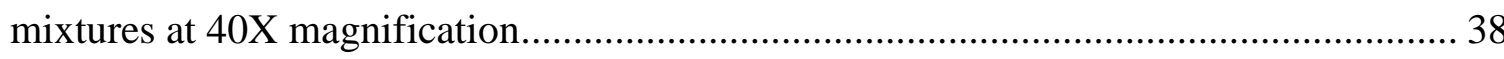

Figure 22: Asphaltene-water and asphaltene-2\% brine interactions for both n-pentane and n-heptane insoluble fractions of crude oils within porous media prepared by sand-clay mixtures at $5 \mathrm{X}$ magnification.

Figure 23: Asphaltene-water and asphaltene-4\%, 6\% and 8\% brine interactions for $n-$ pentane insoluble fractions of crude oils within porous media prepared by sand-clay mixtures at $5 \mathrm{X}$ magnification

Figure 24: Asphaltene-water and asphaltene-4\%, 6\% and 8\% brine interactions for $n$ heptane insoluble fractions of crude oils within porous media prepared by sand-clay mixtures at $5 \mathrm{X}$ magnification. 40 
Figure 25: n-pentane asphaltenes from Oil 5 with clay+sand in $8 \% \mathrm{NaCl}$..................... 43

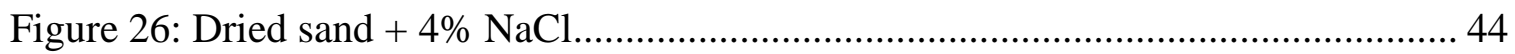

Figure 27: Dried sample of n-pentane asphaltenes of Oil 3 in $4 \% \mathrm{NaCl}$ with Sand+Clay44

Figure 28: Results of Contact Angle Measurements

Figure A - 1: Jenoptik Microscope Attached with ProgRes CT5 Camera........................ 56

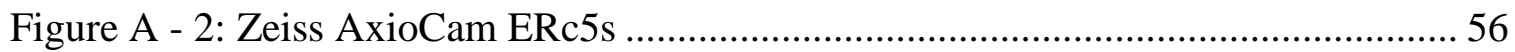

Figure A - 3: : Structural Formulas of Different Illites (Gaudette et al. 1966) ................. 57

Figure A - 4: Kruss DSA30S Contact Angle Measurement Device ................................ 57

Figure A - 5: Ca Content of Five Crude Oil Samples (ppm) ….................................... 58

Figure A - 6: Na Content of Five Crude Oil Samples (ppm) ....................................... 58

Figure A - 7: Fe Content of Five Crude Oil Samples (ppm) …................................... 58

Figure A - 8: V Content of Five Crude Oil Samples (ppm).......................................... 59

Figure A - 9: Ni Content of Five Crude Oil Samples (ppm) ........................................ 59

Figure A - 10: Metal Content of Five Crude Oil Samples (ppm) ................................. 59

Figure A - 11: Heteroatoms Content of Five Crude Oil Samples (\%wt) ......................... 60

Figure A - 12: FTIR Spectrum of Oil 1 and Oil 2 and asphaltenes separated with n-pentane and n-heptane. (red, black, and gray lines refer crude oil, n-pentane, and n-heptane,

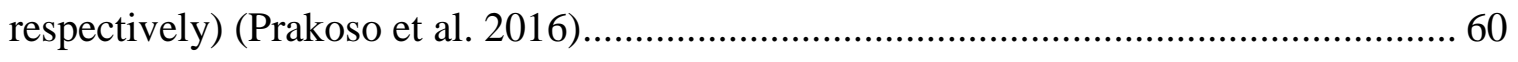

Figure A - 13: FTIR Spectrum of Oil 3 and Oil 4 and asphaltenes separated with n-pentane and n-heptane. (red, black, and gray lines refer crude oil, n-pentane, and n-heptane,

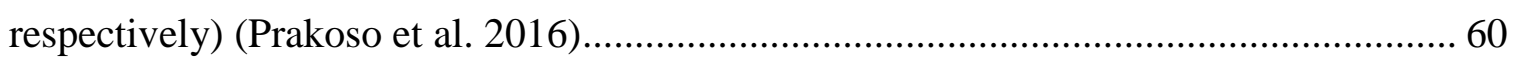

Figure A - 14: FTIR Spectrum of Oil 5 and asphaltenes separated with n-pentane and nheptane. (red, black, and gray lines refer crude oil, n-pentane, and n-heptane, respectively) (Prakoso et al. 2016) 


\section{NOMENCLATURE}

API: American Petroleum Institute gravity

FTIR: Fourier Transform Infrared

CCC: Critical Coagulation Concentration

SAR: Sodium Adsorption Ratio

IW: Intermediate Wet

WW: Water Wet

OW: Oil Wet

CEC: Cation Exchange Capacity

SA: Specific Surface Area

OM: Organic Matter

n-pentane: normal-pentane

n-heptane: normal-heptane

wt\%: weight percentage

ASTM: American Society of Testing and Materials

$\mathrm{NaCl}$ : Sodium Chloride

$\mathrm{CaCl}_{2}$ : Calcium Chloride

nC5: normal pentane

nC7: normal heptane 


\section{CHAPTER 1 INTRODUCTION}

Asphaltene phase is affected by changes in pressure, temperature, and their composition. Since the greatest pressure and temperature changes occur near-wellbore area, asphaltene deposition during oil production has several detrimental impacts.

While there are significant efforts which investigate the impact of pressure and temperature on asphaltene stability, the contribution of reservoir rock and reservoir brine still is not known. Therefore, this research focuses on the effect of reservoir rock and brine on asphaltenes depositional behavior.

Different scenarios are examined to mimic asphaltenes behavior at near-wellbore area. Hence, precipitation tendency of asphatenes from five different crude oils were determined in different reservoir rock and brine environments. As reservoir rock, sand (20-40 mesh size Ottawa Sand), clay (kaolinite+illite mixture), and clay+sand mixture were tested. Brine solutions were prepared with $0.2 \%, 2 \%, 4 \%, 6 \%$, and $8 \%$ concentrations of either $\mathrm{NaCl}$ or $\mathrm{CaCl}_{2}$. Some experiments were also conducted with distilled water.

In addition to the investigation of asphaltene deposition behavior in reservoir rock, the contact angle measurements were also carried out in this research to determine wettability alteration due to asphaltene-brine interaction. These measurements are important to determine the relationship between asphaltene deposition behavior and water wettability alteration in the reservoir which directly impacts oil production. 


\section{CHAPTER 2 LITERATURE REVIEW}

The crude oil is defined as "a mixture of hydrocarbons that exist in liquid phase in natural underground reservoirs and remains liquid at atmospheric pressure after passing through surface separating facilities" (Wilson and Burgh. 2007). Until recent years, light crude oil has met world's energy demand, but by the year of 2007, the worldwide energy demand of crude oil started to increase sharply (Meyer et al. 2007). Therefore, the importance of heavy oil and bitumen resources gained importance.

Crude oils are categorized based on their API gravity and viscosity as light oil, heavy oil, extra-heavy oil, and natural bitumen (Meyer and Attanasi. August 2003). Light oil or conventional oil has an API gravity greater than $25^{\circ}$. Heavy oil has an API gravity more than $20^{\circ}$ API but less than $25^{\circ}$ API. Heavy oil has an API gravity between $10^{\circ}$ and $20^{\circ}$ API and their viscosity is more than $100 \mathrm{cP}$. The natural bitumen has less than $10^{\circ}$ API gravity and more than 10,000 cp viscosity (Meyer et al. 2007).

As heavier the oil gets, more complex molecular structures are observed in crude oils and molecular level of the crude oil characterization becomes difficult and impractical. Hence for simplicity, crude oil components divided into four main groups based on their polarizability SARA fractions and solubility which are saturates, aromatics, resins, and asphaltenes (SARA) (Yoon et al. 2009; Woods et al. 2012). Saturates and aromatics are nonpolar components of crude oil while aromatics are more polarizable than saturates (Ashoori et al. 2016). On the other hand, other two components of crude oil are polar components whereas asphaltenes are more polar than resins (Ashoori et al. 2016; Andersen and Speight. 2001).

The stability of crude oil is related to mutual interactions of SARA fractions which are explained by Colloidal Instability Index (CII) that depends on the chemical composition of crude oil and given with the following formula (Loeber et al. 1998).

$$
C I I=\frac{\text { asphaltenes }[w t \%]+\text { saturates }[w t \%]}{\text { resins }[w t \%]+\text { aromatics }[w t \%]}
$$


CII values below 0.7 exhibit stable asphaltenes and above 0.9 unstable asphaltenes (Ashoori et al. 2016).

Asphaltenes were known as insoluble in alcohol and soluble in turpentine in the past (Auflem. June 2002). The current definition is still similar. They are insoluble in n-alkanes, such as n-pentane or n-heptane and soluble in aromatic solvents such as toluene (Akbarzadeh et al. 2005; Mullins et al. 2007).

The chemical compositions of asphaltenes are complex. They consist of polycyclic hydrocarbons that have heteroatoms and metals. (Wattana et al. 2005). These heteroatoms are nitrogen, oxygen, and sulfur. Also, asphaltenes have some metal elements such as nickel and vanadium (Speight. 2004). The percentage of carbon and hydrogen atoms in the asphaltenes are $82 \pm 3 \%$ and $8.1 \pm 0.7 \%$, respectively (Speight. 1994). These values correspond to an $\mathrm{H} / \mathrm{C}$ ratio of $1.15 \pm 0.05$.

The stability of asphaltene is affected by the changes in temperature, pressure, and chemical composition of crude oil (Spiecker et al. 2003; Escrochi et al. 2008; Espinat et al. 2004). In addition to these well-known parameters, brine ion content, the effect of reservoir brine on asphaltene stability was reported by few researchers (Hu et al. 2015; Kabay et al. 2006).

In laboratory conditions, $\mathrm{n}$-alkanes have been used for asphaltene separation from the crude oil. The precipitated amount of asphaltene from the crude oil highly depends on the type of n-alkane used. The precipitated asphaltene amount increases while the carbon number in n-alkanes decreases. Figure 1 shows how the amount of precipitated asphaltene changes with different n-alkanes; n-pentane, n-hexane, and n-heptane, for Athabasca bitumen at 23 ${ }^{\circ} \mathrm{C}$ and 0.1 Mpa (Sabbagh et al. 2006). 


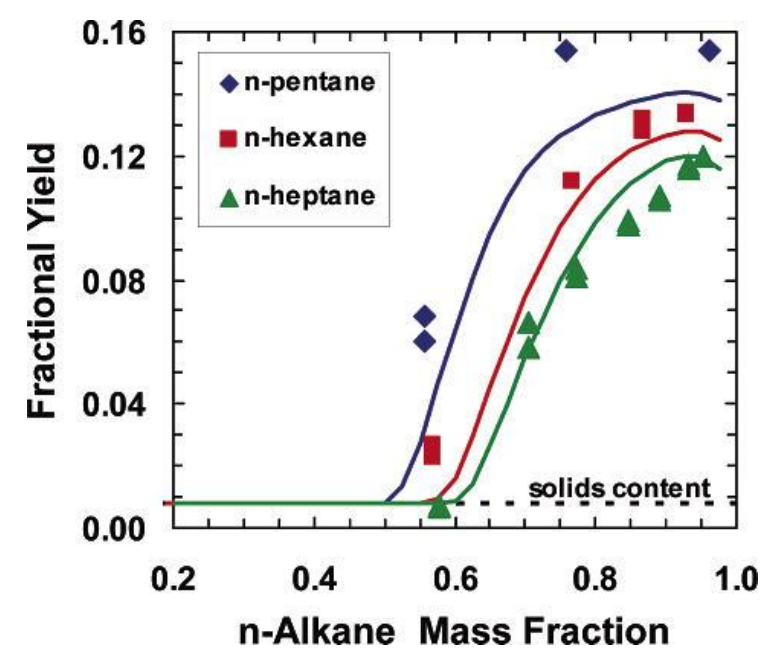

Figure 1: Fractional yield from Athabasca bitumen diluted with different n-alkanes (Sabbagh et al. 2006)

The effect of temperature and pressure on asphaltene precipitation also clearly explained in the same publication. Alteration of temperature is more effective than change of pressure for the amount of precipitated asphaltene. Figure 2 and Figure 3 show this idea clearly for the Athabasca bitumen.

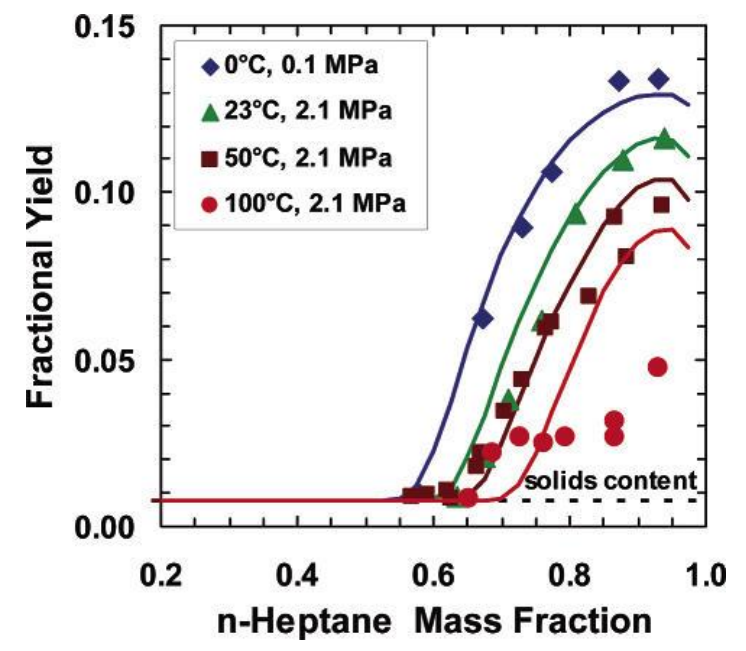

Figure 2: Fractional yield from Athabasca bitumen diluted with n-heptane at $0{ }^{\circ} \mathrm{C}$ and $0.1 \mathrm{MPa}$ and at 23, 50, and $100{ }^{\circ} \mathrm{C}$ all at $2.1 \mathrm{MPa}$ (Sabbagh et al. 2006) 


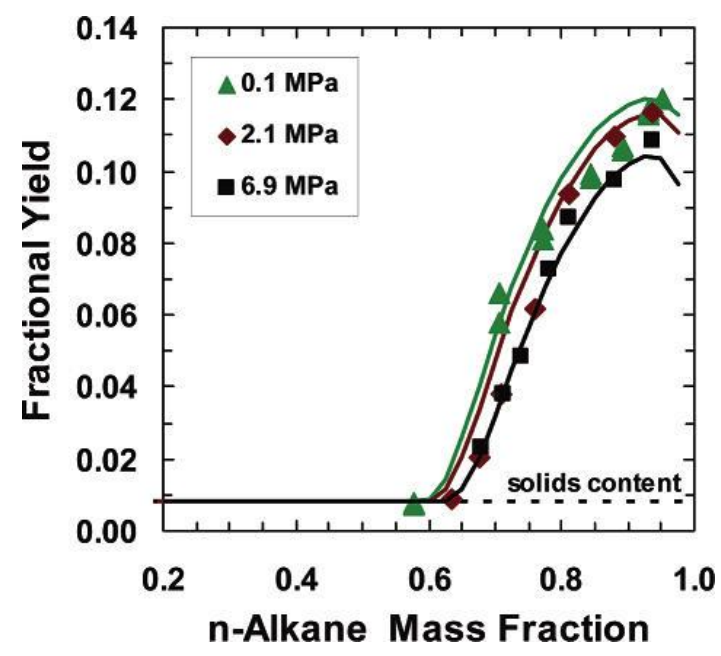

Figure 3: Fractional yield from Athabasca bitumen diluted with n-heptane at $23{ }^{\circ} \mathrm{C}$ and $0.1,2.1$, and 6.9 MPa (Sabbagh et al. 2006)

Asphaltene deposition leads operational problems, by decreasing oil production, and increasing operational cost (Kokal and Sayegh. 1995). In general, asphaltenes deposition occur near-wellbore area by filling pore throats, changing wettability from water-wet to oil-wet, and by increasing oil viscosity (Leontaritis et al. 1994). In addition to reservoirrelated problems, asphaltenes also causes problems in wellbore, tubing and surface facilities which increase the cost of oil production and transportation (Kokal and Sayegh. 1995).

In the literature, two models explain asphaltene behavior in crude oil; colloidal model and thermodynamic model (Yarranton et al. 2000). According to colloidal model, asphaltene molecule stands exist as suspended colloids in crude oil (Carlos da et al. 2001; Mullins et al. 2012). In this model, asphaltene clusters are composed of asphaltene nanoaggregates, and nanoaggregates comprise from asphaltene molecules (Mullins. 2010). However, based on the thermodynamic model, asphaltenes are dissolved in the crude oil. In pursuant of thermodynamic model, asphaltene precipitation is reversible whereas this mechanism is irreversible in the colloidal model (Yarranton et al. 2000).

The polarity of the molecules is created due to imbalance in chemical bond angles and impurity content of given molecules (Demir et al. 2016; Chang and Overby. 2003). Polar features and cluster sizes of asphaltenes highly depend on the type of n-alkane used as a precipitation agent. As the carbon number of precipitating agent increases, the amount of 
precipitated asphaltene decreases (Punase et al. 2016). The relation between the type of nalkanes used and polarity and cluster size is not as noticeable as the amount of asphaltene precipitated. Some of the researchers believe that the asphaltene polarity and cluster size increase with the increase in carbon number of n-alkane while some of them believe totally opposite (Punase et al. 2016; Calles et al. 2007). Speight were reported in 1994 for 4 crude oil samples that $\mathrm{H} / \mathrm{C}$ ratio was higher for $n$-pentane insoluble asphaltenes while N/C, O/C, and $\mathrm{S} / \mathrm{C}$ ratios are smaller in $\mathrm{n}$-pentane insoluble asphaltenes. Increasing nitrogen, oxygen, and sulfur rating is evidence to increasing polarity when the carbon number of asphaltene insoluble increase (Speight. 1994).

Because of brine's highly use in the petroleum industry as a completion fluid and an injection fluid, there are many studies published about the relationship between crude oil/brine/reservoir rock (sand+clay). In the case where brine is used as a completion fluid, brine/sand/clay interaction becomes significant due to the high cation exchange ability of clays. Brine concentration and flow rate in a well have to be strictly checked to prevent formation damage near-wellbore area. If the salinity becomes more than usual, this causes deflocculation in clays due to high rate of clay dispersion. As a result, formation damage might happen near-wellbore area (Scheuerman and Bergersen. 1990). In the case where brine is used as an injection fluid to recover oil or for pressure maintenance, it might be produced back with oil. At this stage, brine-crude oil interaction becomes more important, because crude oil has some heavy polar constituents which might interact with brine. These interactions called as crude oil/brine/rock interactions and have been studied by some researchers (Tang and Morrow. 1999; Tang and Morrow. 1997; Gonzalez et al. 2016).

In this study, asphaltene stability was examined at reservoir conditions for varying brine type and concentrations, and clay presence in both brine/sand/clay and oilbrine/rock systems. Thus, five crude oils and the behavior of asphaltenes from these crudes were investigated with experimental efforts. An optical microscope was used to visualize the asphaltenes behavior under the influence of water, brine, clays, and sand. Contact angle measurements were carried out to investigate the alteration in wetting characteristics of rock in water and brine systems. 


\section{CHAPTER 3}

\section{EXPERIMENTAL METHODOLOGY}

This section describes the preparation of samples and experimental procedures. Mainly, there are two experiments; optical microscopy analysis of asphaltenes and contact angle measurements.

\subsection{Asphaltene}

\subsubsection{Asphaltene Sample Preparation}

In this research, five different crude oil samples were used. These samples were selected based on the differences in their API gravity, viscosity, and asphaltene content. Based on their API gravity and viscosity, these oils are categorized as heavy oil for Oil 1 and Oil 2 samples, extra-heavy oil for Oil 3 and Oil 4 samples, and bitumen for Oil 5 sample (Meyer et al. 2007). Note that the oil gravities were measured under standard conditions but viscosities were measured under reservoir temperature. Asphaltene contents reported in Table 1 were determined by following two ASTM Methods; ASTM-2011 method uses npentane and ASTM D-1250 method uses n-heptane to separate asphaltenes. As expected, the amount of n-pentane asphaltenes are higher than n-heptane asphaltenes.

Table 1: Properties of crude oils used in this study (Prakoso et al. 2015)

\begin{tabular}{|c|c|c|c|c|}
\hline \multirow{2}{*}{ Sample Name } & \multirow{2}{*}{$\begin{array}{c}\text { API Gravity } \\
@ 15^{\circ} \mathrm{C}\end{array}$} & $\begin{array}{c}\text { Viscosity, cP } \\
\text { @ Reservoir } \\
\text { Temperature }\end{array}$ & \multicolumn{2}{|c|}{ Asphaltenes Content, wt $\%$} \\
\cline { 4 - 5 } & 17.12 & 500 & 12.57 & 1.72 \\
\hline Oil 1 & 18.84 & 900 & 23.76 & 5.71 \\
\hline Oil 2 & 7.97 & 251,000 & 22.26 & 13.40 \\
\hline Oil 3 & 11.56 & 209,000 & 38.76 & 21.42 \\
\hline Oil 4 & 6.11 & $12,000,000$ & 40.08 & 21.27 \\
\hline Oil 5 & & & & \\
\hline
\end{tabular}


Asphaltene content of crude oil is not directly related to crude oil's viscosity and API gravity. Table 1 shows almost same amounts of n-pentane asphaltene for Oil 2 and Oil 3 samples, but their gravities and viscosities are completely different. Same results can also be drawn for n-heptane asphaltene for Oil 4 and Oil 5 samples.

Table 2: CII Index, Carbon, Hydrogen, and Heteroatoms Content of the Crude Oils (Prakoso et al. 2016a)

\begin{tabular}{|c|c|c|c|c|}
\hline \multirow{2}{*}{ Sample } & CII & Carbon & Hydrogen & Heteroatoms** \\
& & wt. $\%$ & wt. $\%$ & 8.9 \\
\hline Oil 1 & 0.74 & 80.60 & 10.50 & 8.0 \\
\hline Oil 2 & 0.86 & 81.00 & 11.00 & 5.9 \\
\hline Oil 3 & 0.54 & 83.50 & 10.60 & 8.4 \\
\hline Oil 4 & 1.03 & 81.30 & 11.50 & 7.2 \\
\hline
\end{tabular}

*CII values are calculated by using equation on Page 2 .

** Heteroatoms are the elements other than Carbon and Hydrogen, hence calculated by subtracting the sum of carbon and hydrogen weight percent from 100.

According to Ashoori and his colleagues CII values below 0.7 exhibits stable asphaltenes and above 0.9 unstable asphaltenes. Consequently, Oil 4 and Oil 5 samples have unstable and Oil 3 sample has stable asphaltenes, whereas Oil 1 and Oil 2 samples have asphaltenes whose stability cannot be determined by using their study (Ashoori et al. 2016).

The lowest carbon content was detected for Oil 1 sample and the highest for Oil 3 sample. Hence, the lowest heteroatom (elements other than carbon and hydrogen) content was 
measured for Oil 3 sample and the highest for Oil 1 sample. Crude oils' heteroatom content was further characterized by metal analysis (Table 3).

While Oil 1 sample is rich in heteroatom content (Table 2), it is poor in metal content (Table 3). Hence, Oil 1 sample's heteroatom content should be mainly oxygen.

On the other side, while Oil 3 sample is poor in heteroatoms (Table 2), it is rich in metal content (Table 3).

Oil 4 sample has the greatest metal content (1271 ppm) among all crude oils tested which is mainly due to vanadium, iron, and molybdenum contents.

Oil 5 sample has the second highest metal content ( $845 \mathrm{ppm})$ which is mainly due to sodium, silica, and vanadium.

For Oil 4 and Oil 5 samples, Sulphur contents also are significantly high.

For Oil 3 sample, vanadium content is considerably high. Note that vanadium and nickel are considered as organometallic compounds, however, sodium and silica have most probably inorganic origin (Wilkinson and Birmingham. 1954; Carey and Sundberg. 2007; Crabtree and Mingos. 2007). Sodium might be originated from reservoir brine and silica from reservoir rock. Therefore, these inorganic constitutes of asphaltenes may decrease the stability of asphaltenes and result in CII values higher than 0.9 . 
Table 3: Elemental Analysis for 5 Crude Oil Samples (ppm) (Prakoso et al. 2016)

\begin{tabular}{|c|c|c|c|c|c|}
\hline Elements & Oil 1 & Oil 2 & Oil 3 & Oil 4 & Oil 5 \\
\hline $\mathrm{Al}$ & 1.2 & 0 & 0 & 0 & 0 \\
\hline B & 9.41 & 4.02 & 1.87 & 1.59 & 18.1 \\
\hline $\mathrm{Ba}$ & 0 & 0 & 0 & 0 & 0 \\
\hline $\mathrm{Ca}$ & 6.96 & 7.14 & 2.5 & 0 & 10.2 \\
\hline $\mathrm{Cr}$ & 0 & 0 & 0 & 0 & 0 \\
\hline $\mathrm{Cu}$ & 1.77 & 0 & 0 & 0 & 0 \\
\hline $\mathrm{Fe}$ & 6.4 & 6.82 & 3.68 & 224 & 31.9 \\
\hline $\mathrm{K}$ & 5.1 & 5 & 5.7 & 5.2 & 13 \\
\hline $\mathrm{Mg}$ & 12.4 & 2.08 & 0 & 0 & 0 \\
\hline Mo & 0 & 0 & 1.4 & 475 & 14.6 \\
\hline $\mathrm{Na}$ & 21.5 & 74.5 & 58.1 & 8.46 & 504 \\
\hline $\mathrm{Ni}$ & 4.31 & 20 & 95.3 & 88.4 & 9.76 \\
\hline $\mathrm{P}$ & 2.1 & 2 & 2.3 & 2.1 & 2.1 \\
\hline $\mathrm{Pb}$ & 0 & 0 & 0 & 0 & 0 \\
\hline$S$ & 32000 & 14300 & 36000 & 52400 & 58200 \\
\hline $\mathrm{Si}$ & 3.49 & 0 & 0 & 45.1 & 131 \\
\hline $\mathrm{Sn}$ & 0 & 0 & 0 & 1.4 & 0 \\
\hline $\mathrm{Ti}$ & 0 & 0 & 2.68 & 0 & 3.9 \\
\hline $\mathrm{V}$ & 10.4 & 38.8 & 402 & 469 & 258 \\
\hline $\mathrm{Zn}$ & 0 & 0 & 4.09 & 0 & 0 \\
\hline Metals* & 70 & 154 & 575 & 1271 & 845 \\
\hline
\end{tabular}

*Metals (in ppm) is the sum of all metallic elements (i.e. Al, $\mathrm{Ca}, \mathrm{Cr}, \mathrm{Cu}, \mathrm{Fe}, \mathrm{K}, \mathrm{Mg}, \mathrm{Mo}, \mathrm{Na}, \mathrm{Ni}, \mathrm{Pb}, \mathrm{Sn}$, $\mathrm{Ti}, \mathrm{V}$, and $\mathrm{Zn}$ )

\subsubsection{Separation of Asphaltenes}

The asphaltene separation standards were defined by ASTM. In our experiments, two ASTM methods were followed (ASTM D2007-11. May 1, 2011 and ASTM D1250-08. Sep1, 2008). Hence, two different precipitation agents were used; n-pentane (nC5) (ASTM D2007) and n-heptane (nC7) (ASTM D1250-08). 
The separation of asphaltene from crude oil starts with measuring 10 grams of crude oil from each sample. The measured oil samples were diluted with $200 \mathrm{ml} \mathrm{n}$-pentane or nheptane. In ASTM method, oil/solvent ratio has been proposed to be $1 \mathrm{gr}$ of oil/10 $\mathrm{ml}$ of solvent. However, researchers shown that the increase in the solvent ratio increases the amount of separated asphaltene (Speight et al. 1984). After the addition of solvent, crude oil and solvent were blended with ultrasonic shaker.

After 30 minutes of stagnation period, mixture charged through filter paper (Sterlitech CFP43 - $2.5 \mu \mathrm{m})$. At the same time, asphaltenes that are collected in filter paper washed with n-pentane or n-heptane. This process takes longer time for the separation of n-heptane asphaltenes than n-pentane asphaltenes. Later on, separated asphaltenes dried at room temperature.

Sigma-Aldrich HPLC and Fischer Scientific HPLC n-pentane and n-heptane were used for separation of asphaltenes. Due to heterogeneities in asphaltene molecules, the amount of separated asphaltenes were different for each measurement. These differences also related to precipitation agents used in separation, temperature, and pressure (Buenrostro-Gonzalez et al. 2004). Our separation is performed at room temperature and standard pressure. Hence, the differences we observed in measurements are due to mainly variances in asphaltene molecules present within crude oils.

\subsubsection{Visualizing Asphaltene Behavior Under Optic Microscope}

Prepared asphaltene samples were visualized as quickly as possible due to asphaltene's high oxidation features (Antonishin et al. 1977). Initially, dried asphaltenes crushed with mortar to make asphaltene particles smaller. In the crude oil, asphaltene sizes vary between $2.5 \mu \mathrm{m}$ and $500 \mu \mathrm{m}$ but after asphaltenes dried on the filter paper, they created bigger clusters. Crushing was necessary to represent reservoir conditions. After crushing, asphaltenes samples were characterized under microscope at dry and wet conditions.

The behavior of asphaltenes were examined with systematic analysis using sand, clay, and sand+clay with asphaltenes with water and brine. Two optical microscopes were used; 
ProgRes CT5 and Zeiss AxioCam ERc5s (See Figure A - 1 and Figure A - 2 for the photographs of optical microscopes).

\subsection{Characterization of Clay}

The clay used in the experiments consisted of $90 \%$ of kaolinite and $10 \%$ of illite (Kar et al. 2015). In the following sections, kaolinite and illite features are discussed.

\subsubsection{Kaolinite}

The first kaolinite crystal structure was proposed by Pauling (Pauling. 1930). Since that day, kaolinite appeals to researchers due to its retention capabilities (Kim et al. 1996). Kaolinite has 1:1 layer formed by a tetrahedral $\mathrm{SiO}_{4}$ connected to octahedral $\mathrm{Al}(\mathrm{OH})_{6}$ sheets and some inorganic structure (Reinoso-Maset and Ly. 2014). The chemical composition of Kaolinite is given as $\mathrm{Al}_{2} \mathrm{Si}_{2} \mathrm{O}_{5}(\mathrm{OH})_{4}$ (Vasconcelos et al. 2007; Kar et al. 2015). The $\mathrm{Al}(\mathrm{OH})_{6}$ layer of kaolinite is named as gibbsite aluminum octahedral sheet and $\mathrm{SiO}_{4}$ layer is named as siloxane silicon tetrahedral sheet. These two layers are connected to each other with oxygens.

There are two different adsorption mechanisms on kaolinite with two separate places. One of the adsorptions is related to the surface charges of kaolinite. These charged sites also known as permanently charged sites which have negative charges. Second adsorption mechanism depends on $\mathrm{pH}$ and named as hydroxylated sites (Reinoso-Maset and Ly. 2014). Hydroxylated sites of the kaolinite have a small percentage of adsorption ability between $\mathrm{pH} 4.5$ and 6 . However, at $\mathrm{pH}>6$, adsorption starts to increase until $\mathrm{pH} 8$ (Vasconcelos et al. 2007). Thus, $\mathrm{pH}$ is a major factor that can affect our results due to the presence of the high percentage of kaolinite in our clay sample.

\subsubsection{Illite}

The chemical formula of illite has been studied for a long time because of its complexity. Published chemical data were obtained from mudrock samples using indirect analysis methods (Newman. 1987; Weaver and Pollard. 1973; Deer et al. 1992). These studies show that illite has variable chemical composition. After the modern techniques applied to clay science, direct analysis techniques performed to investigate illite chemical composition by 
using electron microscope (Merino and Ransom. 1982; Velde. 2000). In contrast to indirect researches, direct studies prove that the chemical composition of illite is not as variable as shown before and different chemical formulas for illite were proposed. One of the chemical formulas for illite is $\mathrm{M}_{\mathrm{x}}\left[\mathrm{Si}_{6.8} \mathrm{Al}_{1.2}\right]-\mathrm{Al}_{3} \mathrm{Fe}_{0.25} \mathrm{Mg}_{0.75} \mathrm{O}_{20}(\mathrm{OH})_{4}$ where $\mathrm{M}$ is a monovalent interlamellar cation (Sposito. 2008). Illite is a part of the 2:1 clay family and it has aluminosilicate layers containing two tetrahedral (silica) sheets squeezing in one octahedral (alumina) layer (Hatch et al. 2012). In addition to this chemical formula, other formulas have been proposed. The examples are $\mathrm{K}_{0.88} \mathrm{Al}_{2}\left(\mathrm{Si}_{3.12} \mathrm{Al}_{0.88}\right) \mathrm{O}_{10}(\mathrm{OH})_{2}$ and $\left(\mathrm{K}, \mathrm{H}_{3} \mathrm{O}\right)(\mathrm{Al}, \mathrm{Fe})_{2}(\mathrm{Si}, \mathrm{Al})_{4} \mathrm{O}_{10}\left[(\mathrm{OH})_{2},\left(\mathrm{H}_{2} \mathrm{O}\right)\right]$ (Martinez et al. 2010; Kar et al. 2015). As seen from these examples, the chemical formula of illite can vary according to the origin of the illite clay minerals. Different illite types and their chemical compositions are given in Figure A - 3 (Marshall. 1949).

\subsubsection{Cation Exchange Capacity of the Clay Minerals}

The adsorption ability of clay can be explained with the cation exchange capacity (CEC). Cation exchange capacity defined as "the amount of positive ion substitution that takes place per unit weight of dry rock" (Johnson and Linke. 1977). Different clays have different adsorption affinity. For example, illite has $15 \mathrm{meq} / 100 \mathrm{~g}$ cation exchange capacity and kaolinite has $3 \mathrm{meq} / 100 \mathrm{~g}$ (Scheuerman and Bergersen. 1990). In addition to cation exchange capacity, flocculation salinity of clay is also important. Because clays have negatively charged sites on them (permanently charged sites), clay attracts metallic ions in the aqueous phase. Because of this attraction, clay particle is surrounded by cations (counter-ions) located on and near the clay surface to provide neutralization of electrical charges of clay lattice. The opposing forces of electrostatic attraction to the negative clay lattice and diffusion into the surrounding bulk solution determine the distribution of counter-ions. The diffused concentration of cations around the clay particle is named as the counter-ion cloud. Flocculation salinity is the cation concentration of the brine at which diffusion forces are equal to van der Waals attractive forces on the clay particle surfaces. If diffusion forces exceed the van der Waals attractive forces, the clay particles start to disperse in the solution. 
Flocculation salinity is influenced by three factors; clay type, cation type, and temperature. The flocculation salinity decreases with cation exchange capacity. For instance, the flocculation salinities of illite $(\mathrm{CEC}=15 \mathrm{meq} / 100 \mathrm{~g})$ and kaolinite $(\mathrm{CEC}=3 \mathrm{meq} / 100 \mathrm{~g})$ are 200 and $17 \mathrm{meq} / \mathrm{L}$, respectively. The second and most complicated factor on flocculation salinity is cation type. Lyotropic series sorts hydrated anions and cations based on their affinity. At the same valence, flocculating power declines with increasing hydrated ionic radius. In other words, flocculation power decreases in the order of $\mathrm{Cs}^{+}>\mathrm{Rb}^{+}>\mathrm{K}^{+}>\mathrm{Na}^{+}>\mathrm{Li}^{+}$ for monovalent cations (Gaudin et al. 1952). This sorting is given for divalent cations as $\mathrm{Ba}^{+2}>\mathrm{Sr}^{+2}>\mathrm{Ca}^{+2}>\mathrm{Mg}^{+2}$ (Malati and Estefan. 1966; Van Olphen and Hsu. 1978; Vinegar and Waxman. 1984). In addition, the affinity of different valence cations can sort as trivalent $>$ divalent $>$ monovalent cations. The effect of divalent cations on flocculating are 50 to 100 times more than monovalent cations depending on clay type. In other words, at the same ion concentrations of the $\mathrm{Ca}^{+2}$ and $\mathrm{Na}^{+}, \mathrm{Ca}^{+2}$ ions disperse more clay particles than $\mathrm{Na}^{+}$ions. The last factor that affects flocculation salinity is temperature. When formation temperature increases, the flocculation salinity decreases (Khilar and Fogler. 1984).

Based on the information given about the kaolinite and illite, it can be inferred that the asphaltene stability depends on clays polarity and the $\mathrm{pH}$. The $\mathrm{pH}$ of salt solution is theoretically same for all concentrations of salt because $\mathrm{pH}$ only depends on the $\mathrm{H}^{+}$or $\mathrm{OH}^{-}$ ions presence in aqueous solution (Bates and Vijh. 1973). In this study, distilled water was used in all experiments. The $\mathrm{pH}$ of distilled water is 7.0 which means neither acidic or basic. In our interpretations, this information will be considered.

\subsection{Characterization of the Sand}

The features of Ottawa sand have been studied before and chemical composition was obtained from energy-dispersive X-ray spectroscopy (EDS). The elemental composition results show that Ottawa sand consists of a high percentage of oxygen $(\mathrm{O})$ and sulfur $(\mathrm{S})$ as expected. Additionally, there are less amounts of carbon (C), aluminum (Al), iron ( $\mathrm{Fe})$, and calcium (Ca). The percentage of these elements are given in Figure 4 (Kar et al. 2015). In addition to elemental analysis of Ottawa Sand, some other valuable features are provided in Table 4 (Zhuang et al. 2003). 


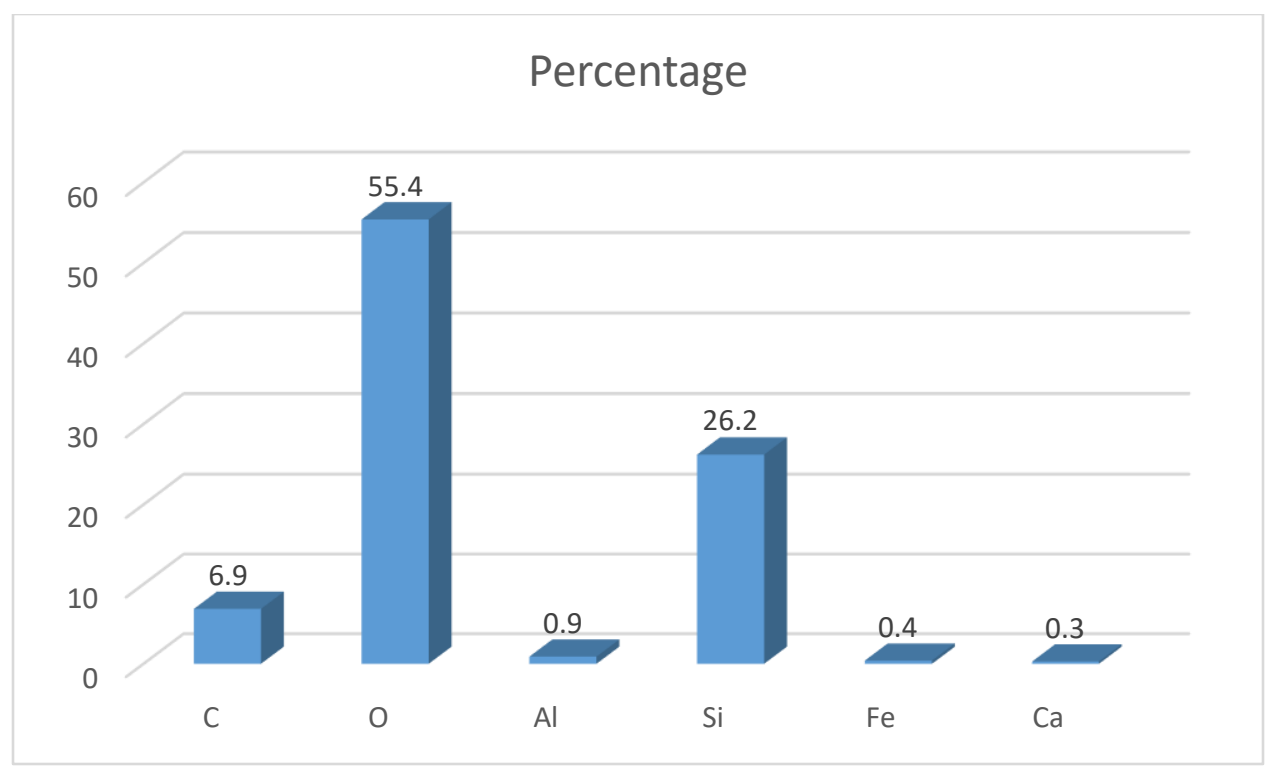

Figure 4: Elemental Analysis of Ottawa Sand (wt\%)

Table 4: Features of Ottawa Sand (Zhuang et al. 2003)

\begin{tabular}{|c|c|c|c|c|c|c|}
\hline Material & $\begin{array}{c}\mathrm{CEC} \\
(\mathrm{cmol} / \mathrm{Kg})\end{array}$ & $\mathrm{SA}\left(\mathrm{m}^{2} / \mathrm{g}\right)$ & $\mathrm{Fe}_{0}(\mathrm{mg} / \mathrm{kg})$ & $\mathrm{Al}_{0}(\mathrm{mg} / \mathrm{kg})$ & $\mathrm{OM}(\mathrm{g} / \mathrm{kg})$ & $\mathrm{Dg}(\mathrm{mm})$ \\
\hline $\begin{array}{c}\text { Ottawa } \\
\text { Sand }\end{array}$ & 0.6 & 0.07 & 28.7 & 18.4 & 0.4 & 0.44 \\
\hline
\end{tabular}

In this table, $\mathrm{CEC}$ is the cation exchange capacity, $\mathrm{SA}$ is specific surface area, $\mathrm{Fe}_{0}$ and $\mathrm{Al}_{0}$ are dissolved $\mathrm{Fe}$ and $\mathrm{Al}$ metals in $6 \mathrm{M} \mathrm{HNO}_{3}, \mathrm{OM}$ is organic matter content, and $\mathrm{Dg}$ is the geometric diameter of sand grains.

\subsection{Wettability Alteration}

\subsubsection{Sample Preparation}

In this study, contact angle measurements were conducted to find a relationship between asphaltene deposition and wettability alteration. Before contact angle measurements, pseudo reservoir samples were prepared. The composition of reservoir rock samples consisted of 85 wt\% Ottawa Sand (20-40 mesh size) and 15 wt\% clay (which contains 90 $\mathrm{wt} \%$ kaolinite and $10 \mathrm{wt} \%$ illite) mixture. The pore space of this mixture (26.67\%) was filled with 84 volume $\%$ of oil and 16 volume $\%$ of water or brine. 


\subsubsection{Contact Angle Measurements}

Water-air contact angle measurements were performed by Kruss DSA30S Contact Angle measurement device. These measurements were converted into water-oil contact angles using correlation (Grate et al. 2012). According to wettability definitions, measured contact angle ranges of $0^{\circ}$ to $55^{\circ}, 56^{\circ}$ to $75^{\circ}, 76^{\circ}$ to $115^{\circ}, 116^{\circ}$ to $135^{\circ}$ and $136^{\circ}$ to $180^{\circ}$ refer to water-wet, weakly water-wet, intermediate-wet, weakly oil-wet and oil-wet, respectively (Anderson. 1986). (See Figure A - 4 for the photograph of contact angle measurement device). 


\section{CHAPTER 4 \\ RESULTS AND DISCUSSIONS}

In this study, two different optical microscopes with different magnification scales were used. The results were evaluated by using 10x and 40x magnification microscope images. 20x and 100x images were also captured for detailed observations. 40x and 100x images were obtained with Jenoptik microscope and 10x and 20x images were captured with Zeiss microscope. During the experiments, asphaltenes or asphaltenes-clay mixtures observed to settle or float in the water/brine system on the microscope glass.

All results are presented in figures followed by discussion.

\subsection{Asphaltene-Water/Brine Interaction}

In this section, the asphaltene behavior with water and brine and without porous media was studied. First, systematic control experiments were conducted with asphaltene-water and asphatene-brine systems. Then the contribution of porous media on this interaction was examined.

Figure 5 shows microscopic images of asphaltene alone, mixture of [asphaltene+water], and mixture of $0.2 \%$ [brine+asphaltene] for both n-pentane and n-heptane insoluble at $40 \mathrm{X}$ magnification. Similarly, Figure 6, Figure 7, and Figure 8 show same images for the 2\%, $4 \%, 6 \%$, and $8 \%$ of $\mathrm{NaCl}$ and $\mathrm{CaCl}_{2}$ brines for both $\mathrm{n}$-pentane and $\mathrm{n}$-heptane insoluble at $5 \mathrm{X}$ magnification. Note that these images were captured by two different microscopes, for that reason, they were captured on different magnification. 


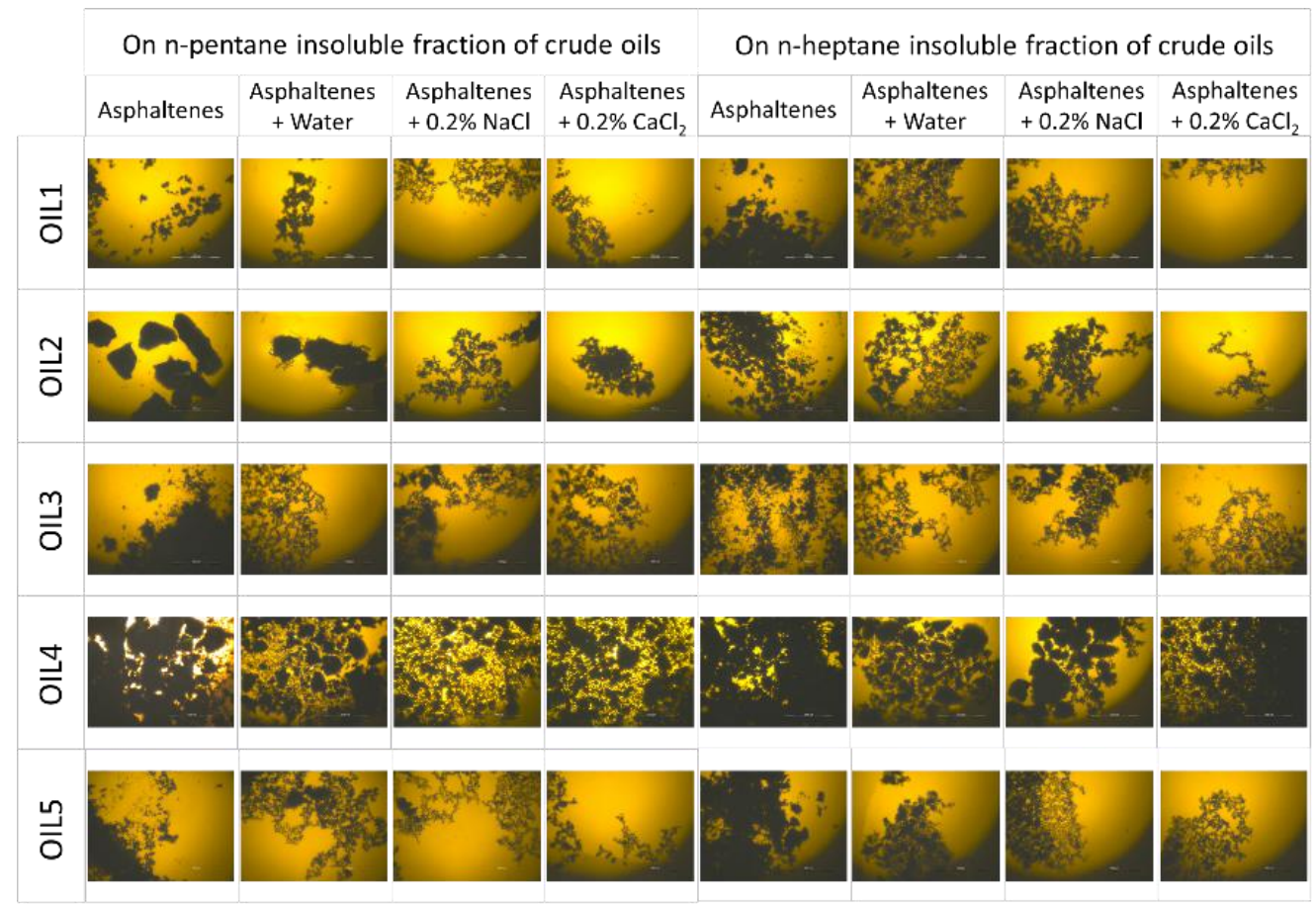

Figure 5: Asphaltene-water and asphaltene- $0.2 \%$ brine interactions for both $n$-pentane and $n$-heptane insoluble fractions of crude oils at $40 \mathrm{X}$ magnification

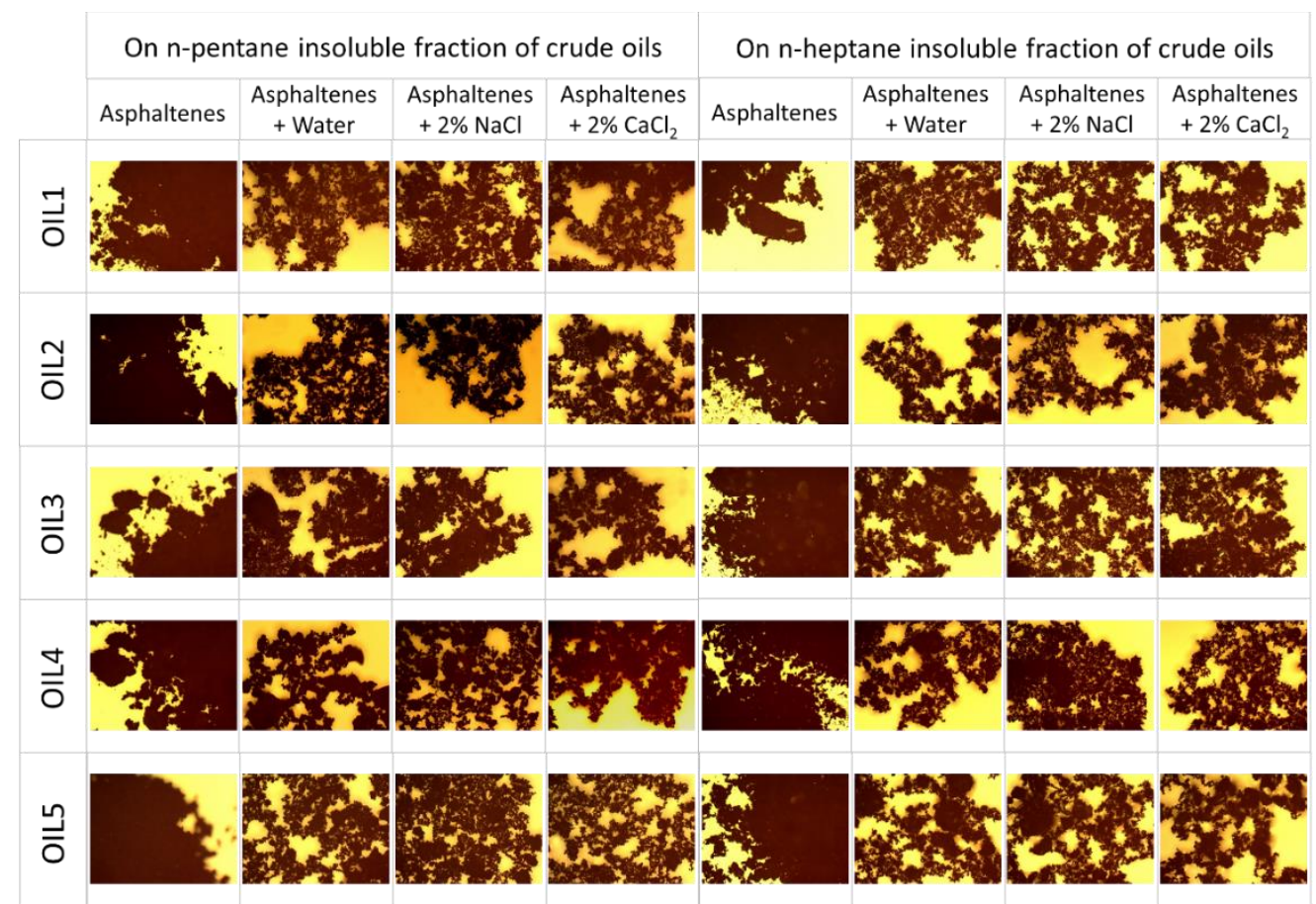

Figure 6: Asphaltene-water and asphaltene-2\% brine interactions for both $\mathrm{n}$-pentane and $\mathrm{n}$-heptane insoluble fractions of crude oils at $5 \mathrm{X}$ magnification 


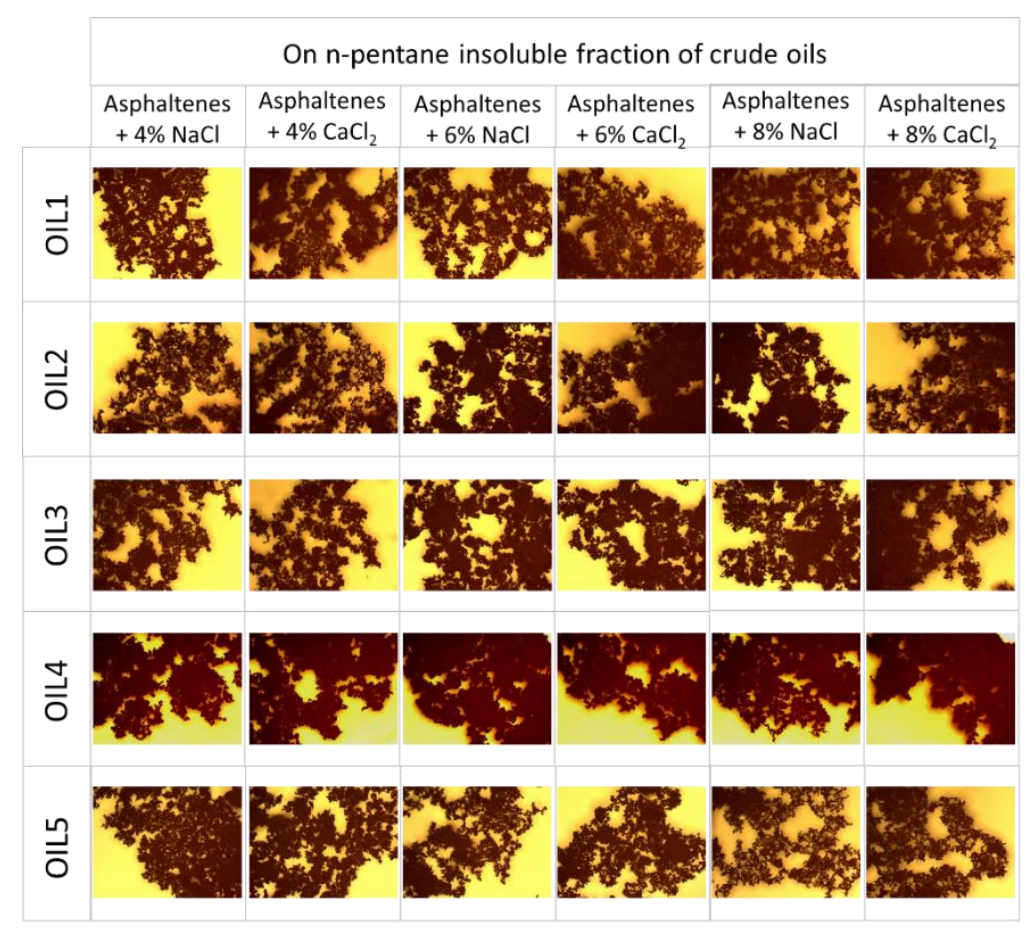

Figure 7: Asphaltene-water and asphaltene-4\%, 6\% and $8 \%$ brine interactions for both $n$-pentane insoluble fractions of crude oils at $5 \mathrm{X}$ magnification

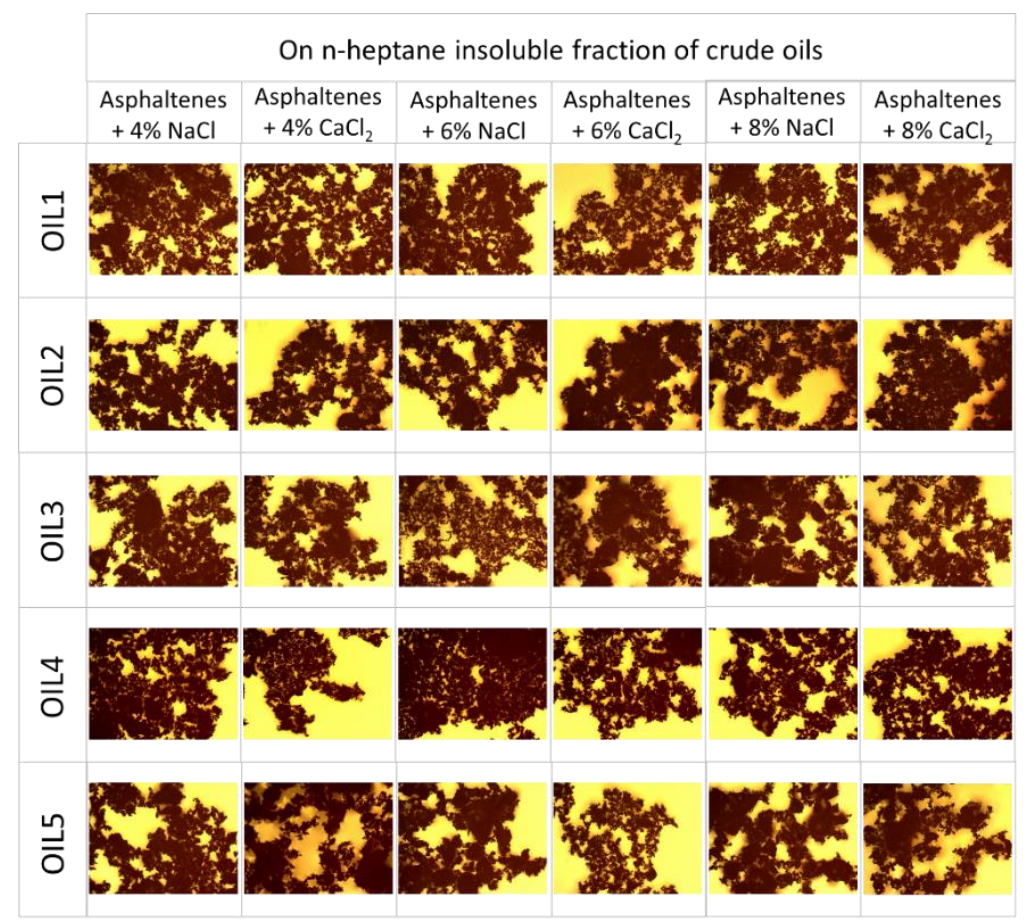

Figure 8: Asphaltene-water and asphaltene- $4 \%, 6 \%$ and $8 \%$ brine interactions for both $\mathrm{n}$-heptane insoluble fractions of crude oils at $5 \mathrm{X}$ magnification 
Based on observations, dry samples of asphaltenes aggregate because of their polar ends. On the other hand, the addition of water makes both n-pentane and n-heptane asphaltenes more disperse in the solution. As a general observation, n-pentane asphaltenes have bigger clusters than n-pentane asphaltenes in water and brine environments. Experimental results show that in the $0.2 \%$ and $2 \%$ of brine addition does not give visible effect on asphaltene flocculation while $4 \%, 6 \%$ and $8 \%$ of brine addition gives good results. Another interesting outcome of these experiments is the increase in cluster size of asphaltenes with the increase in concentration of brines. It was also observed that the brine solution prepared with $\mathrm{CaCl}_{2}$ resulted in bigger asphaltene clusters than the brine solution prepared with $\mathrm{NaCl}$.

The asphaltene stability in dry and wet conditions highly depends on the elemental composition of the crude oil and asphaltene samples. The elemental analysis of crude oil composition was not part of this research and they were imported from a published research and are given in Table 3. To relate published composition with asphaltene behavior presented in this study, graphical forms of elements composition of oil are used (see Figure A - 5 through Figure A - 11).

The first and fifth columns of Figure 5 and Figure 6 show that dry asphaltenes have a tendency to form bigger clusters. As seen from the microscope images, there is no significant difference among dry asphaltene samples. All samples create clusters because of their polar structures. In addition to this behavior, cluster sizes can be examined from the images. nC5 asphaltenes of Oil 2 and Oil 4 samples have bigger cluster sizes than the asphaltenes from other oils.

As expected, adding water caused dispersion of asphaltenes. Figures 5 and 6 show different dispersion behavior for Oil 1 sample than other oils for both nC5 and nC7 asphaltenes. As seen in Figure 6, the asphaltene particles of Oil 1 sample was more dispersed in water than the others. Mainly, small particle sized asphaltenes formed bridges between the bigger asphaltene clusters, thus the total cluster sizes of $\mathrm{nC} 5$ and $\mathrm{nC7}$ asphaltenes become bigger than other oil's asphaltene samples. In addition to the Oil 1 sample, nC5 asphaltenes of Oil 2 and Oil 5 samples also have the same behavior. Higher amounts of small asphaltene particles are visible between bigger asphaltene clusters for nC5 asphaltenes of Oil 2 and 
Oil 5 samples. Further, Oil 3 and Oil 4 samples indicate different behavior for nC5 asphaltenes. They have larger aggregates than the other asphaltene samples while same behavior was not observed for the $\mathrm{nC} 7$ asphaltenes of Oil 3 sample.

However, $\mathrm{nC} 7$ asphaltenes are different. In general, small particle size asphaltenes are encountered more in $\mathrm{n}$-heptane asphaltenes in water environment than $\mathrm{n}$-pentane asphaltenes. This observation can be accepted as normal because some researches show the particle size of asphaltenes getting smaller when the carbon number of precipitated agents increase (Calles et al. 2007). This behavior is also supported with the filtration time of the asphaltene. As mentioned earlier, asphaltene percolated when washed with n-pentane and $\mathrm{n}$-heptane. When the percolation times considered, $\mathrm{n}$-heptane asphaltenes percolation time is greater than n-pentane asphaltenes due to n-heptane asphaltene's small cluster size.

In these experiments, deionized water was used. Due to the surface tension of water, asphaltenes disperse in the water drop. However, due to the asphaltene polarity, asphaltene particles have dipoles on their surface. Moreover, asphaltenes have inorganic content as reported in Table 3 which may create electrical charges.

Due to the ionic content of brine, the behavior of asphaltene dispersion is different than the water environment. $\mathrm{NaCl}$ ionizes in water as $\mathrm{Na}^{+}$and $\mathrm{Cl}^{-}$and $\mathrm{CaCl}_{2}$ ionizes in water as $\mathrm{Ca}^{+2}$ and $\mathrm{Cl}^{-}$. Therefore, these positive and negative ions in brine will affect asphaltene attitude. The effect of brine on asphaltene behavior can be observed in Figure 5 through Figure 8. Figure 5 shows first experimental set and the other three figures are for second experiment set.

The effect of $\mathrm{NaCl}$ and $\mathrm{CaCl}_{2}$ salts is not visible in $0.2 \%$ salt concentration which can be seen in Figure 5. Since the $0.2 \%$ concentration is low, at this magnification, the behavior of asphaltenes is not visible under an optical microscope. These low concentration experiments have to be examined under electrical microscopy to see brine's impact in detail.

However, in the second experiment set, it can be clearly seen that asphaltene distribution varies among different concentrations. Figure 6, Figure 7 and Figure 8 shows the second 
experiment set at concentrations of $2 \%, 4 \%, 6 \%$, and $8 \%$ with $\mathrm{NaCl}$ and $\mathrm{CaCl}_{2}$. The influences of salt are especially visible for Oil 1 and Oil 2 samples for both nC5 and nC7 asphaltenes. Based on same images, when moving from the low concentration to high concentration of salt, asphaltene cluster sizes increase and small particle of asphaltenes become less visible.

nC5 and nC7 asphaltenes of Oil 3 and Oil 5 samples indicate no significant difference from Oil 1 and Oil 2 samples' asphaltenes. There are some differences visible with Oil 1 and Oil 2 samples' asphaltenes in different concentrations of $\mathrm{NaCl}$ and $\mathrm{CaCl}_{2}$. However, nC5 and nC7 asphaltenes of Oil 4 sample show no change in $\mathrm{NaCl}$ and $\mathrm{CaCl}_{2}$ at different concentrations.

The polarity of asphaltenes are related with the heteroatom content of asphaltenes (Prakoso et al. 2016). The connection between crude oil chemical composition and $\mathrm{nC} 5$ and $\mathrm{nC} 7$ insoluble asphaltenes can be explained with the Fourier Transform Infrared Spectroscopy (FTIR). FTIR spectroscopy is a method used to acquire an infrared spectrum of emission or absorption of a solid, liquid, and gas (Griffiths and De Haseth. 2007). FTIR spectroscopy graph draws wavenumbers to absorbance lines. Every peak in the FTIR result refers a functional group, and every functional group has a particular wavenumber range which can help researchers to determine different functional groups.

Previous studies have shown that FTIR spectroscopy of n-pentane and n-heptane asphaltenes illustrate similar peaks, which means a similar molecular structure, and unnoticeable features (Nalwaya et al. 1999). Figure A - 12, Figure A - 13 and Figure A 14 show FTIR spectra of the crude oils which were used in this study. The three figures clearly show similar spectrum for crude oil, n-pentane, and n-heptane asphaltenes although they have different absorbances. In these FTIR spectra, higher absorbance peaks indicate the presence of heteroatoms (Speight and Moschopedis. 1979). These peaks show npentane and n-heptane asphaltenes have a higher concentration of heteroatoms.

Further, same peaks are also observed for crude oil which means the most of the heteroatoms in the crude oil are concentrated in the asphaltene fraction (Speight. 2014). As a conclusion, the elemental analysis of crude oil might be used as a reference of n-pentane 
and n-heptane elemental composition since there is a relation between heteroatom composition of crude oil samples and their n-pentane and n-heptane asphaltenes.

Based on this observation, crude oil elemental data can be used in deciding the polarity of asphaltenes. The heteroatom content of the crude oils from Figure A - 11 suggests that the polarity of asphaltenes can be sorted as the asphaltenes of Oil 4>Oil 5>Oil 2>Oil 1>Oil 3. However, if every heteroatom is examined element by element, it can be seen that every oil has a different type of heteroatom more than other but Oil 4 sample has massive heteroatom content in every type of elements. A different behavior was expected from Oil 4 sample when brine was used in the environment, however, nC5 and nC7 asphaltenes did not show any clue about their attitude in $\mathrm{NaCl}$ and $\mathrm{CaCl}_{2}$ solutions. Nonetheless, this behavior can be related with $\mathrm{Na}$ and $\mathrm{Ca}$ content of Oil 4 sample. Figure A - 5 and Figure A - 6 show $\mathrm{Ca}$ and $\mathrm{Na}$ composition of crude oils. These two graphs show that Oil 4 sample has no Ca content although it has very little amount of $\mathrm{Na}$ which is the least amounts of $\mathrm{Na}$ and $\mathrm{Ca}$ compared to other crude oils. Thus, $\mathrm{Na}$ and $\mathrm{Ca}$ content of the $\mathrm{nC} 5$ and $\mathrm{nC} 7$ asphaltenes of Oil 4 was the lowest of all samples. The strange behavior of asphaltenes of Oil 4 sample can be explained by the lack of $\mathrm{Na}$ and $\mathrm{Ca}$ content. $\mathrm{Na}$ and $\mathrm{Ca}$ atoms can excessively effect the asphaltenes polarity. Asphaltenes behavior will be checked with asphaltene+sand, asphaltene+clay, and asphaltene+sand+clay and results will be reviewed to confirm this idea.

The asphaltene stability in brine might be related to Ca content since the four oils have more $\mathrm{Ca}$ content than the asphaltene of Oil 4 sample and they indicate a difference at every concentration of salt. In addition, when the most affected asphaltenes of Oil 1 and Oil 2 samples are investigated, their low metal content can draw attention. As a normal trend, low metal content asphaltenes expected to indicate more stability because of their less polar structure. However, the nC5 and $\mathrm{nC7}$ asphaltenes of Oil 1 and Oil 2 samples show the opposite behavior and their cluster sizes becomes bigger while the salt concentration increases. The same behavior was observed for Oil 3 and Oil 5 samples.

The effect of brine type was not exactly visible in the experiments. Some of the images show that $\mathrm{NaCl}$ contributes to bigger cluster sizes, other experiments show vice versa. In 
this case, the expectancy is smaller aggregates in $\mathrm{CaCl}_{2}$ brine because of the diameter and affinity of $\mathrm{Ca}^{+2}$ ions. $\mathrm{Ca}^{+2}$ ions are bigger than $\mathrm{Na}^{+}$ions which mean there is more space between asphaltene particles. However, these microscope images do not show any differences because of their magnitudes being smaller than the magnifications of the instrument. 


\subsection{Asphaltene+Clay-Water/Brine Interaction}

In this section, the results for [asphaltene+clay] interaction in dry and wet conditions are presented. Figure 9 shows the microscope images obtained at 40X magnification for dry asphaltenes, asphaltene-water mixture and asphaltene-brine mixture prepared with $0.2 \%$ $\mathrm{NaCl}$ or $\mathrm{CaCl}_{2}$ concentrations for $\mathrm{n}$-pentane and $\mathrm{n}$-heptane insoluble. Figure 10, Figure 11 and Figure 12 show similar microscope images at $5 \mathrm{X}$ magnification for salt concentrations of $2 \%, 4 \%, 6 \%$, and $8 \%$ for both $n$-pentane and $n$-heptane insoluble.



Figure 9: Asphaltene-water and asphaltene- $0.2 \%$ brine interactions for both $n$-pentane and $n$-heptane insoluble fractions of crude oils within porous media prepared by only clay at $40 \mathrm{X}$ magnification 


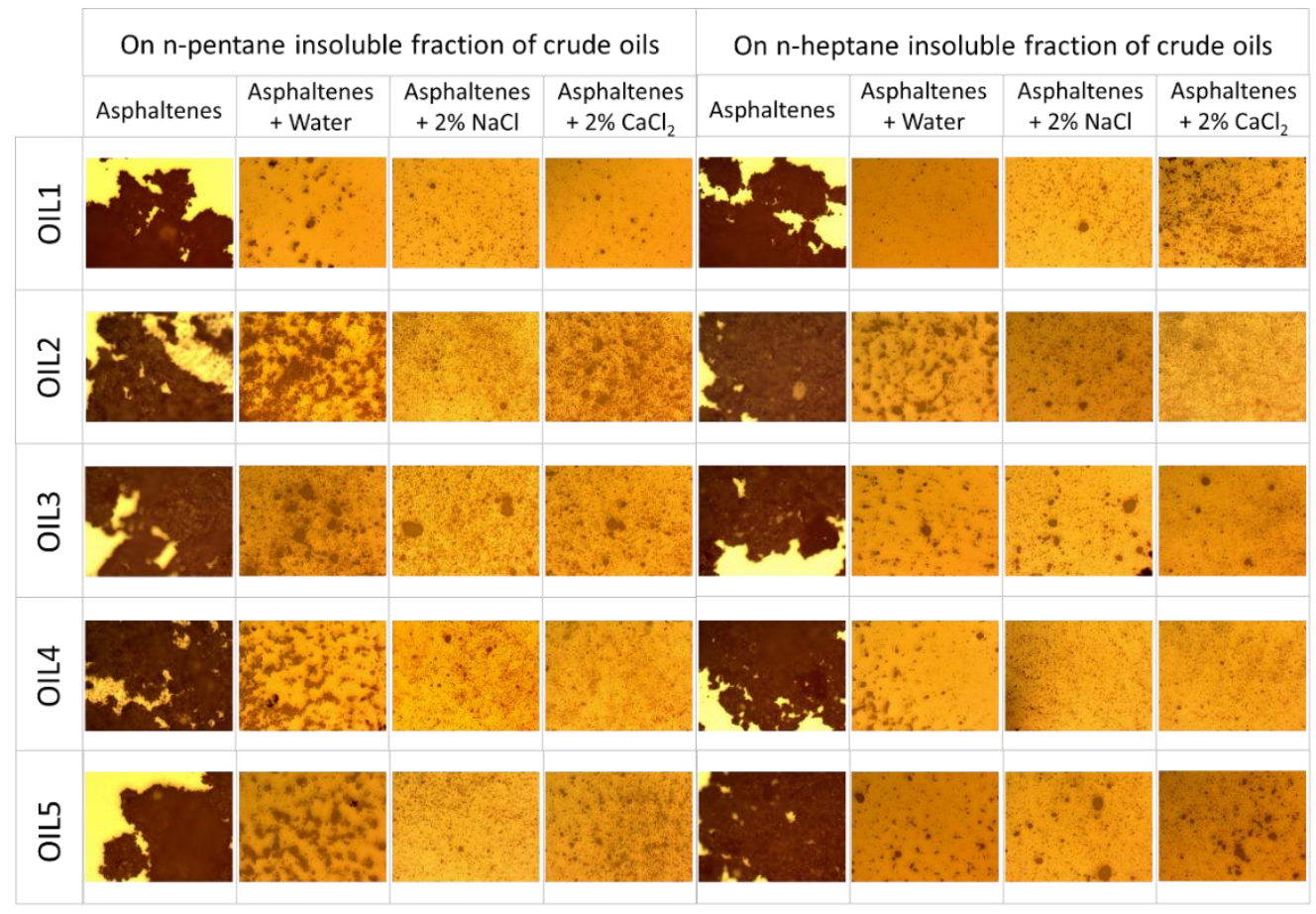

Figure 10: Asphaltene-water and asphaltene-2\% brine interactions for both $\mathrm{n}$-pentane and $\mathrm{n}$-heptane insoluble fractions of crude oils within porous media prepared by only clay at $5 \mathrm{X}$ magnification

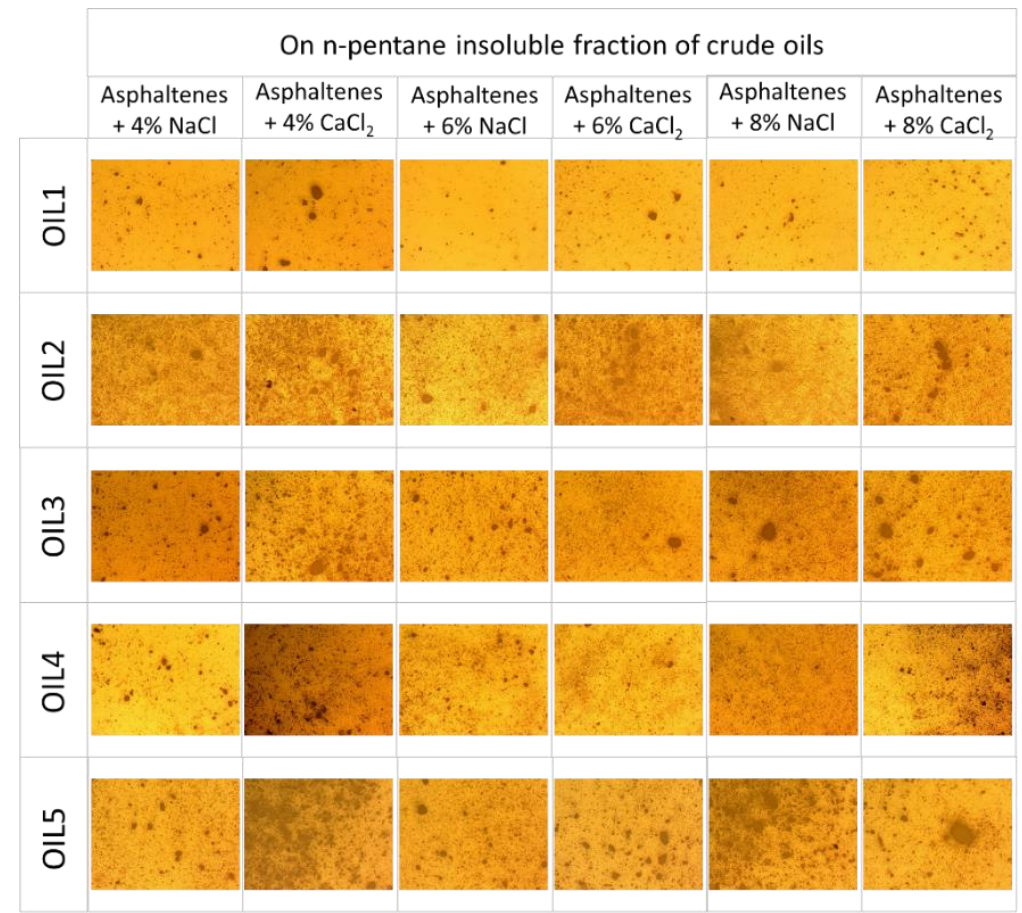

Figure 11: Asphaltene-water and asphaltene- $4 \%, 6 \%$ and $8 \%$ brine interactions for both $\mathrm{n}$-pentane insoluble fractions of crude oils within porous media prepared by only clay at $5 \mathrm{X}$ magnification 


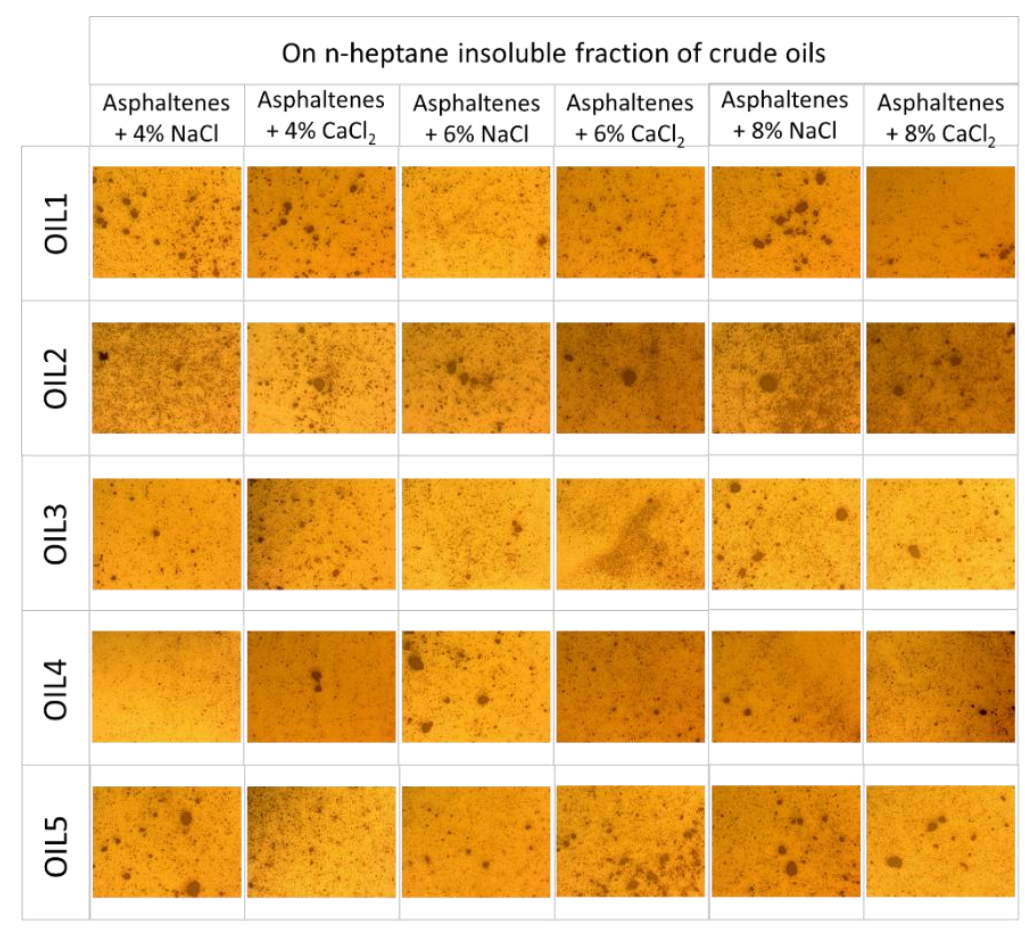

Figure 12: Asphaltene-water and asphaltene- $4 \%, 6 \%$ and $8 \%$ brine interactions for both $n$-heptane insoluble fractions of crude oils within porous media prepared by only clay at $5 \mathrm{X}$ magnification

The clay used in this experiments was consisted of $90 \%$ of kaolinite and $10 \%$ of illite. As a first observation, in the dry [asphaltene+clay] environment, clay particles encircled asphaltene clusters, herewith, [asphaltene+clay] mixtures' sizes are increased when we compared to dry asphaltene environment. It was also observed that with the clay addition, the size of asphaltenes' aggregates are grown in water while their sizes decreased in brine solutions at the constant concentration of $2 \%$. Therefore, it is concluded that clays dispersed more in brine than in water resulting in lesser aggregation of asphaltenes. As observed for the first set of experiments (Figure 5 through Figure 8) with the absence of clay, the results of the second set concluded with the same findings with the presence of clay; asphaltene clusters in brine with $\mathrm{CaCl}_{2}$ are bigger than the brine with $\mathrm{NaCl}$. Additionally, the exact sizes of aggregates were not observable on the flocculated particles.

It is worth to highlight it again that some of the clay and asphaltene particles floated on water/brine while some other particles settled on the microscope slide. Figure 10, Figure 11 and Figure 12 show the location of asphaltenes and clays settled on the microscope slide. Based on these images, it was apparently that dry asphaltenes and clay particles create large aggregates due to asphaltenes and clays polar features. Positive or negative 
polar sides of asphaltenes and clays impact each other and forms larger aggregates. Because the clay minerals are smaller than asphaltenes, they filled asphaltenes pores and coated asphaltene particles too.

In the case of settled particles, there were some noticeable results as seen from the figures. Mostly clay minerals settled on the microscope slide. Due to the density difference between asphaltenes and clays, mainly clay minerals are observed in the settled part. However, some small particle-sized asphaltenes were also observed with the settled clay. The reason for this interaction is attributed to the polar sides of clay and asphaltenes as clay has positive and negative ion attracted sides on its surfaces. These surfaces attracted small particle-sized asphaltenes. In asphaltenes water/brine solutions, there was no observation that asphaltenes sink in water. However, the gravity forces between the clays and small particle-asphaltenes were strong enough to settled together on the microscope slides.

The dispersion pattern of clays was another important observation for settled particles. As clearly shown in images, clay minerals create big clusters in water because there is no ion in the environment. Thus, the polar sites of clay minerals attract each other, and they tend to create clay clusters. On the other hand, the addition of either $\mathrm{NaCl}$ or $\mathrm{CaCl}_{2}$ changes clays behavior in aqueous phase totally. Dispersion of clay minerals on the microscope glass increased with salinity. In the aqueous phase, $\mathrm{NaCl}$ and $\mathrm{CaCl}_{2}$ ionized as $\mathrm{Na}^{+} \mathrm{Ca}^{+2}$ and $\mathrm{Cl}^{-}$and clay, either kaolinite or illite, have positive and negative sites. Negative charge sites called as permanently charged sites and their adsorption features do not depend on $\mathrm{pH}$. However, positive charge sites depend on $\mathrm{pH}$ and optimum $\mathrm{pH}$ range is 6-8. The experimental conditions were proper to observe both these two mechanisms of adsorption because the $\mathrm{pH}$ of distilled water is 7 . Consequently, increasing monovalent and divalent salts ions cause adsorption on the clay surface. In this way, clay minerals lose their polar features due to adsorbed ions, and they become neutral. This effect causes decreasing interaction with another clay particle. Then clay minerals start to dissociate in brine. This dissociation is more obvious in high-concentration-brines. Increasing salt concentration causes more adsorption in more clay particle surfaces. 
The distribution behavior of clay in different brines can be explained by the flocculation salinity. The temperature of the laboratory was constant during the experiments. Therefore, the temperature effect was negligible for all cases and the same clay type was used in all experiments. Therefore, the lyotropic series can help in the interpretation of results. Due to the high dispersion power of $\mathrm{Ca}^{+2}$ ions than $\mathrm{Na}^{+}$ions, the amount of settled clay on the microscope slide must be more in brine solution prepared by $\mathrm{CaCl}_{2}$. As expected, Figure 10 through Figure 12 show that the settled (dispersed) clay particles are more in $\mathrm{CaCl}_{2}$. Our results with divalent cations having more dispersion ability to clays than monovalent cations are similar to results published in literature.

The distribution behavior of clay in different salt concentrations is explained by the critical coagulation concentration (CCC). Critical coagulation concentration defined as the minimum concentration of an electrolyte necessary to flocculate a given colloidal dispersion in each time (Van Olphen and Hsu. 1978). In other means, clay dispersion occurs if the electrolyte concentration is less than CCC. To give more insight, Figure 13 is presented for CCC of kaolinite/illite. In this graph, SAR is sodium adsorption ratio, and it is related to the concentration of brine in the environment (Goldberg et al. 1991).

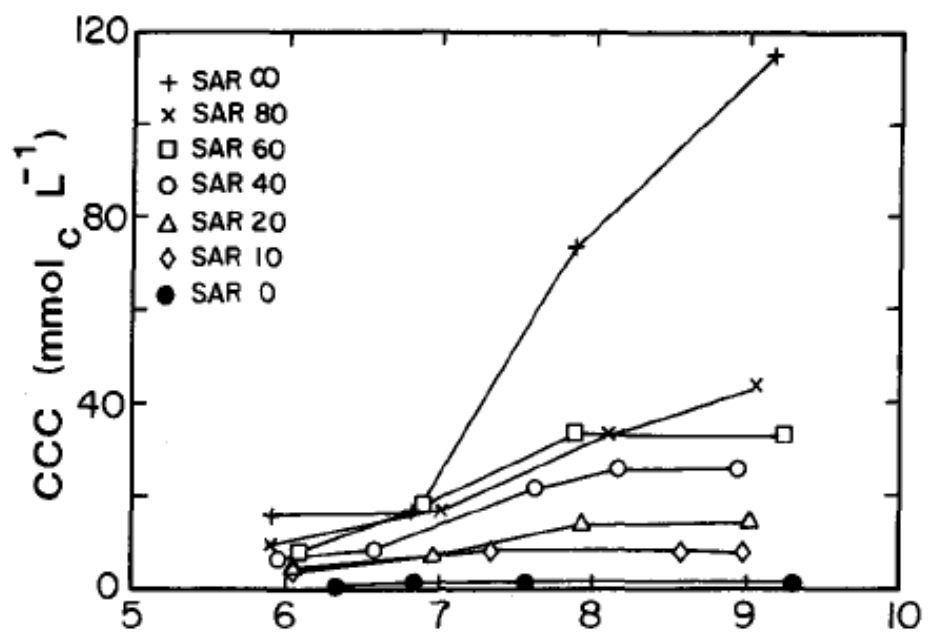

Figure 13: Critical coagulation concentrations of kaolinite/illite as a function of $\mathrm{pH}$ and SAR (Goldberg et al. 1991)

In Figure 13, clay dispersion given as a function of $\mathrm{pH}$ and $\mathrm{SAR}$ for $50 \%$ of kaolinite and $50 \%$ illite mixture. Despite $90 \%$ of kaolinite and $10 \%$ of illite were used in this study, this 
graph can give valuable insight about clay behavior in different concentrations of brine. From the same graph, one can interpret that if sodium adsorption ratio increase, the dispersion tendency of clay increases at a given $\mathrm{pH}$ and the dispersion tendency of clays increases at constant $\mathrm{pH}$.

$\mathrm{pH}$ in brine environment also influences the flocculation characteristic. In Figure 13, SAR can be defined as $\mathrm{Na}$ adsorption ratio onto the kaolinite/illite mixture. From the graph, if adsorbed ion ratio increases, the flocculation value (CCC) increases which means dispersion of clay decreases. However, in our test conditions $(\mathrm{pH}=7)$ this difference was

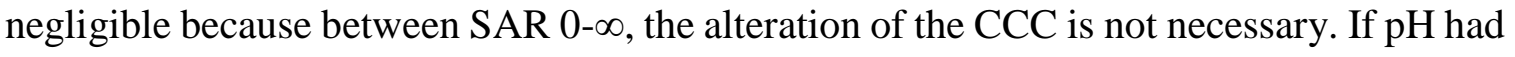
been more than 7 , this effect will be considerable since the presence of divalent ions will affect the flocculation more than $\mathrm{pH}$.

In the flocculated asphaltene and clays, the scenario is different. While it is difficult to observe differences in asphaltenes behavior under optical microscopes, valuable information was extracted from Figure 14 and Figure 15.

The reason for not observing any distinct differences between flocculated samples was again related to clay particles adsorption ability. While the salinity increased in the aqueous phase, the adsorbed $\mathrm{Na}^{+}$and $\mathrm{Ca}^{+2}$ ions by the clay surfaces also increased. Thus, the concentration of the cations decreased in the reservoir fluid. As cations, also $\mathrm{pH}$ depended on positive sides of the clay adsorb $\mathrm{Cl}^{-}$anions on the surface. Thus, the concentrations of cations and anions decreased in the aqueous phase. Namely, asphaltenes positive polar sites just bonded with the clays particles and they were not affected by cation and anions due to clay's higher adsorption ability. However, due to complex nature of asphaltenes, their behavior cannot be easily predicted.

One of the most notable observation was pore filling feature of clays; small clay particles fill the spaces between asphaltenes which results in formation of bigger asphaltenes-clay clusters. The crystallization tendency of $\mathrm{NaCl}$ and $\mathrm{CaCl}_{2}$ salts were observed. Some salt crystals were observed on the asphaltene and clay surface. Figure 16 shows salt crystals and clay bridges between nC5 asphaltene from Oil 3 sample in brine prepared with $\mathrm{CaCl}_{2}$. 


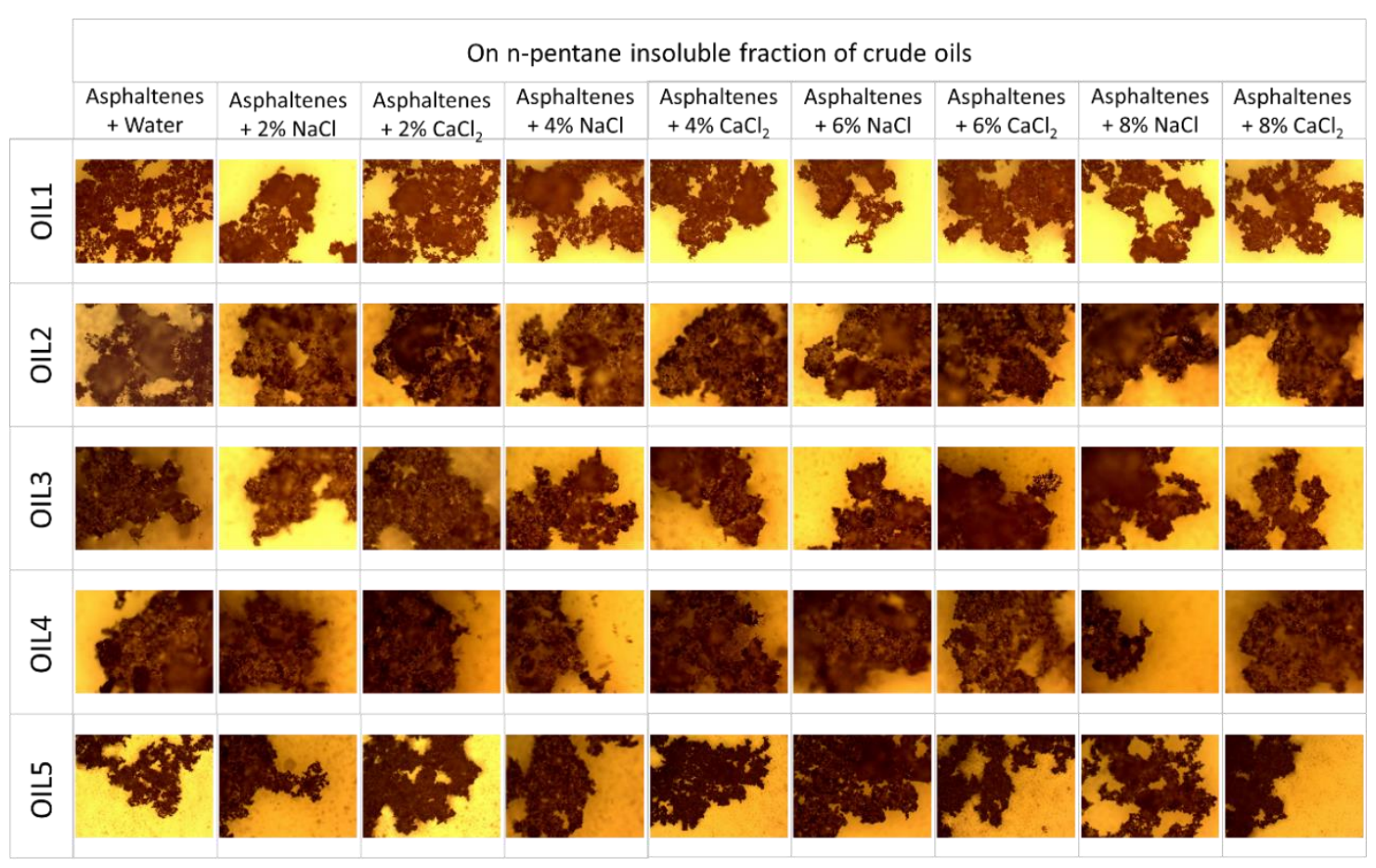

Figure 14: Asphaltene-water and asphaltene-2\%, 4\%. $6 \%$, and $8 \%$ brine interactions for n-pentane insoluble fraction of crude oils within porous media prepared by only clay at $10 \mathrm{X}$ magnification

(Flocculated)

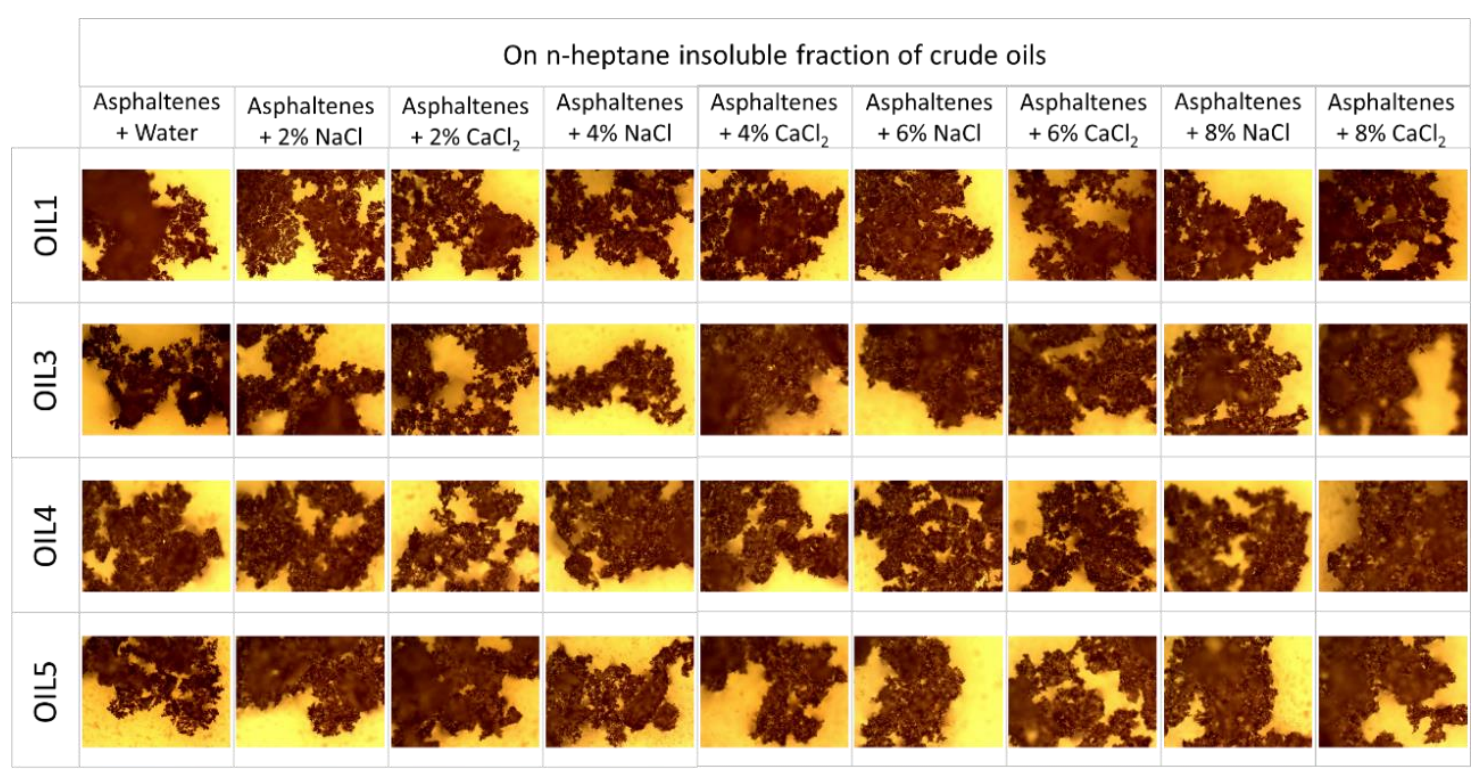

Figure 15: Asphaltene-water and asphaltene- $2 \%, 4 \% .6 \%$, and $8 \%$ brine interactions for $\mathrm{n}$-heptane insoluble fraction of crude oils within porous media prepared by only clay at $10 \mathrm{X}$ magnification

(Flocculated) 


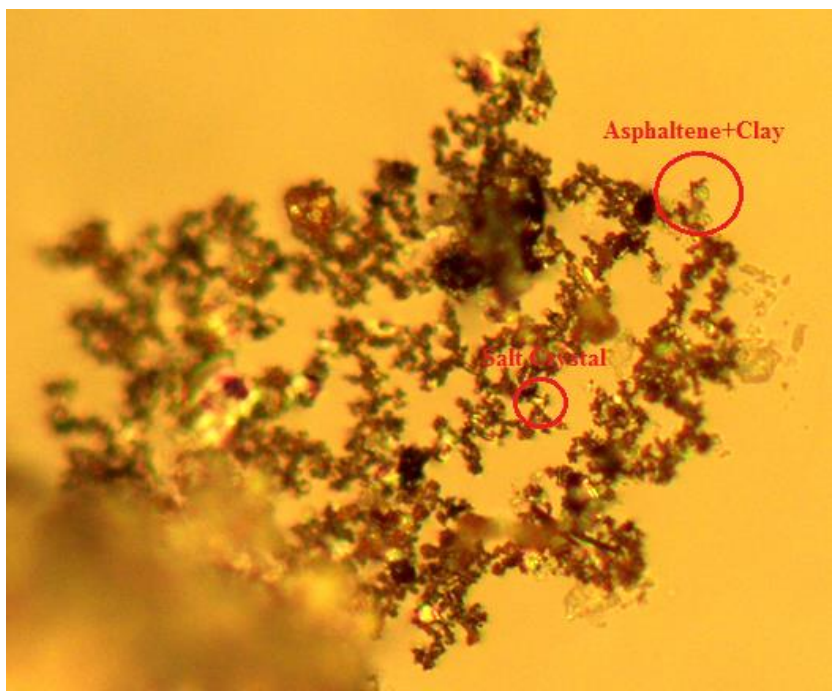

Figure 16: $\mathrm{nC5}$ asphaltene from Oil 3. Clay and Salt $\left(6 \% \mathrm{CaCl}_{2}\right)$ 


\subsection{Asphaltene+Sand-Water/Brine Interaction}

In this section, the results for [asphaltene+sand] interactions for dry and wet conditions are discussed. Figure 17 shows microscope images at 40X magnitude for [asphaltene+sand] with $0.2 \%$ brine concentration for $\mathrm{n}$-pentane and $\mathrm{n}$-heptane asphaltenes. In the same way, Figure 18 through Figure 20 shows similar microscope images at $5 \mathrm{X}$ magnification for 2\%, $4 \%, 6 \%$, and $8 \%$ brines.

These results were obtained on floated asphaltenes around sand granules and there were no asphaltene particles observed as settled on microscope slides. This was because of the air pockets retained in asphaltene clusters. These air pockets reduced asphaltenes density and resulted in the flotation of asphaltenes on water surface.

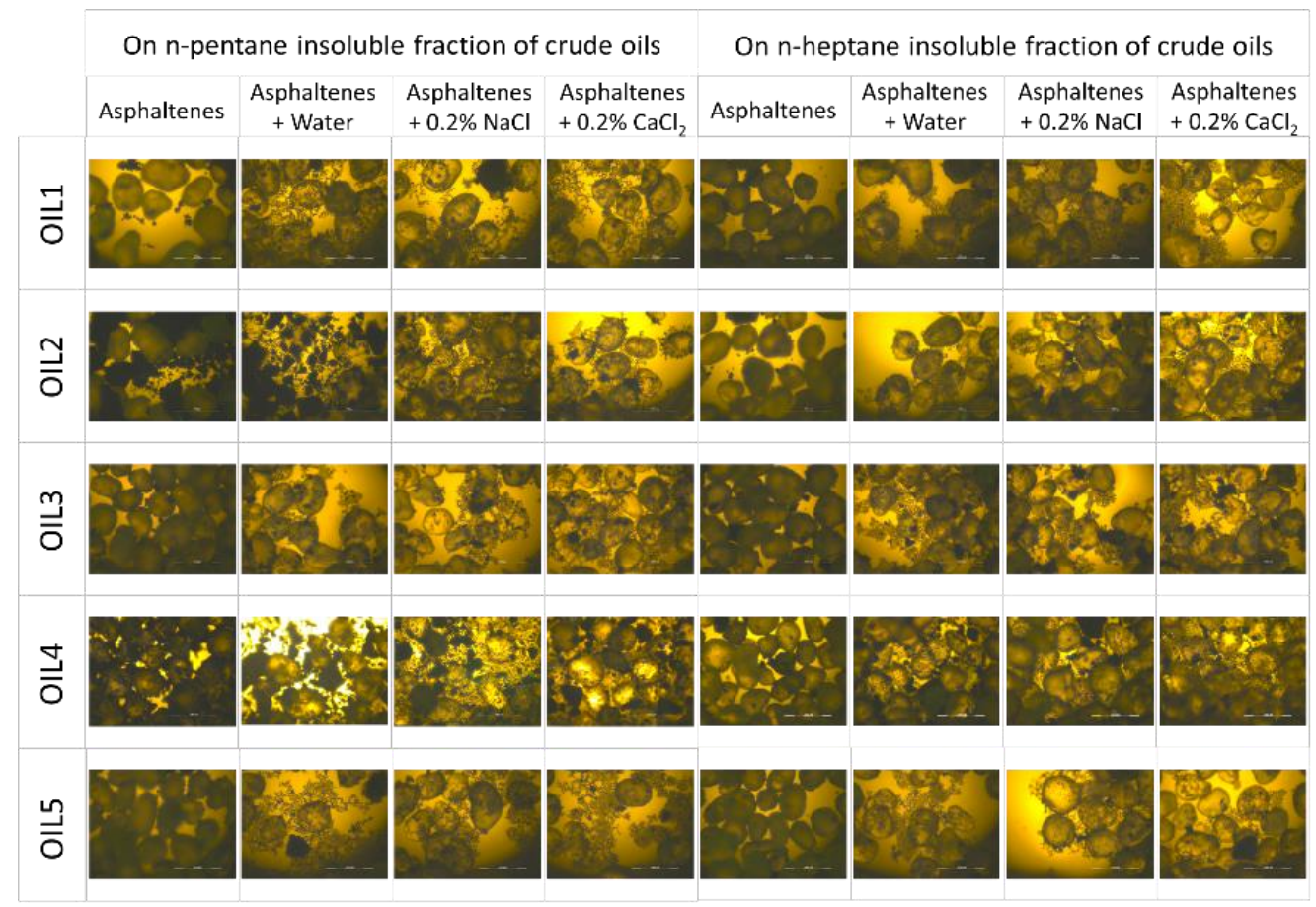

Figure 17: Asphaltene-water and asphaltene- $0.2 \%$ brine interactions for both $\mathrm{n}$-pentane and $\mathrm{n}$-heptane insoluble fractions of crude oils within porous media prepared by only sand at $40 \mathrm{X}$ magnification 


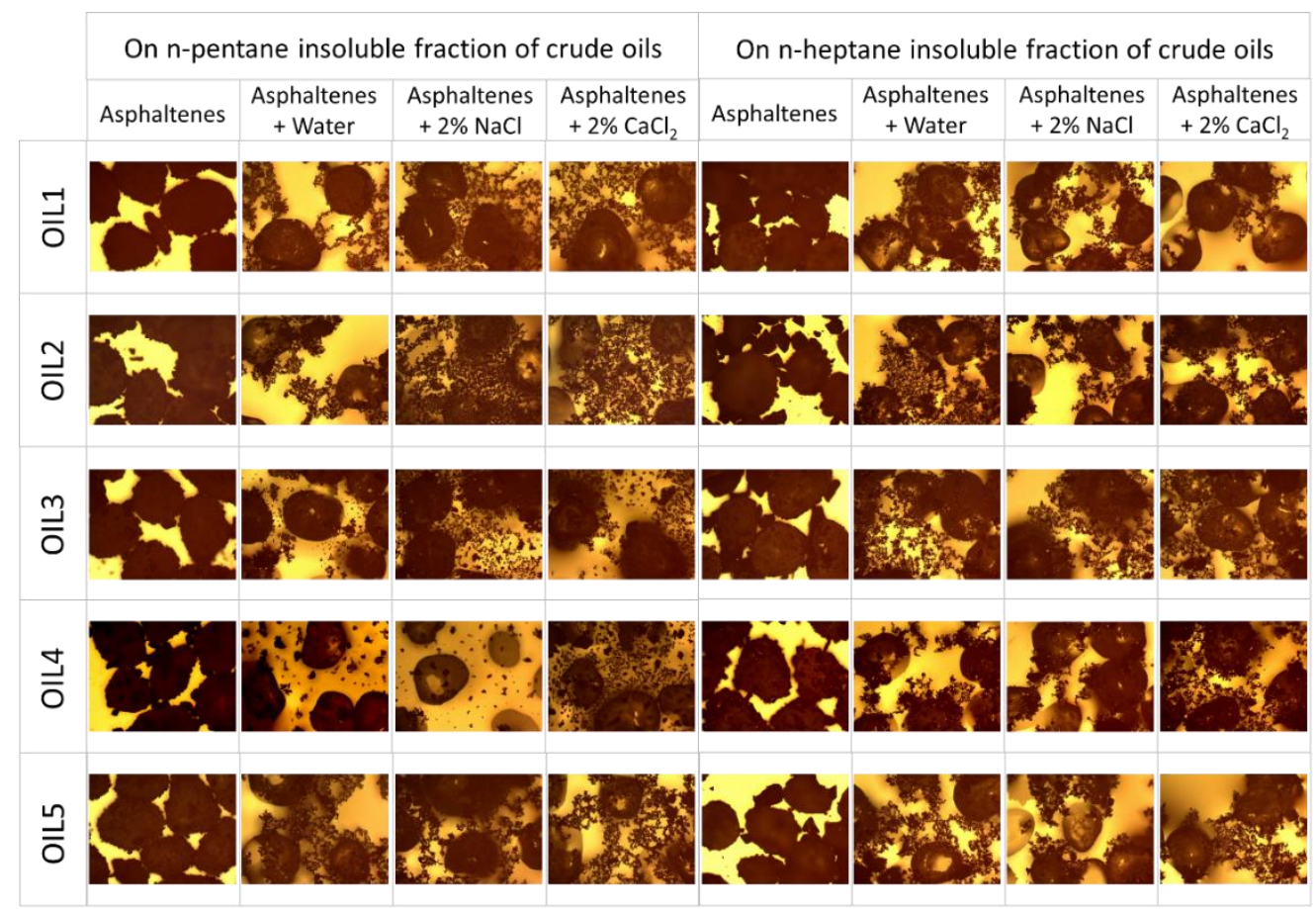

Figure 18: Asphaltene-water and asphaltene-2\% brine interactions for both $n$-pentane and $n$-heptane insoluble fractions of crude oils within porous media prepared by only sand at $5 \mathrm{X}$ magnification

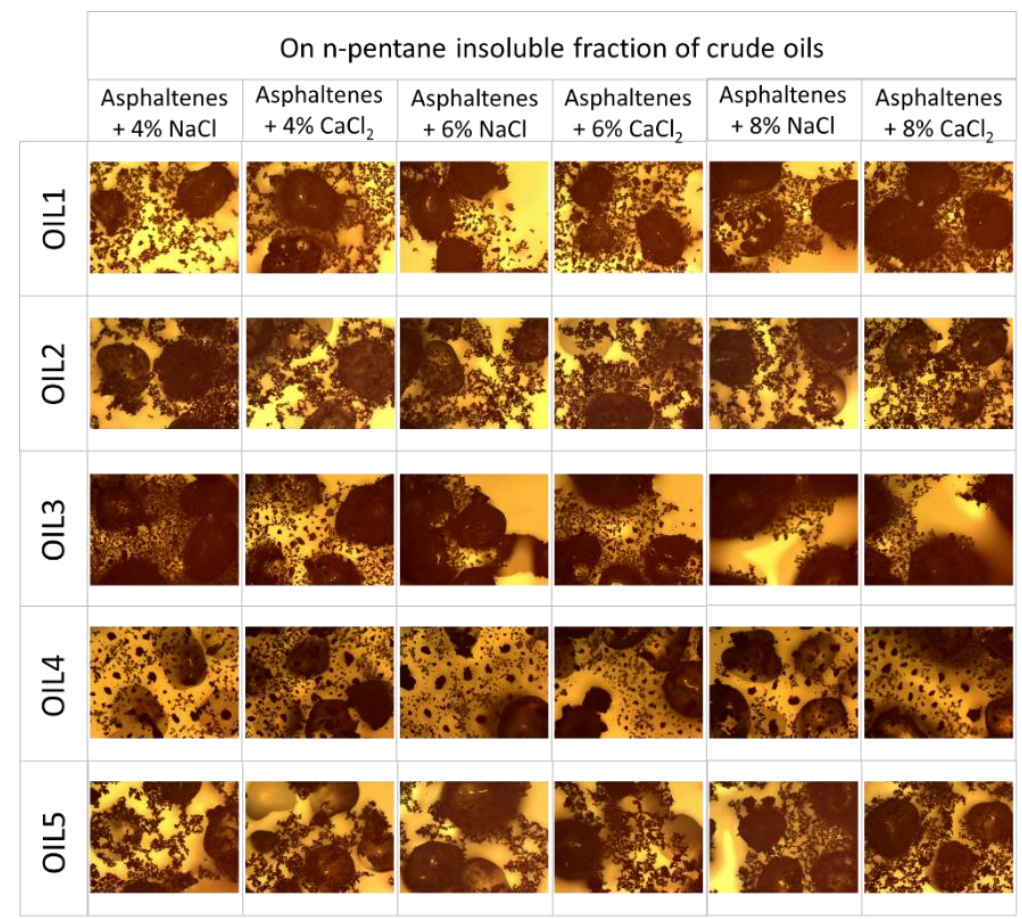

Figure 19: Asphaltene-water and asphaltene- $4 \%, 6 \%$ and $8 \%$ brine interactions for both n-pentane and insoluble fractions of crude oils within porous media prepared by only sand at $5 \mathrm{X}$ magnification 


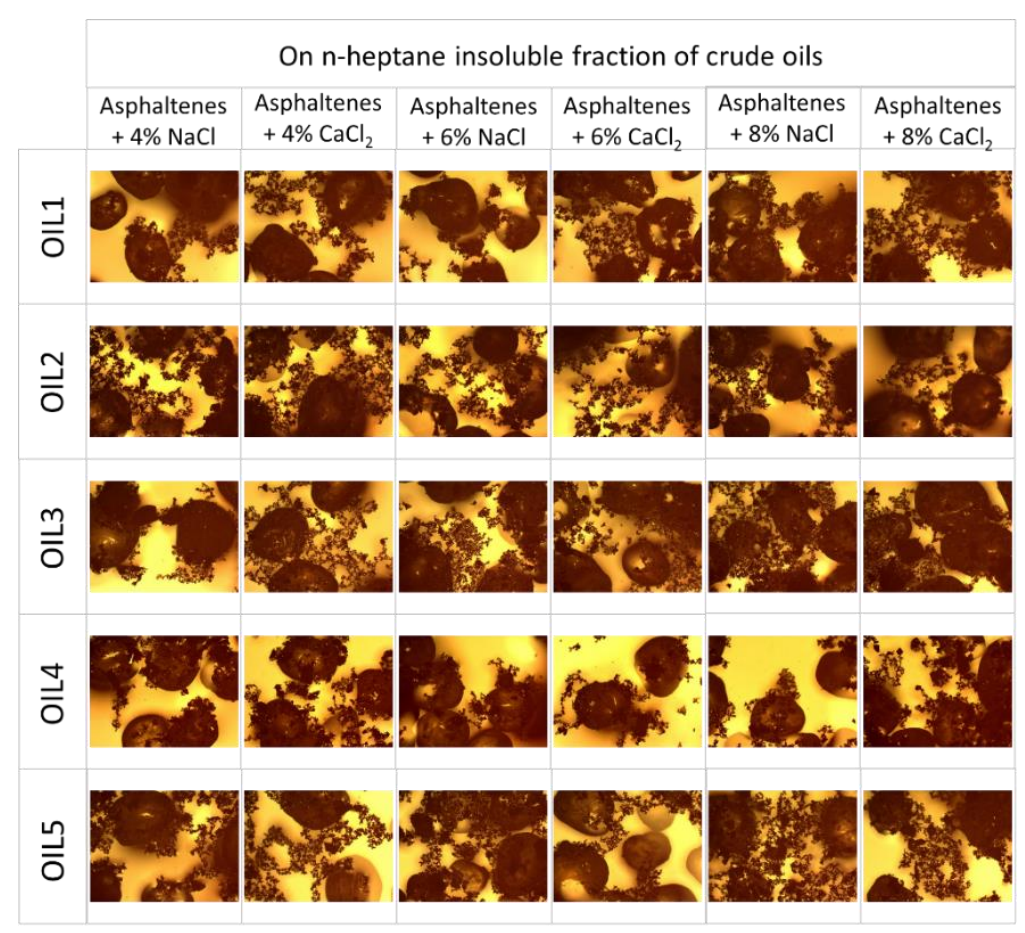

Figure 20: Asphaltene-water and asphaltene- $4 \%, 6 \%$ and $8 \%$ brine interactions for both $\mathrm{n}$-heptane and insoluble fractions of crude oils within porous media prepared by only sand at $5 \mathrm{X}$ magnification

These experiments were conducted with 20-40 mesh size Ottawa sand. In dry samples of [asphaltene+sand], it was clearly seen that asphaltene particles adsorbed onto sand granules for all cases. Hence, the pore spaces of sands were filled by asphaltenes. On the other hand, with the addition of water/brine, asphaltenes were dispersed to the water/brine, however, this dispersion behavior cannot be generalized for all oil samples. In this set, especially Oil 4 sample indicated different features than the other oil samples. With the presence of sand in the medium, n-pentane insoluble asphaltenes aggregated in smaller groups which were apart from each other. These aggregates got smaller in the brine prepared with $\mathrm{NaCl}$ and aggregates got bigger and more connected in the brine prepared by $\mathrm{CaCl}_{2}$. In general, except for Oil 4 sample, all the n-pentane asphaltenes created bigger clusters than the $\mathrm{n}$ heptane asphaltenes. When different concentrations of salts were examined, no direct relation was observed between brine concentration and asphaltene cluster size. For some oil samples, asphaltene aggregate sizes enlarged with increase in salt concentration.

The evaluation of asphaltene attraction between sand granules was similar to the results with the attraction between asphaltene and clay particles in the dry environment. In this case, sand granules attracted asphaltenes electrically and were coated by asphaltene 
particles. This interaction was almost the same with the asphaltene clay interaction although sand granules have low cation exchange capacity and heteroatom content. The electrical charge interaction occured between sand and asphaltenes and between clay and asphaltenes due to high polarity of asphaltenes and due to high heteroatom content of asphaltenes.

The interaction of asphaltene and sand in aqueous environment gave interesting results. nC5 asphaltenes of Oil 4 sample behaved differently than other asphaltenes. This behavior is seen Figure 18 and Figure 19. The nC5 asphaltenes of Oil 4 had a tendency of avoiding electrical attraction with sand granules. Thus, they formed smaller clusters than the other asphaltene types. Surprisingly, sand granules also effected of the interaction of asphaltene particles. In the absence of sand, nC5 asphaltenes of Oil 4 sample tend to create bigger clusters.

The same behavior can also be seen on nC5 asphaltene of Oil 3 sample although it is not as obvious as nC5 asphaltenes of Oil 4 sample. These asphaltenes were attracted by sand while they avoided interacting with each other. Further, their clusters were less small than nC5 asphaltenes of Oil 4 sample. For this asphaltene type, nC7 asphaltenes indicated almost same affinity when they were compared with other n-heptane insoluble asphaltenes. On the contrary, other asphaltenes had a tendency of flocculation with sand granules.

Calcium and sodium contents of Oil 3 and Oil 4 samples were reported low, hence, the anomalies observed for these two asphaltenes might be due to low calcium and sodium concentrations of crude oils. Moreover, these oils were reported having big vanadium and nickel contents. From this information, it was concluded that if an asphaltene has a low percentage of low-valence metals $(\mathrm{V}, \mathrm{Ni})$ and a high percentage of high-valence metals $\mathrm{Ca}$, $\mathrm{Na}$ ), these asphaltenes behave like positively charged particles. Due to $\mathrm{Al}, \mathrm{Fe}$, and $\mathrm{Ca}$ content, sand granules were also positively charged and in this way, asphaltenes and sands did not bond with each other. In addition, these electrical charges changed asphaltenes behavior and asphaltenes disturbed each other, consequently, asphaltenes did not form big clusters. 
$\mathrm{NaCl}$ and $\mathrm{CaCl}_{2}$ impacted asphaltene+sand environments considerably. Asphaltene interaction and cluster behavior for nC5 asphaltenes from all oils were reduced with increased salinity. However, similar observation could not be obtained for C7 asphaltenes. In this experimental set, nC5 asphaltenes for Oil 4 sample displayed different results when compared to other samples. Despite, more visible small particles in brine solution than water, asphaltenes did not have a tendency of flocculation around sand granules or forming bigger asphaltenes particles. Further, increase in salt concentration indicated more stable asphaltenes. Like nC5 asphaltenes of Oil 4 sample, n-pentane asphaltenes of Oil 3, Oil 1 and Oil 2 samples also showed same features, and they created small clusters as a result of increase in concentration of either $\mathrm{NaCl}$ and $\mathrm{CaCl}_{2}$. Therefore, they become more stable than the only water environment.

The polarity of asphaltene increased with increasing carbon number of precipitated agent used. In other words, n-heptane asphaltenes were more polar than n-pentane asphaltenes (Demir et al. 2016). However, nC7 asphaltenes-water interaction did not provide significant observation under optical microscope. The polar-polar interaction was complex and while both water and asphaltenes were polar, asphaltenes-asphaltenes interaction might be favored for $\mathrm{nC} 7$ asphaltenes rather than asphaltenes-water interaction. 


\subsection{Asphaltene+Sand+Clay-Water/Brine Interaction}

The results are presented for experiments conducted within porous media prepared by mixing clay and sand. Figure 21 shows the images at $40 \mathrm{X}$ magnification for the dry [asphaltene+sand+clay] and [asphaltene+sand+clay] with water/brine solutions for both $\mathrm{n}$ pentane and $\mathrm{n}$-heptane insoluble. Optical microscopic images at $5 \mathrm{X}$ magnification are given in Figure 22 through Figure 24.

In this experiment set, some [asphaltene+clay] clusters floated above water/brine and some [asphatene+clay] clusters settled on the microscope slide. For all the evaluations, these two situations are considered. Air pockets remaining in asphaltenes made the asphaltene density lesser than water and brine and caused the asphaltenes cluster to float in solution. This observation helped to explain important findings.

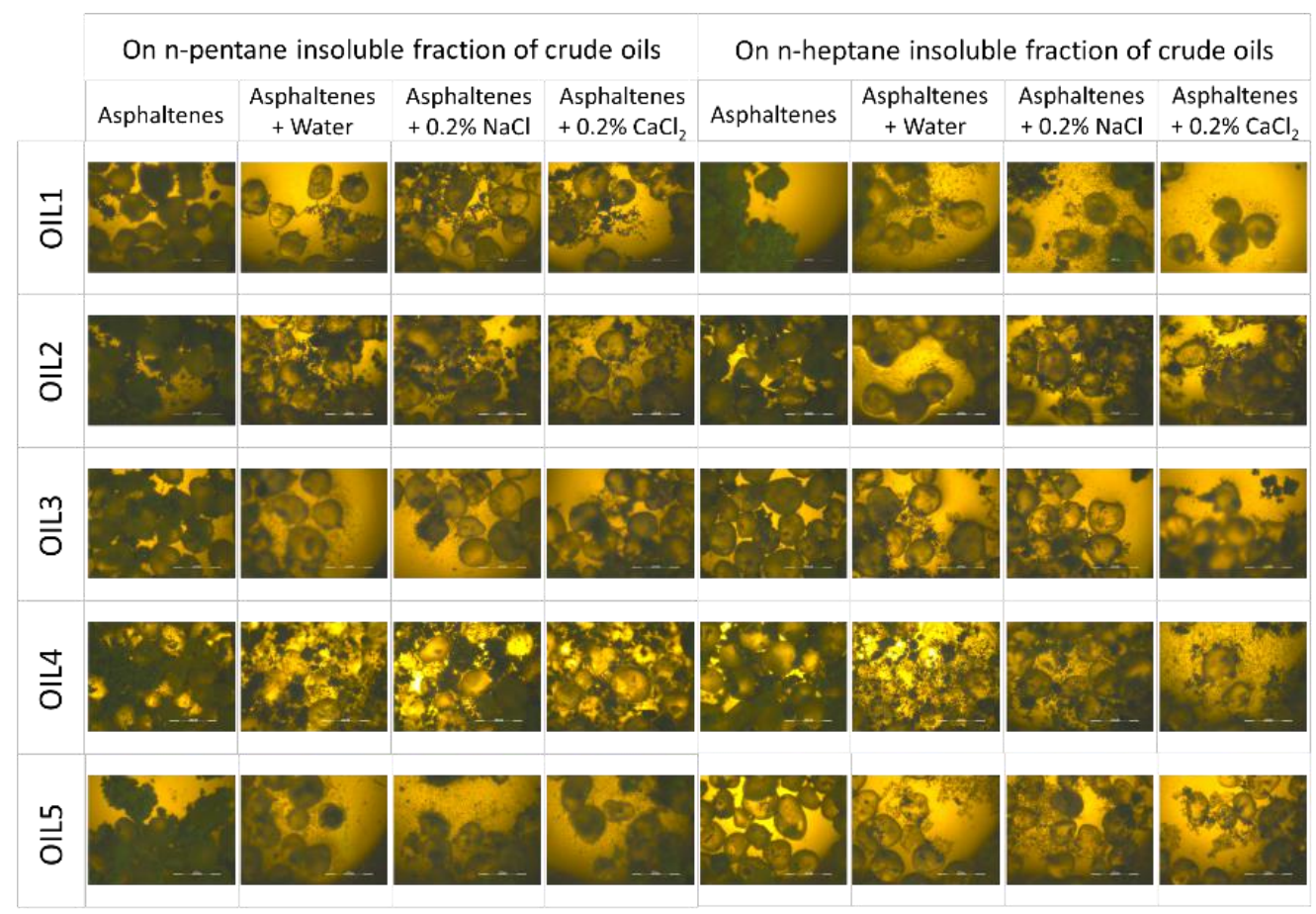

Figure 21: Asphaltene-water and asphaltene- $0.2 \%$ brine interactions for both n-pentane and n-heptane insoluble fractions of crude oils within porous media prepared by sand-clay mixtures at $40 \mathrm{X}$ magnification 


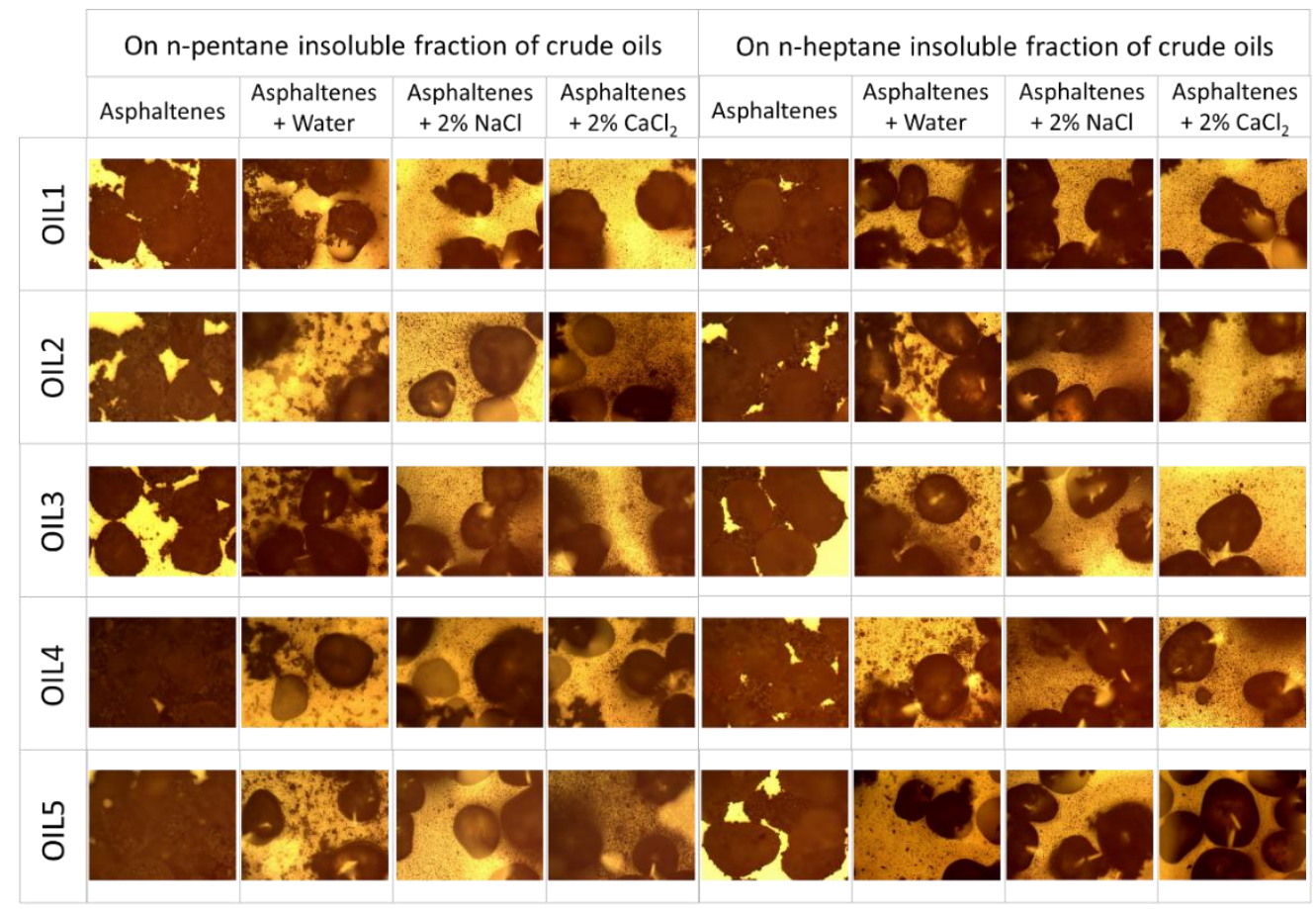

Figure 22: Asphaltene-water and asphaltene-2\% brine interactions for both $n$-pentane and $n$-heptane insoluble fractions of crude oils within porous media prepared by sand-clay mixtures at $5 \mathrm{X}$ magnification

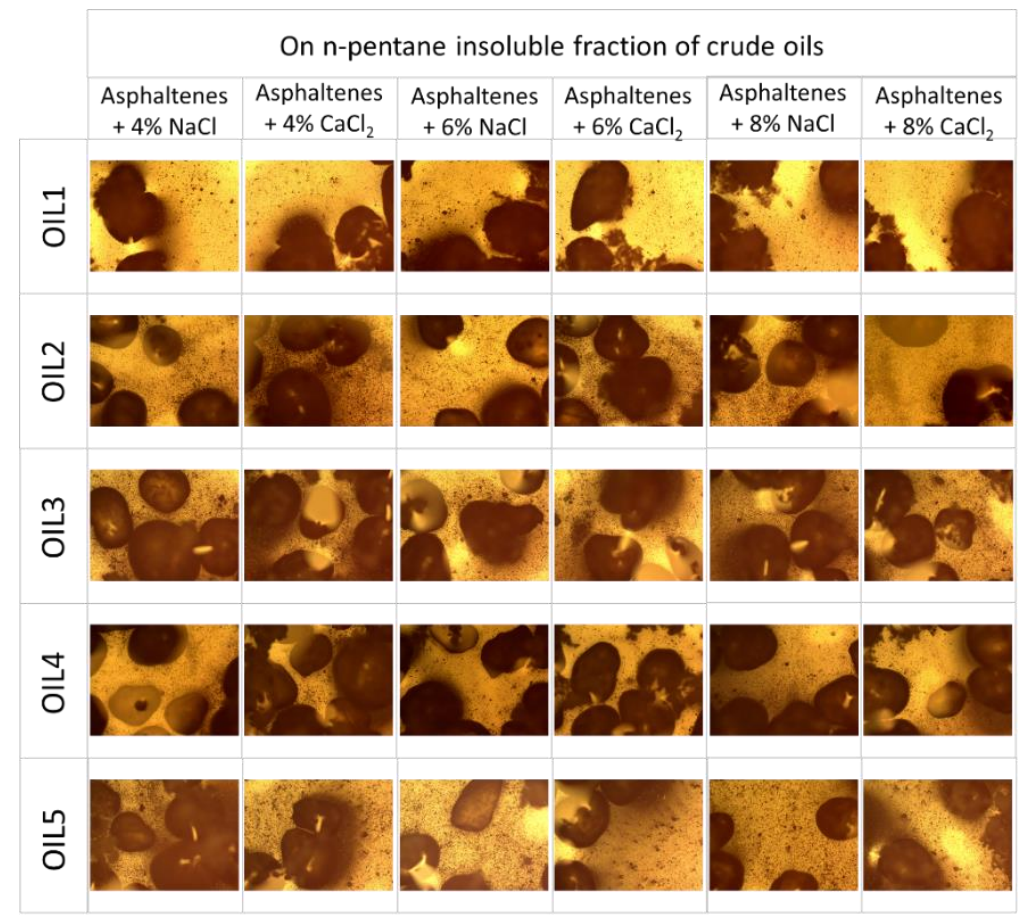

Figure 23: Asphaltene-water and asphaltene- $4 \%, 6 \%$ and $8 \%$ brine interactions for n-pentane insoluble fractions of crude oils within porous media prepared by sand-clay mixtures at $5 \mathrm{X}$ magnification 


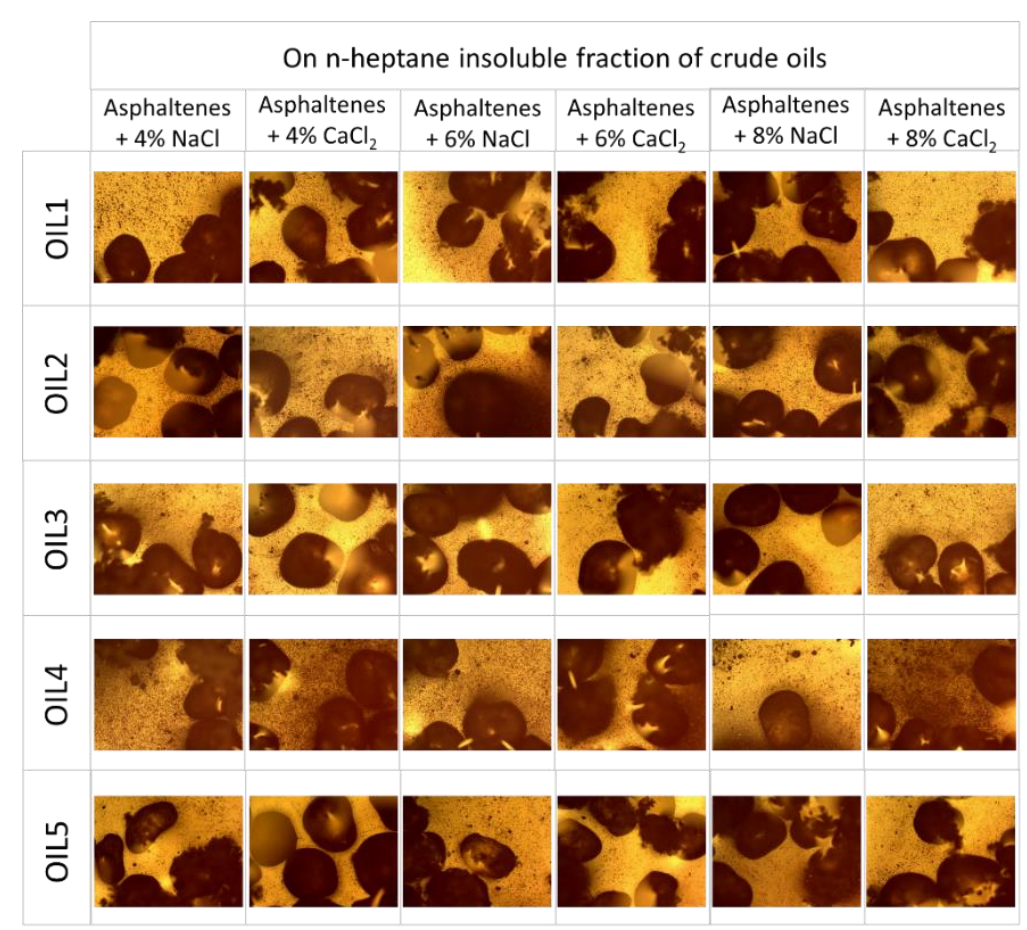

Figure 24: Asphaltene-water and asphaltene- $4 \%, 6 \%$ and $8 \%$ brine interactions for $n$-heptane insoluble fractions of crude oils within porous media prepared by sand-clay mixtures at $5 \mathrm{X}$ magnification

Bigger clay clusters were observed in water environment than the clay clusters in brine environment when the settled particle were compared. In other words, clay particles dispersed more in brine. The dispersion was higher for $\mathrm{n}$-heptane insoluble asphaltenes because $\mathrm{n}$-heptane insoluble asphaltenes adsorbed more clay minerals on their surface than n-pentane insoluble asphaltenes. In the same way, on the microscope slide, the amount of clay was less in the brine prepared with $\mathrm{CaCl}_{2}$. The reason for this finding was the same; the asphaltene in $\mathrm{CaCl}_{2}$ solutions hold more clay particles on their surface. The last observation of this experiment set was about clay dispersion by salt concentrations. When the salt concentration increased, clay dispersed more on a microscope slide, and this dispersion amount was more in brine prepared with $\mathrm{CaCl}_{2}$.

The first and fifth columns in Figure 21 and Figure 22 show results for dry asphaltene+sand+clay. These results were similar to the dry results of asphaltene+sand and asphaltene+clay. Here, sand granules were covered by asphaltene+clay. In this way, asphaltenes and clay particles filled pores. Pore bridging, pore lining, and pore filling behaviors were observed for all asphaltene samples due to these three components' polar 
features. Especially clay particles have more electrical charges on the surfaces, and they provided a strong connection between asphaltenes and sands.

The second and sixth columns of Figure 21 and Figure 22 represents nC5 and nC7 asphaltenes of five oils in a water environment. These images show settled clay and a small part of asphaltenes with sand granules. From the images, where the clay particles settled on the microscope slides, the results were similar to ones obtained with the asphaltene+clay systems. The main difference was that clay particles accumulated more around sand granules in water systems. This observation is valuable to understand clay behavior with sand in real reservoir conditions. In addition to clay particles, there were some small-sized asphaltenes that were seen in the figures but these asphaltenes were in low quantities.

As seen earlier, kaolinite and illite have positive and negative sites on their surface. Some of the sites are permanently charged while the others are with $\mathrm{pH}$ depended charges. In the test conditions, ( $\mathrm{pH}$ is 7$), \mathrm{pH}$ depended electrical sites also have high ability to adsorb. The positive charges of sand granules are also due to their metallic contents. Further, like asphaltenes+clay systems, clay minerals create bigger clusters because of their high polar features even dispersed in water. There are no ions in water environment which can neutralize their electrically charged sites and they tend to flocculate.

Addition of brine dispersed more flocculated-clay. Increasing brine concentration contributed to more clay dispersion. In these experiments, clay minerals tended to accumulate around sands as well as they accumulated in the water environment. In comparison with asphaltene+clay system, fewer clay particles settled on the microscope slide in most of the cases in this system. Due to the $\mathrm{Na}^{+}$or $\mathrm{Ca}^{+2}$ and $\mathrm{Cl}^{-}$ions in the solution, these ions neutralized clay polarity with binding the positive and negative sides of the clay. Therefore, clay has shown less flocculation affinity than the water environment. On the other hand, sand granules have some positive metals on their surface, and they attract clay minerals that were settled on the microscope slide. Thus, clay minerals accumulated around sand granules with clay filling the pores between sands and preventing flow significantly in the reservoir. 
Increasing $\mathrm{NaCl}$ and $\mathrm{CaCl}_{2}$ concentrations affected dispersed clay minerals. Rising ion concentration in the aqueous phase caused more dispersed clay minerals on the microscope around sand granules and pore spaces. This mechanism was covered in detail in the experiment section of asphaltene+clay. As a summary, the flocculation ratio of clay decreases with increasing ion adsorption on the clay surface (Goldberg et al. 1991). This dispersion features are not an advantage for the oil production. Because increasing dispersion causes increase in accumulated clay particles around sand granules and this causes to fill pores in the reservoir rock. In addition, increasing salt concentration cause crystallization problems on the surface of asphaltenes and cause bigger asphaltene clusters. This situation can be handled with the flocculated asphaltene+sand+clay systems.

For the flocculated asphaltene+sand+clay mixture, the results were not surprising. For the most part, asphaltene and clay particle created clusters and they were accumulated around sand granules. On the other hand, there is no significant difference reported between asphaltene+sand+clay in water or in brine solutions. The observations did not give distinct results, but like asphaltene+clay images, some bright points were investigated which might refer to salt crystals.

Figure 25 shows one of the examples of this situation. In here, asphaltene clusters were connected to each other with clay minerals which can be seen as white or gray color. However, there are some bright spots that looked like the starting of a crystallization of salt between asphaltenes and clay clusters. Another important dried sample of asphaltene+sand+clay is given in Figure 26. As a control experiment, dried sand in $4 \%$ $\mathrm{NaCl}$ solution images were taken. In Figure 26, the $\mathrm{NaCl}$ crystals seemed to accumulate preferably around sands and their form was firm and connected with each other. On the other hand, adding asphaltene+clay to this system forced $\mathrm{NaCl}$ to crystallize around asphaltene and clay particles. Thus, crystals dispersed around the solution. This case can be seen in Figure 27. These results prove that $\mathrm{NaCl}$ crystallization starts with the surface of asphaltenes and clay. Thereby, the bright area that was indicated in Figure 25 was highly possibly refers to salt crystallization. 


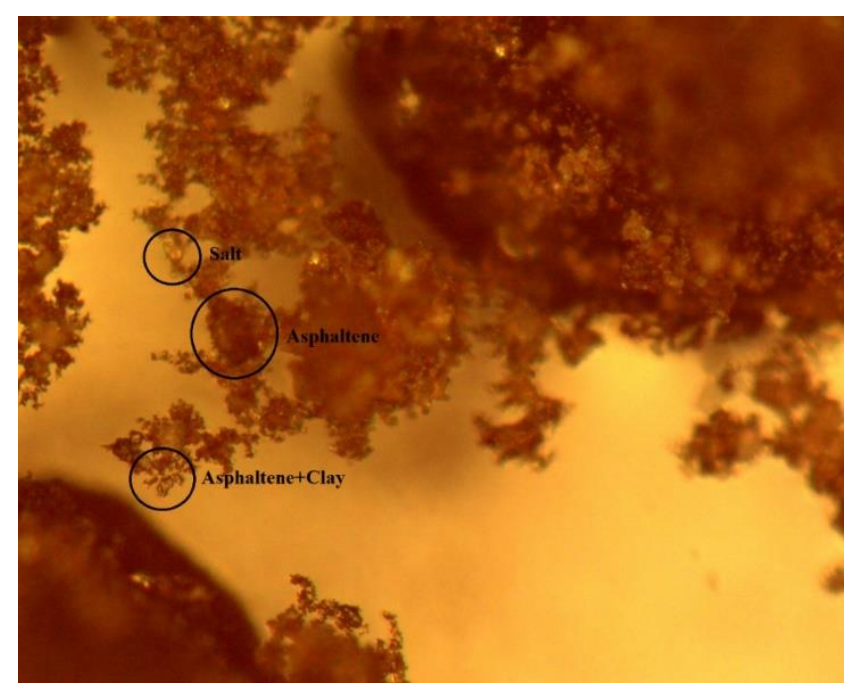

Figure 25: n-pentane asphaltenes from Oil 5 with clay+sand in $8 \% \mathrm{NaCl}$

Consequently, increasing salinity was not beneficial for the flocculated asphaltene+clay+sand and settled clay particles. Increasing salinity caused more dispersed clay particles due to their high cation exchange capacities, and their clay particles accumulated around sand. This behavior might cause near-wellbore formation damage reducing hydrocarbon production. In addition, dispersed clay particles and asphaltenes started to interact and they created bigger clusters. Larger clusters might also fill the pores and reduce oil production. Finally, some of the salt crystals were observed on the surface of asphaltenes. There are some local points that may trigger salt crystallization on the asphaltene surfaces. This also contributes to bigger clusters and results are not positive in case of oil production. 


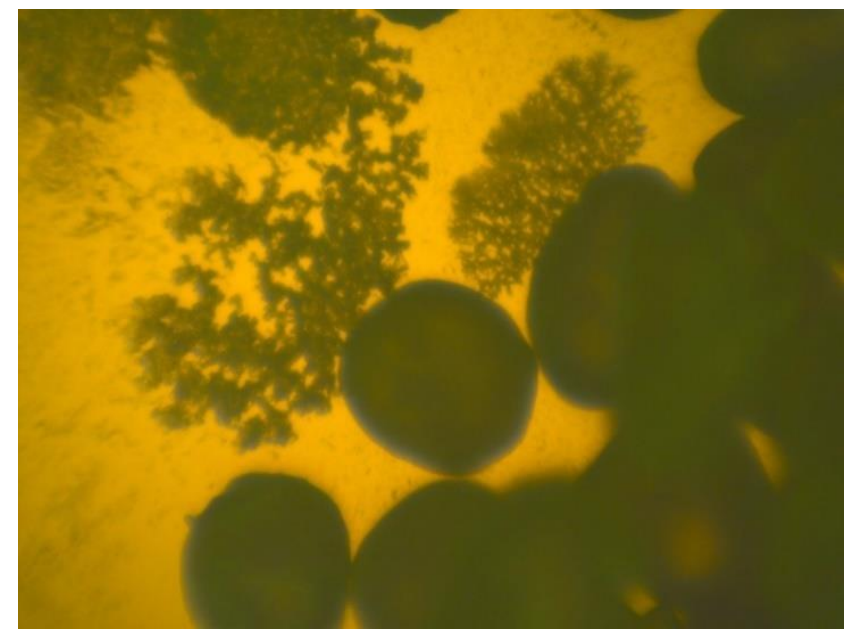

Figure 26: Dried sand $+4 \% \mathrm{NaCl}$

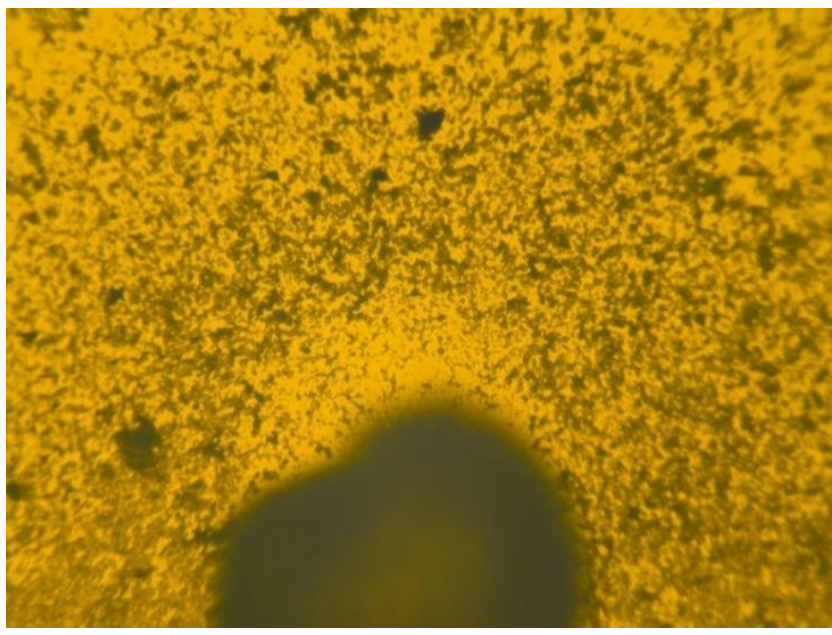

Figure 27: Dried sample of n-pentane asphaltenes of Oil 3 in $4 \% \mathrm{NaCl}$ with Sand+Clay 


\subsection{Contact Angle Measurements}

Contact angle measurements were conducted for $0.2 \%$ brine for all five oils and for $4 \%$ brine for two different oils. The aim of these experiments was to understand the relation between asphaltene behavior on porous media and crude oil-porous reservoir rock. The results are given in Table 5, Table 6 and Figure 28.

Table 5: Water-air Contact angle measurements and the calculated water-oil contact angle values for $0.2 \%$ of $\mathrm{NaCl}$ and $\mathrm{CaCl}_{2}$

\begin{tabular}{|c|c|c|c|c|c|c|c|c|c|}
\hline \multirow{2}{*}{ Sample } & \multicolumn{2}{|c|}{$\begin{array}{c}\text { Water-Sand-Clay } \\
\text { System }\end{array}$} & \multirow[t]{2}{*}{ Wet. } & \multicolumn{2}{|c|}{$\begin{array}{l}\text { Brine }(0.2 \% \mathrm{NaCl})- \\
\text { Sand-Clay System }\end{array}$} & \multirow[t]{2}{*}{ Wet. } & \multicolumn{2}{|c|}{$\begin{array}{c}\text { Brine }\left(0.2 \% \mathrm{CaCl}_{2}\right)- \\
\text { Sand-Clay System }\end{array}$} & \multirow[t]{2}{*}{ Wet. } \\
\hline & $\begin{array}{l}\text { Water- } \\
\text { Air }\end{array}$ & $\begin{array}{l}\text { Water- } \\
\text { Oil }\end{array}$ & & $\begin{array}{l}\text { Water- } \\
\text { Air }\end{array}$ & $\begin{array}{c}\text { Water- } \\
\text { Oil }\end{array}$ & & $\begin{array}{c}\text { Water- } \\
\text { Air }\end{array}$ & $\begin{array}{l}\text { Water- } \\
\text { Oil }\end{array}$ & \\
\hline OIL1 & 71 & 100 & IW & 77 & 108 & IW & 74 & 104 & IW \\
\hline OIL2 & 77 & 108 & IW & 80 & 113 & IW & 97 & 137 & OW \\
\hline OIL3 & 111 & 156 & OW & 103 & 145 & OW & 97 & 137 & OW \\
\hline OIL4 & 104 & 146 & OW & 106 & 149 & OW & 101 & 142 & OW \\
\hline OIL5 & 93 & 131 & IW & 109 & 154 & OW & 111 & 156 & OW \\
\hline
\end{tabular}

Table 6: Water-air Contact angle measurements and the calculated water-oil contact angle values for $4 \%$ of $\mathrm{NaCl}$ and $\mathrm{CaCl}_{2}$

\begin{tabular}{|c|c|c|c|c|c|c|c|c|c|}
\hline \multirow{2}{*}{ Sample } & \multicolumn{2}{|c|}{$\begin{array}{c}\text { Water-Sand-Clay } \\
\text { System }\end{array}$} & \multirow[t]{2}{*}{ Wet. } & \multicolumn{2}{|c|}{$\begin{array}{l}\text { Brine }(4 \% \mathrm{NaCl})- \\
\text { Sand-Clay System }\end{array}$} & \multirow[t]{2}{*}{ Wet. } & \multicolumn{2}{|c|}{$\begin{array}{l}\text { Brine }\left(4 \% \mathrm{CaCl}_{2}\right)- \\
\text { Sand-Clay System }\end{array}$} & \multirow[t]{2}{*}{ Wet. } \\
\hline & $\begin{array}{l}\text { Water- } \\
\text { Air }\end{array}$ & $\begin{array}{c}\text { Water- } \\
\text { Oil }\end{array}$ & & $\begin{array}{l}\text { Water- } \\
\text { Air }\end{array}$ & $\begin{array}{l}\text { Water- } \\
\text { Oil }\end{array}$ & & $\begin{array}{c}\text { Water- } \\
\text { Air }\end{array}$ & $\begin{array}{l}\text { Water- } \\
\text { Oil }\end{array}$ & \\
\hline OIl & 70 & 99 & IW & 69 & 97 & IW & 77 & 108 & IW \\
\hline OIL5 & 102 & 144 & OW & 100 & 141 & OW & 115 & 162 & OW \\
\hline
\end{tabular}

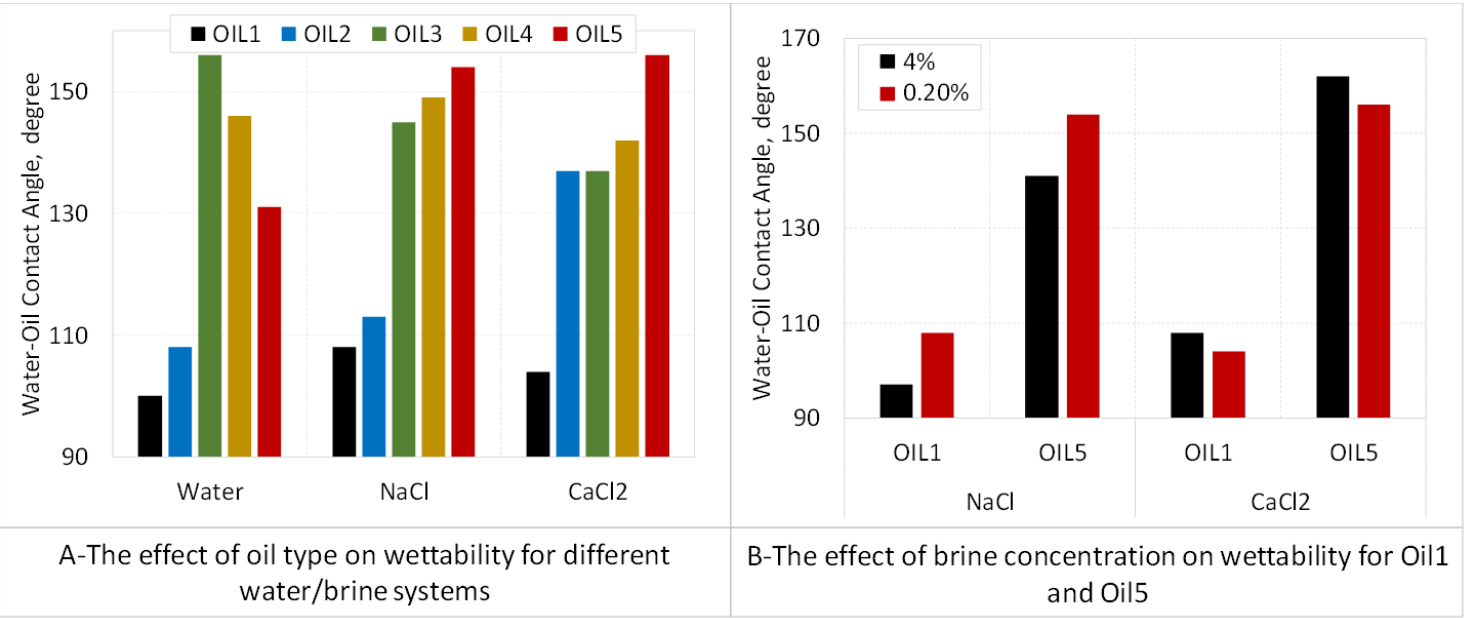

Figure 28: Results of Contact Angle Measurements 
Contact angle measurements are important to understand asphaltene behavior in the reservoir system. In this research, the asphaltenes behavior was observed after separation from crude oil, however, asphaltene is a component of crude oil and must be considered with the crude oil. To accomplish this, all crude oil samples were tested using $0.2 \%$ of $\mathrm{NaCl}$ and $\mathrm{CaCl}_{2}$ and further with $4 \%$ of $\mathrm{NaCl}$ and $\mathrm{CaCl}_{2}$ with two oils that have the lowest and highest viscosity. The results from both test conditions were compared to understand the connection of asphaltene stability and reservoir conditions.

The contact angle results show that the [sand+clay+water] systems prepared with Oil 1 and Oil 2 samples represent intermediate-wet systems and Oil 3, Oil 4, and Oil 5 samples represent oil-wet systems. The brine addition changed the wettability towards more oil-wet conditions. The lowest contact angle was calculated for Oil 1 sample and the highest for Oil 5 sample. Thus, the impact of salt concentration on wettability alteration was investigated only with these two oil samples. Both oil samples exhibit more oil-wet behavior for a higher concentration of $\mathrm{CaCl}_{2}$. However, for the high concentration of $\mathrm{NaCl}$, both oil samples yield slightly less contact angle values.

Based on asphaltene+clay-water/brine and asphaltene+clay+sand-water/brine experiments, increasing salinity caused more clay dispersion and bigger asphaltene+clay clusters around sand granules. Further, divalent cation $\left(\mathrm{Ca}^{+2}\right)$ contributed more than monovalent cation $\left(\mathrm{Na}^{+}\right)$to the dispersion ratio. At given concentrations, $\mathrm{CaCl}_{2}$ brine dispersed more clay particles into the liquid phase. Observations show that contact angle increased in $0.2 \%$ brine environment for both $\mathrm{NaCl}$ and $\mathrm{CaCl}_{2}$ compared to water environment. However, increasing salinity from $0.2 \%$ to $4 \%$ gave the significant results. $\mathrm{NaCl}$ brine gave more water-wet feature than $0.2 \%$ although $\mathrm{CaCl}_{2}$ shows more oil-wet features at this concentration. From the asphaltane+sand+clay images, there was not significant differences in cluster sizes at different concentrations of salt. On the other hand, images show that high concentration brines disperse more clay into the liquid phase causing bonding of more clay particles with asphaltenes and making asphaltenes+clay particles bigger. In addition, some salt crystals were observed on the surface of asphaltenes in high salinity brines. 
In asphaltene+sand+water/brine experiments, different behavior was observed. This behavior might be related with the Vanadium and Nickel contents of Oil 3 and Oil 4 samples. Contact angle measurements showed same results as asphaltene experiments. Addition of brine decreased contact angle for Oil 3 and Oil 4 samples. These results are attributed to the high metallic contents of these two crude oils.

The results for oils with high metallic content showed similar results with asphaltene experiments. The stability of crude oil was defined with the CII index before. The contact angle measurements demonstrated that CII index was not the only parameter that provides information about crude oil stability. In addition to asphaltenes, resins, saturates, and aromatics content of crude oil, heavy metal content of crude oil can provide insight for asphaltene and crude oil stability. For generalizing this behavior, more experiments are needed. 


\section{CHAPTER 5 \\ CONCLUSIONS}

In this study, the impact of salinity and clay presence on asphaltene stability was investigated. Five different systems were analyzed; asphaltene-water/brine, asphaltene+clay - water/brine, asphaltene+sand - water/brine, asphaltene+sand+clay water/brine, and crude oil+sand+clay - water/brine. Asphaltenes were obtained from five different crude oils with either n-pentane and n-heptane dissolution, and their behavior was tested at five different brine concentrations, namely $0.2 \%, 2 \%, 4 \%, 6 \%$, and $8 \%$. The clay type used in this study was the mixture of kaolinite (\%90 wt $\%)$ and illite $(10 \mathrm{wt} \%)$. Following results were acquired from this research.

1. The clay is the most important parameter for asphaltene stability. Due to the high cation exchange capacity of clay than the asphaltenes and sand granules, high salinity affects clay particles more than asphaltenes and sands. High salinity promotes more clay dispersion. This dispersion causes bigger asphaltene+clay aggregates in the reservoir. In addition, high clay dispersion might cause nearwellbore formation damage in the reservoir.

2. The stability of crude oil (indirectly asphaltenes) was defined with the CII index. This stability index considers amount of SARA fractions in the crude oil. On the other hand, asphaltene+sand images demonstrated that asphaltene stability also related to the heavy metal content of crude oil. Moreover, contact angle measurements supported this idea. Thus, CII index cannot be the only parameter to understand asphaltene and crude oil stability.

3. Divalent salt $\left(\mathrm{CaCl}_{2}\right)$ caused more clay dispersion than monovalent salt $(\mathrm{NaCl})$. In addition, the contact angle measurements indicated that the high salinity of divalent salt (4\%) made reservoir rock samples more oil-wet. Hence, divalent salts might be more effective than monovalent salts on asphaltene stability. 


\section{REFERENCES}

1. Akbarzadeh, K., Alboudwarej, H., Svrcek, W. Y., \& Yarranton, H. W. (2005). A generalized regular solution model for asphaltene precipitation from n-alkane diluted heavy oils and bitumens. Fluid Phase Equilibria, 232(1), 159-170.

2. Andersen, S. I., \& Speight, J. G. (2001). Petroleum resins: separation, character, and role in petroleum. Petroleum science and technology, 19(1-2), 1-34.

3. Anderson, W. G. (1986, October). Wettability Literature Survey-Part 1: Rock/Oil/Brine Interactions and the Effects of Core Handling on Wettability. J. of Petr. Techn, 1125-1144.

4. Antonishin, V. I., Gumenetskii, V. V., \& Grinenko, B. S. (1977). Oxidation of petroleum asphaltenes to aliphatic dicarboxylic and benzene carboxylic acids. Petroleum Chemistry USSR, 17(4), 244-256.

5. Ashoori, S., Sharifi, M., Masoumi, M., \& Salehi, M. M. (2016). The relationship between SARA fractions and crude oil stability. Egyptian Journal of Petroleum.

6. ASTM International. (2013). ASTM D1250-08(2013)e1 Standard Guide for Use of the Petroleum Measurement Tables. Retrieved from https://doi.org/10.1520/D125008R13E01

7. ASTM International. (2016). ASTM D2007-11(2016) Standard Test Method for Characteristic Groups in Rubber Extender and Processing Oils and Other PetroleumDerived Oils by the Clay-Gel Absorption Chromatographic Method. Retrieved from https://doi.org/10.1520/D2007-11R16

8. Auflem, I. H. (2002). Influence of asphaltene aggregation and pressure on crude oil emulsion stability (Doctoral dissertation, Norwegian University of Science and Technology Trondheim).

9. Bates, R. G., \& Vijh, A. K. (1973). Determination of pH: theory and practice. Journal of The Electrochemical Society, 120(8), 263C-263C.

10. Buenrostro-Gonzalez, E., Lira-Galeana, C., Gil-Villegas, A., \& Wu, J. (2004). Asphaltene precipitation in crude oils: Theory and experiments. AIChE Journal, 50(10), 2552-2570.

11. Calles, J. A., Dufour, J., Marugán, J., Peña, J. L., Giménez-Aguirre, R., \& MerinoGarcía, D. (2007). Properties of Asphaltenes Precipitated with Different n-Alkanes. A 
Study To Assess the Most Representative Species for Modeling†. Energy \& Fuels, 22(2), 763-769.

12. Carey, F. A., \& Sundberg, R. J. (2007). Advanced Organic Chemistry: Part A: Structure and Mechanisms. Springer Science \& Business Media.

13. da Silva Ramos, A. C., Haraguchi, L., Notrispe, F. R., Loh, W., \& Mohamed, R. S. (2001). Interfacial and colloidal behavior of asphaltenes obtained from Brazilian crude oils. Journal of Petroleum Science and Engineering, 32(2), 201-216.

14. Chang, R., \& Overby, J. S. (2003). General chemistry: the essential concepts (Vol. 3). New York: McGraw-Hill.

15. Crabtree, R., \& Mingos, M. (2007). Comprehensive organometallic chemistry III. Elsevier Science.

16. Deer, W. A., Howie, R. A., \& Zussman, J. (1992). An introduction to the rock-forming minerals (Vol. 696). London: Longman.

17. Demir, A. B., Bilgesu, H. I., \& Hascakir, B. (2016, May). The Effect of Clay and Salinity on Asphaltene Stability. SPE Western Regional Meeting. Society of Petroleum Engineers.

18. Escrochi, M., Nabipour, M., Ayatollahi, S. S., \& Mehranbod, N. (2008, January). Wettability alteration at elevated temperatures: the consequences of asphaltene precipitation. SPE International Symposium and Exhibition on Formation Damage Control. Society of Petroleum Engineers.

19. Espinat, D., Fenistein, D., Barre, L., Frot, D., \& Briolant, Y. (2004). Effects of temperature and pressure on asphaltenes agglomeration in toluene. A light, X-ray, and neutron scattering investigation. Energy \& fuels, 18(5), 1243-1249.

20. Gaudette, H. E., Eades, J. L., \& Grim, R. E. (1966). The nature of illite. Clays and Clay Minerals, 13th Natl. Conf. (pp. 33-48).

21. Gaudin, A. M., Spedden, H. R., \& Laxen, P. A. (1952). Adsorption of sodium ion on quartz. Mining Engineering, 4, 693-696.

22. Goldberg, S., Forster, H. S., \& Heick, E. L. (1991). Flocculation of illite/kaolinite and illite/montmorillonite mixtures as affected by sodium adsorption ratio and $\mathrm{pH}$. Clays Clay Miner, 39, 375-380. 
23. Gonzalez, V., Jones, M., \& Taylor, S. E. (2016). Spin-Spin Relaxation Time Investigation of Oil/Brine/Sand Systems. Kinetics, Effects of Salinity, and Implications for Wettability and Bitumen Recovery. Energy \& Fuels, 30(2), 844-853.

24. Grate, J. W., Dehoff, K. J., Warner, M. G., Pittman, J. W., Wietsma, T. W., Zhang, C., \& Oostrom, M. (2012). Correlation of oil-water and air-water contact angles of diverse silanized surfaces and relationship to fluid interfacial tensions. Langmuir, 28(18), 7182-7188.

25. Griffiths, P. R., \& De Haseth, J. A. (2007). Fourier transform infrared spectrometry (Vol. 171). John Wiley \& Sons.

26. Hatch, C. D., Wiese, J. S., Crane, C. C., Harris, K. J., Kloss, H. G., \& Baltrusaitis, J. (2012). Water adsorption on clay minerals as a function of relative humidity: application of BET and Freundlich adsorption models. Langmuir, 28(3), 1790-1803.

27. Hu, C., Sabio, J. C., Yen, A., Joshi, N., \& Hartman, R. L. (2015). Role of water on the precipitation and deposition of asphaltenes in packed-bed microreactors. Industrial \& Engineering Chemistry Research, 54(16), 4103-4112.

28. Johnson, W. L., \& Linke, W. A. (1977). Some practical applications to improve formation evaluation of sandstones in the Mackenzie Delta: Canadian Well Log Society. 6th Annual Logging Symposium Trans., paper R.

29. Kabay, N., İpek, Ö., Kahveci, H., \& Yüksel, M. (2006). Effect of salt combination on separation of monovalent and divalent salts by electrodialysis. Desalination, 198(1), 84-91.

30. Kar, T., Mukhametshina, A., Unal, Y., \& Hascakir, B. (2015). The Effect of Clay Type on Steam-Assisted-Gravity-Drainage Performance. Journal of Canadian Petroleum Technology.

31. Khilar, K. C., \& Fogler, H. S. (1984). The existence of a critical salt concentration for particle release. Journal of Colloid and Interface Science, 101(1), 214-224.

32. Kim, Y., Cygan, R. T., \& Kirkpatrick, R. J. (1996). 133 Cs NMR and XPS investigation of cesium adsorbed on clay minerals and related phases. Geochimica et Cosmochimica Acta, 60(6), 1041-1052.

33. Kokal, S. L., \& Sayegh, S. G. (1995, January). Asphaltenes: The cholesterol of petroleum. Middle East Oil Show. Society of Petroleum Engineers. 
34. Leontaritis, K. J., Amaefule, J. O., \& Charles, R. E. (1994). A systematic approach for the prevention and treatment of formation damage caused by asphaltene deposition. SPE Production \& Facilities, 9(03), 157-164.

35. Loeber, L., Muller, G., Morel, J., \& Sutton, O. (1998). Bitumen in colloid science: a chemical, structural and rheological approach. Fuel, 77(13), 1443-1450.

36. Malati, M. A., \& Estefan, S. F. (1966). The role of hydration in the adsorption of alkaline earth ions onto quarts. Journal of Colloid and Interface Science, 22(3), 306307.

37. Marshall, C. E. (1949). The colloid chemistry of the silicate minerals (No. 04; RMD, QE389.62 M3.).

38. Martinez, R. E., Sharma, P., \& Kappler, A. (2010). Surface binding site analysis of Ca 2+-homoionized clay-humic acid complexes. Journal of colloid and interface science, 352(2), 526-534.

39. Merino, E., \& Ransom, B. (1982). Free energies of formation of illite solid solutions and their compositional dependence. Clays and Clay minerals, 30(1), 29-39.

40. Meyer, R. F., \& Attanasi, E. D. (2003). Heavy oil and natural bitumen-Strategic petroleum resources. World, 434, 650-7.

41. Meyer, R. F., Attanasi, E. D., \& Freeman, P. A. (2007). Heavy oil and natural bitumen resources in geological basins of the world (No. 2007-1084).

42. Mullins, O. C., Seifert, D. J., Zuo, J. Y., \& Zeybek, M. (2012). Clusters of asphaltene nanoaggregates observed in oilfield reservoirs. Energy \& Fuels, 27(4), 1752-1761.

43. Mullins, O. C. (2010). The modified yen model†. Energy \& Fuels, 24(4), 2179-2207.

44. Mullins, O. C., Betancourt, S. S., Cribbs, M. E., Dubost, F. X., Creek, J. L., Andrews, A. B., \& Venkataramanan, L. (2007). The colloidal structure of crude oil and the structure of oil reservoirs. Energy \& Fuels, 21(5), 2785-2794.

45. Nalwaya, V., Tantayakom, V., Piumsomboon, P., \& Fogler, S. (1999). Studies on asphaltenes through analysis of polar fractions. Industrial \& engineering chemistry research, 38(3), 964-972.

46. Newman, A. C. (1987). Chemistry of clays and clay minerals (No. 6). Longman scientific and technical. 
47. Pauling, L. (1930). The structure of the chlorites. Proceedings of the National Academy of Sciences of the United States of America, 16(9), 578.

48. Prakoso, A. A., Punase, A. D., \& Hascakir, B. (2015, November). A Mechanistic Understanding of Asphaltene Precipitation from Varying Saturate Concentration Perspective. In SPE Latin American and Caribbean Petroleum Engineering Conference. Society of Petroleum Engineers.

49. Prakoso, A., Punase, A., Klock, K., Rogel, E., Ovalles, C., \& Hascakir, B. (2016, May). Determination of the Stability of Asphaltenes Through Physicochemical Characterization of Asphaltenes. In SPE Western Regional Meeting. Society of Petroleum Engineers.

50. Punase, A., Prakoso, A., \& Hascakir, B. (2016, May). The Polarity of Crude Oil Fractions Affects the Asphaltenes Stability. In SPE Western Regional Meeting. Society of Petroleum Engineers.

51. Reinoso-Maset, E., \& Ly, J. (2014). Study of major ions sorption equilibria to characterize the ion exchange properties of kaolinite. Journal of Chemical \& Engineering Data, 59(12), 4000-4009.

52. Sabbagh, O., Akbarzadeh, K., Badamchi-Zadeh, A., Svrcek, W. Y., \& Yarranton, H. W. (2006). Applying the PR-EoS to asphaltene precipitation from n-alkane diluted heavy oils and bitumens. Energy \& fuels, 20(2), 625-634.

53. Scheuerman, R. F., \& Bergersen, B. M. (1990). Injection-water salinity, formation pretreatment, and well-operations fluid-selection guidelines. Journal of Petroleum Technology, 42(07), 836-845.

54. Speight, J. G. (2014). The chemistry and technology of petroleum. CRC press.

55. Speight, J. G., \& Moschopedis, S. E. (1979). Some observations on the molecular nature of petroleum asphaltenes. Am. Chem. Soc., Div. Pet. Chem., Prepr.;(United States), 24(CONF-790917-(Vol. 24)(No. 4)).

56. Speight, J. G. (2004). Les asphaltènes, composés pétroliers. Partie 1: Asphaltènes, résines et structure du pétrole Petroleum Asphaltenes-Part 1: Asphaltenes, Resins and the Structure of Petroleum. Oil \& Gas Science and Technology-Rev. IFP Energies nouvelles, 59(5), 467-477. 
57. Speight, J. G. (1994). The molecular nature of petroleum asphaltenes. Arabian Journal for Science and Engineering, 19(2 B), 335-353.

58. Speight, J. G., Long, R. B., \& Trowbridge, T. D. (1984). Factors influencing the separation of asphaltenes from heavy petroleum feedstocks. Fuel, 63(5), 616-620.

59. Spiecker, P. M., Gawrys, K. L., Trail, C. B., \& Kilpatrick, P. K. (2003). Effects of petroleum resins on asphaltene aggregation and water-in-oil emulsion formation. Colloids and surfaces A: Physicochemical and engineering aspects, 220(1), 9-27.

60. Sposito, G. (2008). The chemistry of soils. Oxford university press.

61. Tang, G. Q., \& Morrow, N. R. (1999). Influence of brine composition and fines migration on crude oil/brine/rock interactions and oil recovery. Journal of Petroleum Science and Engineering, 24(2), 99-111.

62. Tang, G. Q., \& Morrow, N. R. (1997). Salinity, temperature, oil composition, and oil recovery by waterflooding. SPE Reservoir Engineering, 12(04), 269-276.

63. Van Olphen, H., \& Hsu, P. H. (1978). An Introduction to Clay Colloid Chemistry. Soil Science, 126(1), 59.

64. Vasconcelos, I. F., Bunker, B. A., \& Cygan, R. T. (2007). Molecular dynamics modeling of ion adsorption to the basal surfaces of kaolinite. The Journal of Physical Chemistry C, 111(18), 6753-6762.

65. Velde, B. (2000). Clay minerals: a physico-chemical explanation of their occurrence (Vol. 40). Elsevier.

66. Vinegar, H. J., \& Waxman, M. H. (1984, January). Induced Polarization of Shaly Sands-The Effect of Clay Counterion Type. In SPWLA 25th Annual Logging Symposium. Society of Petrophysicists and Well-Log Analysts.

67. Wattana, P., Fogler, H. S., Yen, A., Carmen Garcìa, M. D., \& Carbognani, L. (2005). Characterization of polarity-based asphaltene subfractions. Energy \& fuels, 19(1), 101110.

68. Weaver, C. E., \& Pollard, L. D. (1973). The chemistry of clay minerals.

69. Wilkinson, G., \& Birmingham, J. M. (1954). Bis-cyclopentadienyl compounds of Ti, $\mathrm{Zr}, \mathrm{V}, \mathrm{Nb}$ and Ta. Journal of the American Chemical Society, 76(17), 4281-4284. 
70. Wilson, J., \& Burgh, G. (2007). Energizing our future: Rational choices for the 21st century. John Wiley \& Sons.

71. Woods, J. R., Kung, J., Kingston, D., McCracken, T., Kotlyar, L. S., Sparks, B. D., ... \& Moran, K. (2012). The Comparison of Bitumens from Oil Sands with Different Recovery Profiles. Petroleum Science and Technology, 30(22), 2285-2293.

72. Yarranton, H. W., Alboudwarej, H., \& Jakher, R. (2000). Investigation of asphaltene association with vapor pressure osmometry and interfacial tension measurements. Industrial \& engineering chemistry research, 39(8), 2916-2924.

73. Yoon, S., Bhatt, S. D., Lee, W., Lee, H. Y., Jeong, S. Y., Baeg, J. O., \& Lee, C. W. (2009). Separation and characterization of bitumen from Athabasca oil sand. Korean Journal of Chemical Engineering, 26(1), 64-71.

74. Zhuang, J., Flury, M., \& Jin, Y. (2003). Colloid-facilitated Cs transport through watersaturated Hanford sediment and Ottawa sand. Environmental science \& technology, 37(21), 4905-4911. 
APPENDIX

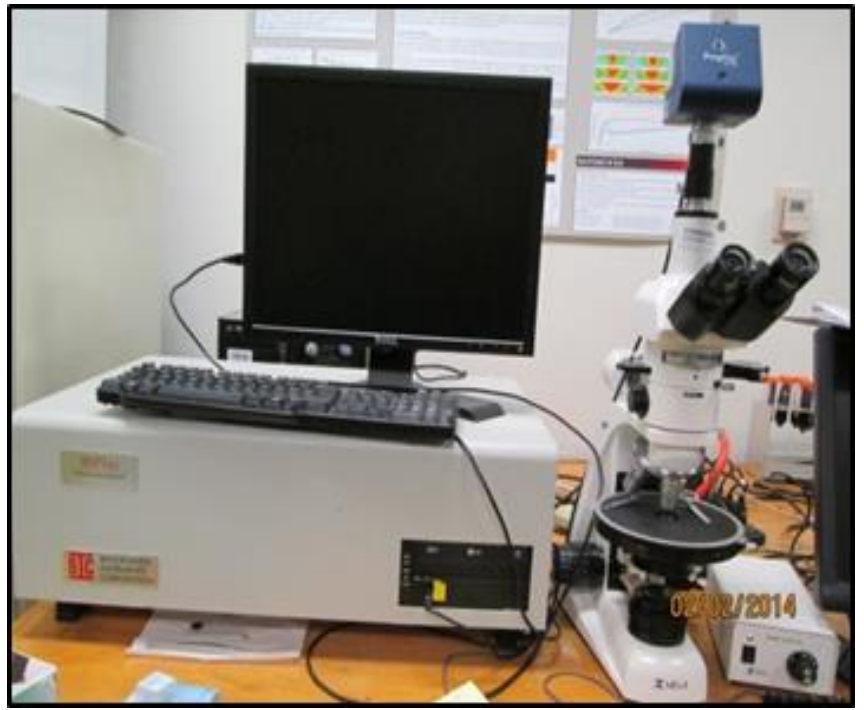

Figure A - 1: Jenoptik Microscope Attached with ProgRes CT5 Camera

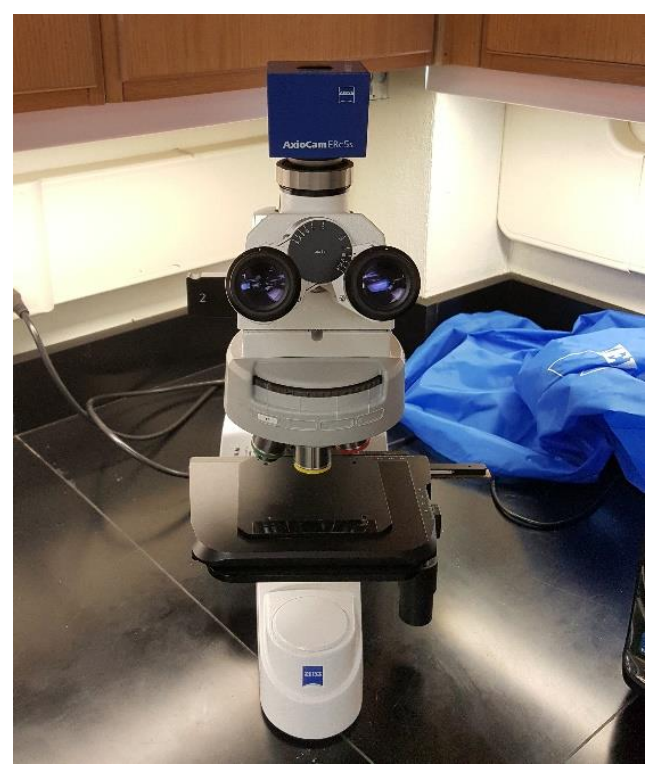

Figure A - 2: Zeiss AxioCam ERc5s 
Beavers Bend Illite

$$
\begin{aligned}
& \left(\mathrm{Al}_{1.29} \mathrm{Fe}^{+++}{ }_{0.41} \mathrm{Fe}^{++}{ }_{0.19} \mathrm{Mg}_{0.18} \mathrm{Ti}_{0.04}\right)\left(\mathrm{Si}_{3.34} \mathrm{Al}_{0.66}\right) \mathrm{O}_{10}(\mathrm{OH})_{2}\left(\mathrm{~K}_{0.61}^{+} \mathrm{Na}_{0.02} \mathrm{Ca}^{++}{ }_{0.01}\right) \\
& \text { Marblehead Illite } \\
& \left(\mathrm{Al}_{1.50} \mathrm{Fe}^{+++}{ }_{0.04} \mathrm{Fe}^{++}{ }_{0.07} \mathrm{Mg}_{0.36} \mathrm{Ti}_{0.05}\right)\left(\mathrm{Si}_{3.54} \mathrm{Al}_{0.46}\right) \mathrm{O}_{10}(\mathrm{OH})_{2}\left(\mathrm{~K}^{+}{ }_{0.68} \mathrm{Na}^{+}{ }_{0.03} \mathrm{Ca}^{++}{ }_{0.08}\right) \\
& \text { Rock IsLand ILIITE } \\
& \left(\mathrm{Al}_{1.01} \mathrm{Fe}^{+++}{ }_{0.07} \mathrm{Fe}^{++}{ }_{0.08} \mathrm{Mg}_{0.20} \mathrm{Ti}_{0.03}\right)\left(\mathrm{Si}_{3.57} \mathrm{Al}_{0.43}\right) \mathrm{O}_{10}(\mathrm{OH})_{2}\left(\mathrm{~K}^{+}{ }_{0.58} \mathrm{Na}_{0.03} \mathrm{Ca}^{++}{ }_{0.03}\right) \\
& \text { Fithian Illite } \\
& \left(\mathrm{Al}_{1.22} \mathrm{Fe}^{+++}{ }_{0.45} \mathrm{Fe}^{++}{ }_{0.22} \mathrm{Mg}_{0.15} \mathrm{Ti}_{0.04}\right)\left(\mathrm{Si}_{3.33} \mathrm{Al}_{0.67}\right) \mathrm{O}_{10}(\mathrm{OH})_{2}\left(\mathrm{~K}_{0.57} \mathrm{Na}_{0.05} \mathrm{Ca}^{++}{ }_{0.07}\right) \\
& \text { "Grundrte" } \\
& \left(\mathrm{Al}_{1.8} \mathrm{Fe}^{+++}{ }_{0.60} \mathrm{Mg}_{0.20}\right)\left(\mathrm{Si}_{3.20} \mathrm{Al}_{0.80}\right) \mathrm{O}_{10}(\mathrm{OH})_{2}\left(\mathrm{~K}^{+}{ }_{0.57} \mathrm{Na}^{+}{ }_{0.04}\right)
\end{aligned}
$$

Figure A - 3: : Structural Formulas of Different Illites (Gaudette et al. 1966)

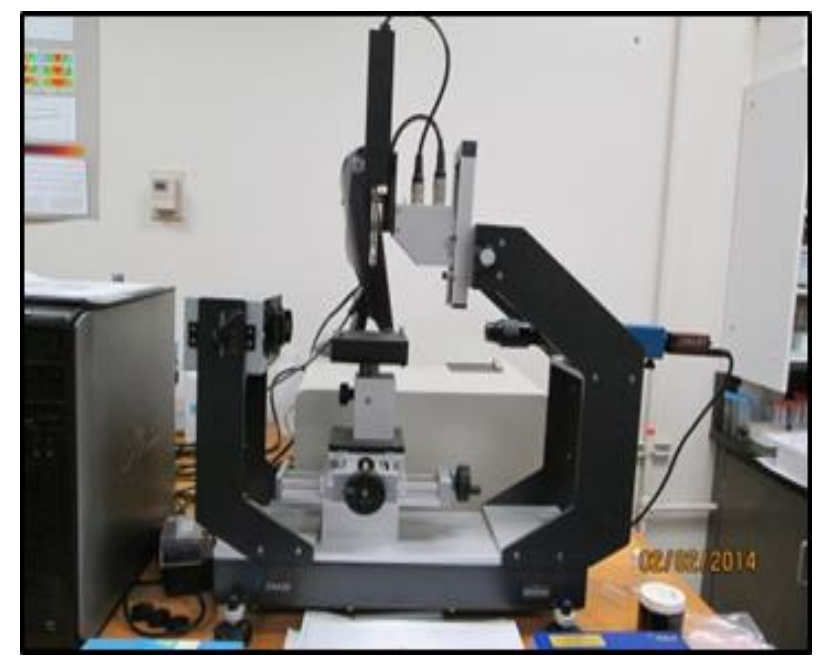

Figure A - 4: Kruss DSA30S Contact Angle Measurement Device 


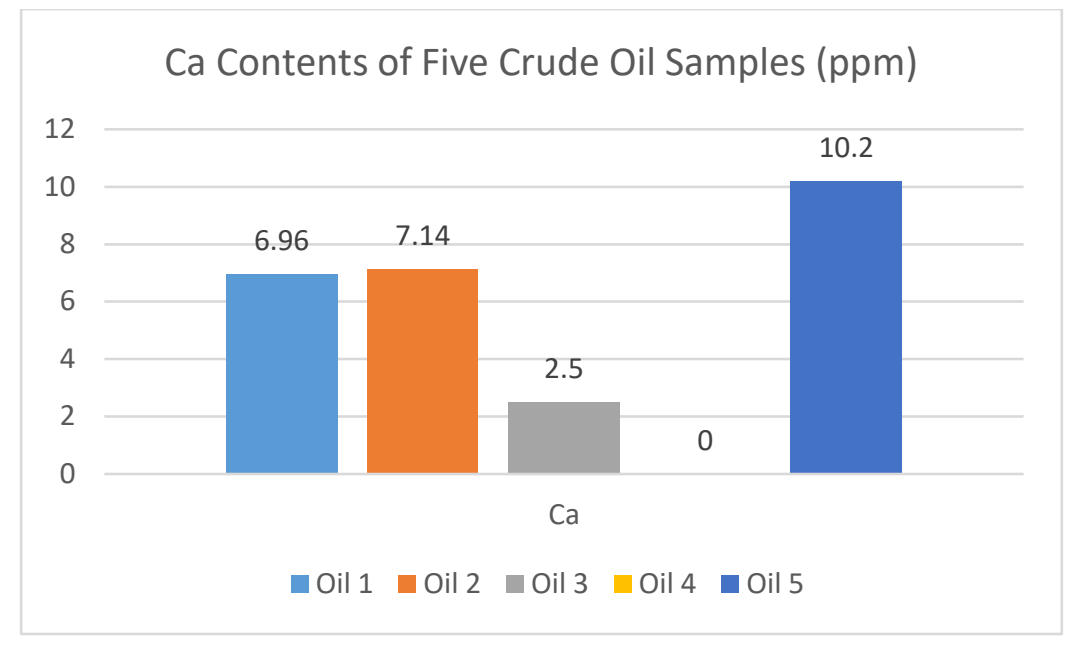

Figure A - 5: Ca Content of Five Crude Oil Samples (ppm)

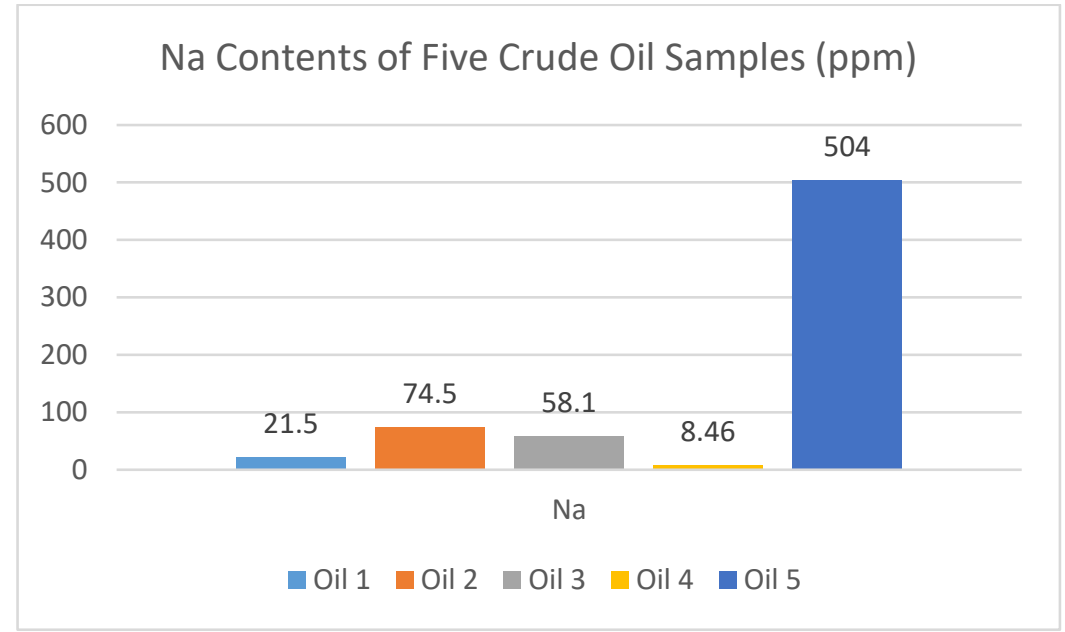

Figure A - 6: Na Content of Five Crude Oil Samples (ppm)

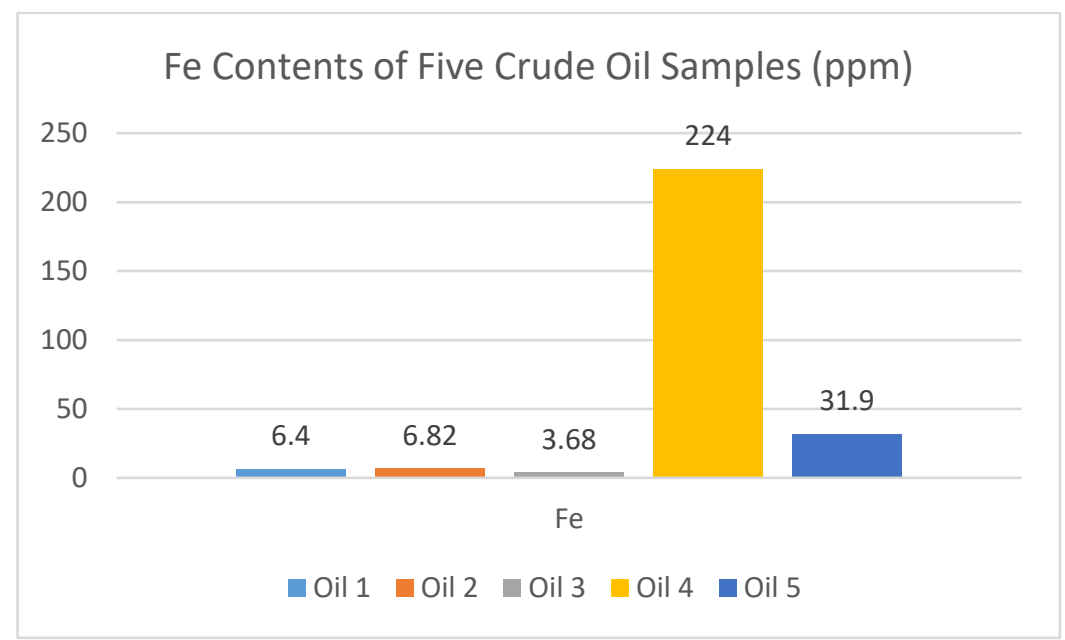

Figure A - 7: Fe Content of Five Crude Oil Samples (ppm) 


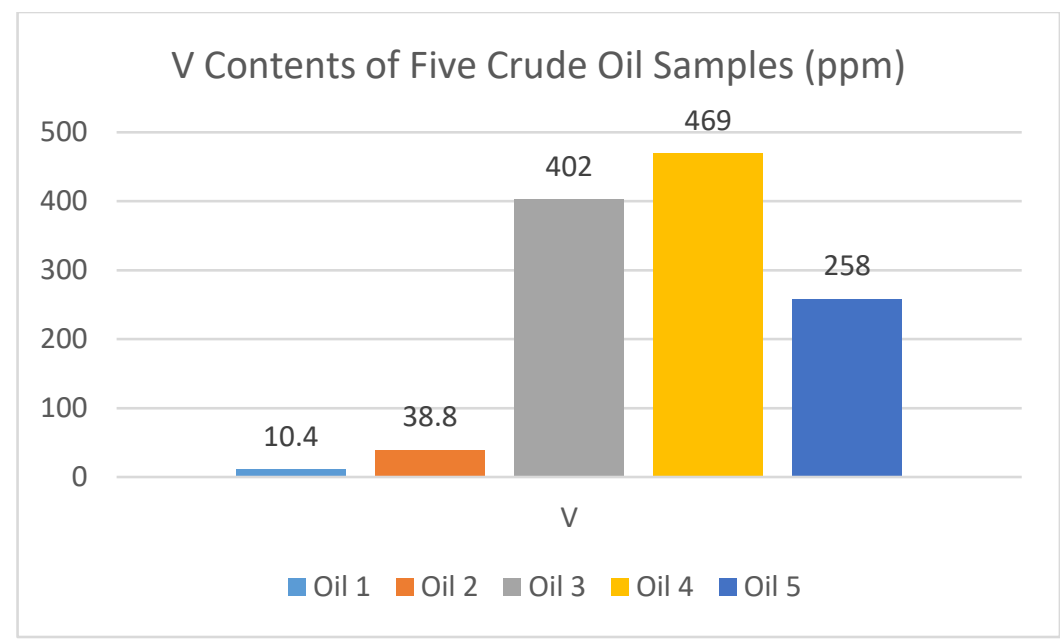

Figure A - 8: V Content of Five Crude Oil Samples (ppm)

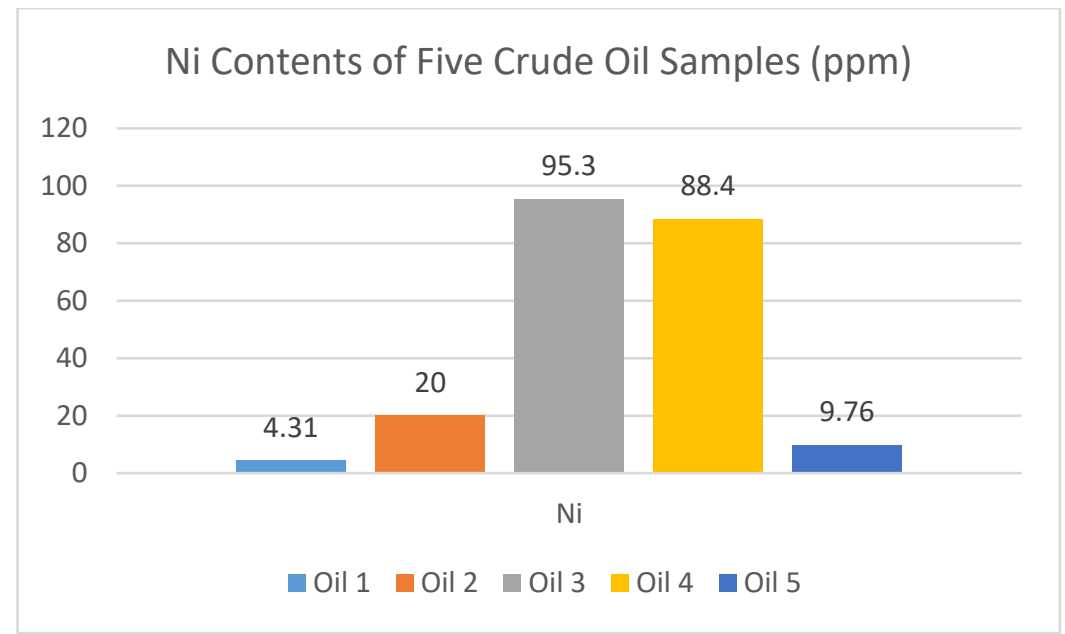

Figure A - 9: Ni Content of Five Crude Oil Samples (ppm)

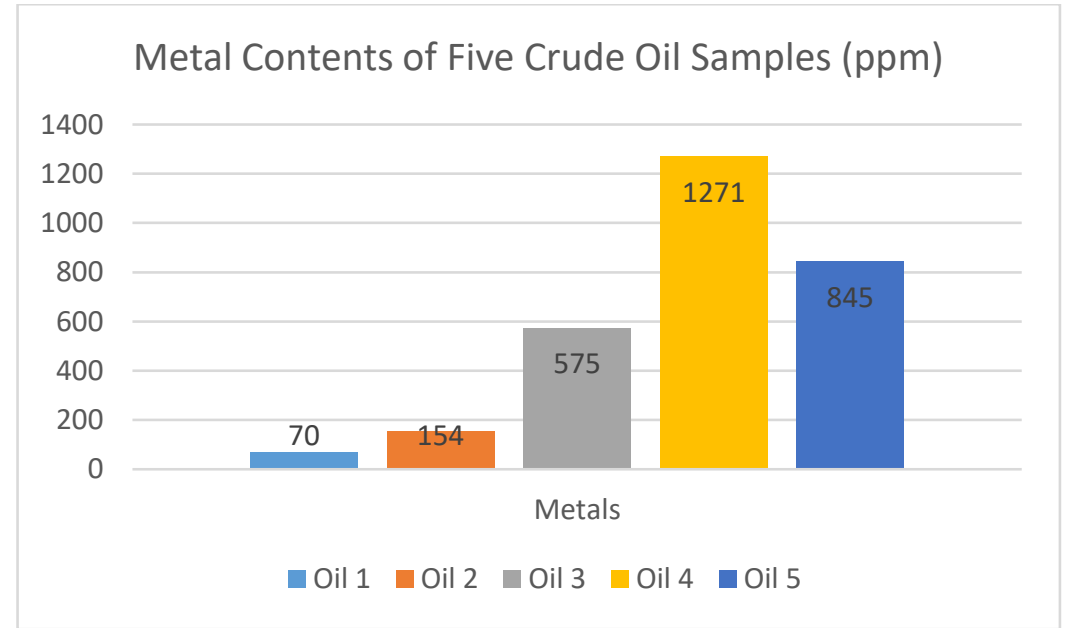

Figure A - 10: Metal Content of Five Crude Oil Samples (ppm) 


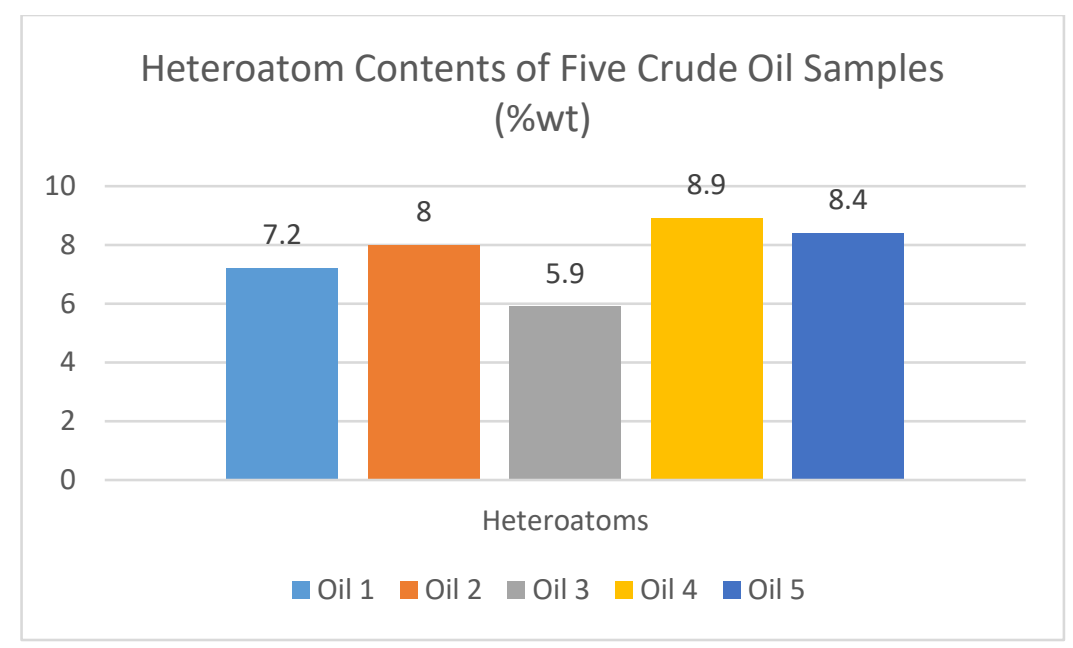

Figure A - 11: Heteroatoms Content of Five Crude Oil Samples (\%wt)
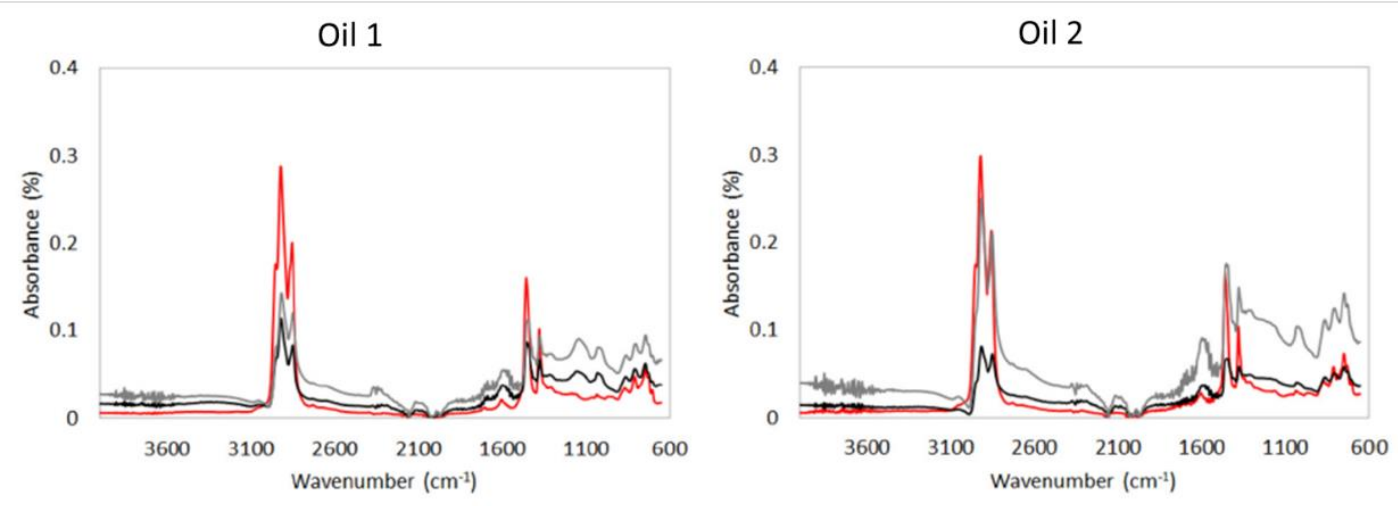

Figure A - 12: FTIR Spectrum of Oil 1 and Oil 2 and asphaltenes separated with n-pentane and n-heptane. (red, black, and gray lines refer crude oil, n-pentane, and n-heptane, respectively) (Prakoso et al. 2016)
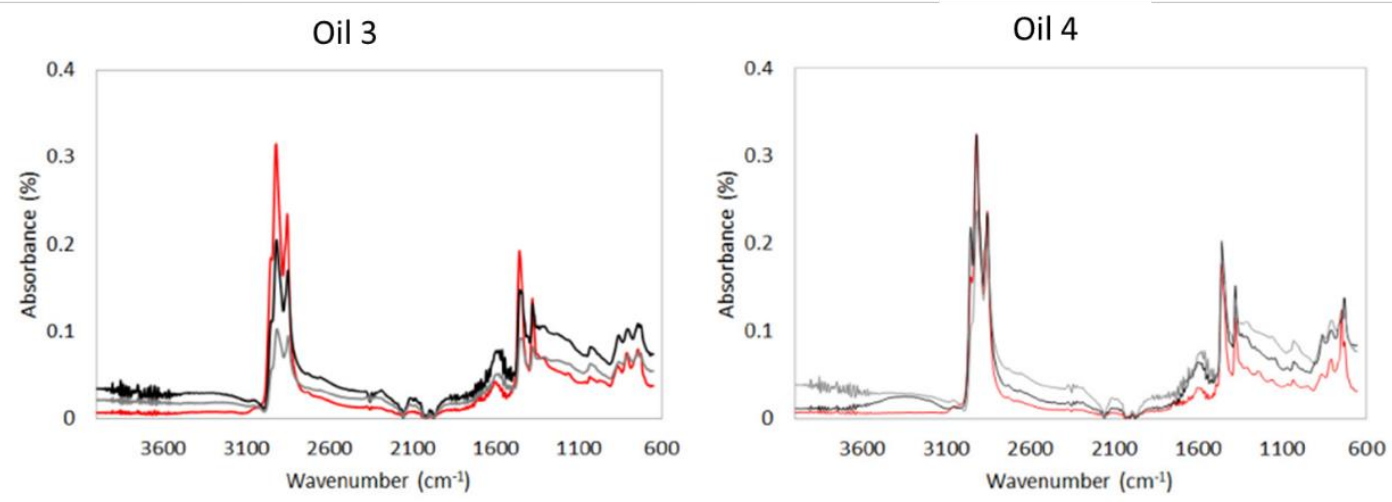

Figure A - 13: FTIR Spectrum of Oil 3 and Oil 4 and asphaltenes separated with n-pentane and n-heptane. (red, black, and gray lines refer crude oil, n-pentane, and n-heptane, respectively) (Prakoso et al. 2016) 


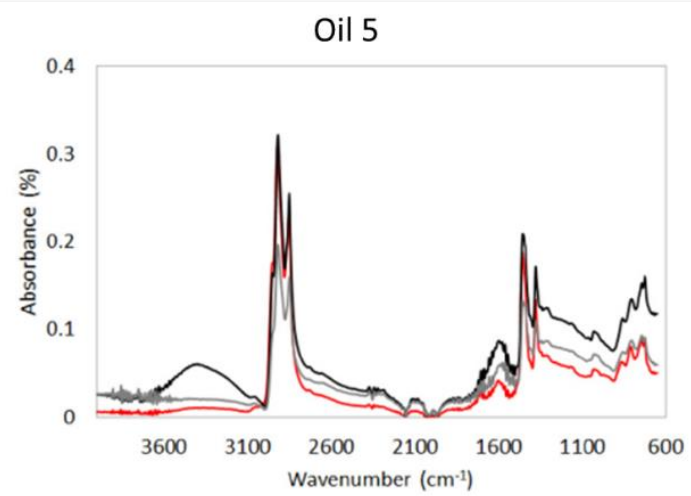

Figure A - 14: FTIR Spectrum of Oil 5 and asphaltenes separated with n-pentane and n-heptane. (red, black, and gray lines refer crude oil, n-pentane, and n-heptane, respectively) (Prakoso et al. 2016) 